\title{
The Economy of
}

the West Bank and Gaza Strip

Recent Experience, Prospects, and Cballenges to Private Sector Development

Steven Barnett

Nur Calika

Dale Chua Oussama Kanaan Milan Zavadjil

Middle Eastern Department International Monetary Fund 1998 


\title{
The Economy of the West Bank and Gaza Strip
}

\author{
Recent Experience, \\ Prospects, and Challenges to \\ Private Sector Development
}

\author{
Steven Barnett \\ Nur Calika \\ Dale Chua \\ Oussama Kanaan \\ Milan Zavadjil
}

International Monetary Fund

1998 
(C)1998 International Monetary Fund

\author{
Cover design and figures: In-Ok Yoon \\ Composition: Alicia Etchebarne-Bourdin \\ IMF Graphics Section
}

\title{
Library of Congress Cataloging-in-Publication Data
}

The economy of the West Bank and Gaza Strip: recent experience, prospects, and challenges to private sector development / by Steven Barnett ... . [et al.].

p. $\mathrm{cm}$.

ISBN 1-55775-725-9 (pbk.)

1. West Bank-Economic conditions. 2. Gaza Strip-Economic conditions. 3. West Bank-Economic policy. 4. Gaza Strip-Economic Policy. I. Barnett, Steven. II. International Monetary Fund.

HC415.254.E26 1998

$338.95694-\mathrm{DC} 21$

$98-18343$

CIP

Price: $\$ 15.00$

Address orders to:

International Monetary Fund, Publication Services 700 19th Street, N.W., Washington DC 20431, U.S.A.

Telephone: (202) 623-7430

Telefax: (202) 623-7201

E-mail: publications@imf.org

Internet: http://www.imf.org 


\section{Acknowledgments}

The authors are grateful for valuable suggestions from a large number of IMF colleagues, and in particular from Salam Fayyad, who provided detailed and insightful comments. Jeff Hayden of the External Relations Department edited and coordinated production of the publication.

The views expressed in this study are those of the authors and should not be attributed to the IMF, its Executive Directors, the Palestinian authorities, or the authorities of IMF member countries. 
This page intentionally left blank

CInternational Monetary Fund. Not for Redistribution 


\section{Contents}

Acknowledgments

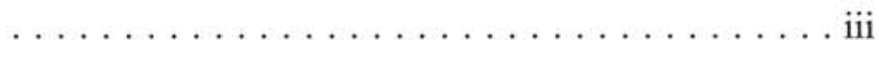

1. Introduction

Milan Zavadjil ...................... ]

2. Recent Experience and Prospects

Oussama Kanaan ...................... 3

3. Private Investment under Uncertainty in the

West Bank and Gaza Strip

Oussama Kanaan ........................ 14

4. Monetary Policy in the West Bank and Gaza Strip in the Absence of a Domestic Currency

Steven Barnett . . . . . . . . . . . . . . . . . . . . . . . 29

5. Fiscal Policy and Its Impact on Private Sector

Activity

Dale Chua

41

6. The Trade System

Nur Calika .........................51 
This page intentionally left blank

CInternational Monetary Fund. Not for Redistribution 


\section{Introduction}

\section{Milan Zavadjil}

$T$ he economy of the West Bank and Gaza

1 Strip faced a difficult external environment in 1997. Two intensified (and at times total) border closures that were triggered by security incidents in Israel jolted the economy, which was already weakened by high unemployment and permanent border controls that raised transportation and other costs, distorted investment incentives, and undermined competitiveness. The closures, coupled with the lack of progress in the peace process, gave rise to a profound pessimism concerning the economic prospects of the West Bank and Gaza Strip. The loss in confidence constrained both private investment and consumption, while public investment continued to be constrained by a broad array of factors, most of which reflected the unfavorable political and security situation. As a result, GNP increased by only 2 percent in real terms, implying a significant drop in per capita income.

On the basis of fiscal data available as of November 1997, preliminary estimates for 1997 indicate that the Palestinian Authority maintained recurrent expenditures on an accrual basis within the budgeted amount, and that the recurrent fiscal deficit has been kept under the $\$ 52$ million envisaged under the budget. Nevertheless, the Ministry of Finance continued to encounter severe liquidity difficulties as revenues continued to be diverted to accounts outside the Ministry of Finance, and, in the third quarter, Israel temporarily suspended the transfer of clearance revenues, resulting in rising payments arrears and overdraft.

Despite all the difficulties, significant progress was made in institution building in 1997. Working closely with the World Bank and the IMF, the min- istries of Finance and Planning and International Cooperation improved their operations, as reflected in the preparation of the 1998 budget and investment plan. The audit function of the Palestinian Authority became fully operational, and further steps are expected in the near future to further improve fiscal transparency and accountability.

Prospects for 1998 remain highly uncertain. On the one hand, the border closure has been relaxed and the Israeli authorities have indicated that in the future the impact of security procedures on the movement of goods and labor will be minimized. On the other hand, there is deep pessimism over political and economic prospects, so that any recovery of private consumption or investment is likely to be limited. Thus, GNP growth of only 2 percent is forecast for 1998 .

Against this background, the Palestinian Authority has formulated a bold budget for 1998 that envisages a small recurrent surplus and, for the first time, a contribution to the public investment program from domestic sources. Most important, the budget envisages a leveling off of the rapid public employment growth evident in the last three years, with virtually all additional employment limited to the education and health sectors in order to cater to the rapid growth of the population. In addition, at the December 1997 Consultative Group meeting held in Paris, donors reiterated their support for Palestinian development and indicated their intention to commit another $\$ 750$ million. It is hoped that a substantial amount will be channeled to development projects and that, with more active monitoring of implementation, the public investment program will finally provide a significant boost to the economy. 


\section{INTRODUCTION}

The revival of private investment hoped for at the time of the Oslo accords has not materialized. Estimates show the share of private investment in GDP fell from 19 percent in 1993 to about 10 percent in 1997. Moreover, private investment has been focused on the residential construction sector rather than on the traded-goods sectors.

Chapter 2 presents an assessment of the recent experience of the Palestinian economy and examines its prospects for 1998 and beyond. Chapter 3 concludes that the current uncertain border status and closures are the key reasons why expectations for a revival of private investment following the signing of the Oslo peace accord have not been met. Other constraints to increased private investment include the absence of an adequate public infrastructure and a legal and regulatory framework, inadequate access to finance in some cases, as well as uncertain prospects for peace. It is also found that the regime of closures, through a reduction in the profitability of the export sector, results in a distorted pattern of investment. Nevertheless, some measures in the trade, fiscal, financial, and regulatory areas could be implemented even in the current circumstances to enhance prospects for an increase in private investment. These measures are the subject of the latter part of this chapter and the following three chapters.

The Palestinian Monetary Authority has been attempting to support private investment by encouraging banks to expand domestic lending, through both moral suasion and its available policy instruments. Chapter 4 finds, however, that attempts to employ monetary policy measures-which in the context of the West Bank and Gaza Strip essentially mean changes in reserve requirements or the use of direct measures - can lead to only minimal increases in output and employment, while entailing risks in terms of the soundness of the banking system. The Palestinian Monetary Authority should therefore focus on policies that create a stable financial environment, notably a stable and thriving banking sector, especially through improving bank supervision and regulation.

Chapter 5 examines how fiscal policy could be employed to improve the prospects for long-term growth in the West Bank and Gaza Strip. In the absence of a national currency, fiscal policy has a crucial role to play in macroeconomic management, as the composition of government expenditures and the efficiency of the tax system will affect total factor productivity growth profoundly, and private sector investment and growth in particular. This chapter reviews the state of the income tax system and how it can be modified to be more efficient, equitable, and simpler. The need to maintain the currently very favorable health and education indicators in the context of a rapidly growing population will represent a major challenge for the Palestinian Authority. In addition, the physical infrastructure is in need of major development, especially in the transportation, water, and social sectors. The need to increase recurrent health and education expenditures in real terms, as well as to make a contribution to the financing of the public investment program, will require that increases in employment and nonwage spending outside these core areas are kept to a minimum, while the efficiency in the delivery of services and the contribution of the population to their financing will have to be increased.

Finally, Chapter 6 examines the trade system of the West Bank and Gaza Strip and finds that it has not only been shaped by the Economic Protocol with Israel, but is also the outgrowth of security measures taken by Israel, trade policy measures implemented by the Palestinian Authority, and to a lesser extent, bilateral trade arrangements concluded by both Israel and the West Bank and Gaza Strip. In addition to reviewing the much-discussed long-term options for the development of the trade system in the West Bank and Gaza Stripcustoms union or free trade area-this chapter examines measures that could be taken immediately by the Palestinian Authority and Israel to improve the trade links of the West Bank and Gaza Strip with the rest of the world. The establishment of a seaport and airport in the Gaza Strip, safe passage between the Gaza Strip and the West Bank, further improvements in Israeli security procedures, the elimination of Palestinian import monopolies, and the utilization by the Palestinian Authority of options available under the Economic Protocol to promote trade independence are considered to be the most promising steps in this respect. 


\title{
2. Recent Experience and Prospects
}

\author{
Oussama Kanaan
}

$\mathrm{E}$ conomic conditions in the West Bank and Gaza Strip have deteriorated substantially since 1993 due to adverse political developments. ${ }^{1}$ The imposition of generalized border closures triggered by security incidents in Israel, which are characterized by strict security controls on the movement of goods and labor into and out of the West Bank and Gaza Strip, as well as intermittent total closures that virtually prohibited such movement, have led to an increase in the rate of unemployment to about 30 percent, a contraction in external trade, disruptions to the implementation of the public investment program, and a steady erosion in private sector confidence. By the end of 1996, the unemployment rate was 15 percentage points higher and income per capita about 20 percent lower than in 1993 , and only modest improvements had been made in developing the domestic productive base and infrastructure (Table 1). On the positive side, despite the unfavorable overall economic and political environment, the Palestinian Authority persevered in the pursuit of a prudent fiscal policy and in strengthening economic institutions and processes.

At the start of 1997, there were hopes that a sustained improvement on the political front would allow a modest economic recovery during the year. The economic outlook at the time, as reflected in IMF staff projections, was for an increase in real income per capita of about 4-5 percent in 1997, reflecting an easing of border closures and an accelerated implementation of

${ }^{1}$ For a detailed review of developments in the West Bank and Gaza Strip prior to 1997 and a discussion of statistical issues, see International Monetary Fund, Recent Economic Developments, Prospects, and Progress in Institution Building in the West Bank and Gaza Strip, Middle Eastern Department, February 1997. public investment projects. This rather optimistic outlook seemed vindicated by developments in early 1997, as restrictions on the flows of goods and labor were gradually relaxed and the rate of unemployment abated to close to 25 percent by the end of February.

\section{Economic Developments and Progress in Institution Building in 1997}

Hopes for a significant improvement in political and security conditions in the West Bank and Gaza Strip and for an associated improvement in economic performance were short-lived. The "onoff" economic cycles inherent in the regime of border closures continued in 1997 with the imposition of two strict blockades on the flows of goods and labor in March-April and August-September triggered by attacks in Israel. Although the intensity of the border restrictions on these flows varied widely during the year, as did the extent of induced disruptions to investment activities, by year-end it was clear that the envisaged recovery had failed to materialize. For the year as a whole, real income per capita is estimated to have declined by 3.5 percent, while the rate of unemployment fell only slightly to an average of 31 percent (Figure 1).

The outward-oriented sectors were again hit severely by the blockades on the movement of goods, as seen in an estimated contraction in real terms of 9 percent in exports of goods and nonfactor services and of 6 percent in imports in 1997 (Tables 2, 3, and 4). While the number of Palestinian workers in Israel increased from an average of about 22,000 in 1996 to about 35,000 in 1997 , the monthly rate of unemployment remained at more than 28 percent 
TABLE 1.

Key Economic Indicators, 1993-98

(In millions of U.S. dollars, unless otherwise indicated)

\begin{tabular}{|c|c|c|c|c|c|c|}
\hline & 1993 & 1994 & $\begin{array}{l}\text { Est. } \\
1995\end{array}$ & $\begin{array}{l}\text { Est. } \\
1996\end{array}$ & $\begin{array}{l}\text { Est. } \\
1997\end{array}$ & $\begin{array}{l}\text { Proj. } \\
1998\end{array}$ \\
\hline $\begin{array}{l}\text { Real GDP (percent change) } \\
\text { Real GNP (percent change) }\end{array}$ & $\begin{array}{r}-1.3 \\
-10.1\end{array}$ & $\begin{array}{r}10.8 \\
3.9\end{array}$ & $\begin{array}{l}-5.6 \\
-9.4\end{array}$ & $\begin{array}{l}-1.7 \\
-3.7\end{array}$ & $\begin{array}{r}-0.8 \\
2.2\end{array}$ & $\begin{array}{l}2.2 \\
1.9\end{array}$ \\
\hline $\begin{array}{l}\text { Real GDP per capita (NIS, } 1986 \text { constant prices) } \\
\text { Real GNP per capita (NIS, } 1986 \text { constant prices) }\end{array}$ & $\begin{array}{l}1,470 \\
1,766\end{array}$ & $\begin{array}{l}1,567 \\
1,764\end{array}$ & $\begin{array}{l}1,424 \\
1,538\end{array}$ & $\begin{array}{l}1,346 \\
1,425\end{array}$ & $\begin{array}{l}1,261 \\
1,375\end{array}$ & $\begin{array}{l}1,219 \\
1,326\end{array}$ \\
\hline $\begin{array}{l}\text { Workers in Israel (in thousands) }{ }^{1} \\
\text { Workers in the West Bank and }\end{array}$ & 83 & 53 & 32 & 22 & 35 & 35 \\
\hline Gaza Strip (in thousands) ${ }^{1}$ & 316 & 329 & 342 & 342 & 381 & 429 \\
\hline Unemployment rate (in percent) & 18.0 & 24.7 & 29.0 & 33.4 & 31.1 & 30.6 \\
\hline Inflation rate (based on $\mathrm{CPI}$ ) & 11.0 & 14.0 & 10.8 & 8.4 & 6.0 & 6.0 \\
\hline $\begin{array}{l}\text { Revenue } \\
\text { Current expenditure } \\
\text { Current deficit } \\
\text { Foreign-financed employment programs } \\
\text { Current deficit including employment programs }\end{array}$ & $\begin{array}{r}296 \\
273 \\
23 \\
- \\
\cdots\end{array}$ & $\begin{array}{r}269 \\
298 \\
-30 \\
- \\
\cdots\end{array}$ & $\begin{array}{l}425 \\
492 \\
-67 \\
-\overline{-67}\end{array}$ & $\begin{array}{r}684 \\
780 \\
-96 \\
49 \\
-145\end{array}$ & $\begin{array}{r}816 \\
866 \\
-50 \\
9 \\
-59\end{array}$ & $\begin{array}{l}\cdots \\
\cdots \\
\cdots \\
\cdots\end{array}$ \\
\hline $\begin{array}{l}\text { Exports of goods and nonfactor services } \\
\text { Imports of goods and nonfactor services } \\
\text { Remittances (receipts) }\end{array}$ & $\begin{array}{r}245 \\
1,333 \\
586\end{array}$ & $\begin{array}{r}312 \\
1,242 \\
400\end{array}$ & $\begin{array}{r}473 \\
1,908 \\
262\end{array}$ & $\begin{array}{r}495 \\
2,150 \\
194\end{array}$ & $\begin{array}{r}475 \\
2,132 \\
306\end{array}$ & $\begin{array}{r}500 \\
2,220 \\
313\end{array}$ \\
\hline & \multicolumn{6}{|c|}{ (End of period) } \\
\hline $\begin{array}{l}\text { Net foreign assets } \\
\text { Domestic loans } \\
\text { Total deposits } \\
\text { Demand deposits } \\
\text { Time and savings deposits }\end{array}$ & $\begin{array}{l}\cdots \\
\cdots \\
\cdots \\
\cdots\end{array}$ & $\begin{array}{r}435 \\
97 \\
523 \\
306 \\
217\end{array}$ & $\begin{array}{r}1,010 \\
270 \\
1,142 \\
465 \\
678\end{array}$ & $\begin{array}{r}1,289 \\
436 \\
1,645 \\
552 \\
1,093\end{array}$ & $\begin{array}{r}1,410 \\
600 \\
1,870 \\
594 \\
1,276\end{array}$ & $\begin{array}{c}1,562 \\
\ldots \\
\ldots \\
\ldots \\
\ldots\end{array}$ \\
\hline
\end{tabular}

Sources: Palestinian and Israeli authorities; and IMF staff estimates.

'Annual averages.

throughout the year, reflecting the subdued pace of expansion in domestic employment (Figure 2). ${ }^{2}$ There was no significant pickup in private investment activities, and the pace of implementation of the public investment projects continued to be slow, with expenditures on the ground limited to about the same level as in 1996. The picture with regard to private consumption was also bleak, as reflected in recent micro-level surveys showing about a 9 percent fall in average real monthly household expenditures in January-September 1997 compared to the same period in $1996 .{ }^{3}$ Finally, because of

\footnotetext{
${ }^{2}$ The rise in the number of Palestinian workers in Israel was especially pronounced in the fourth quarter of 1997 , rising from about 33,000 in September to 47,000 workers in December.

${ }^{3}$ See United Nations, Economic and Social Conditions in the West Bank and Gaza Strip, Quarterly Report, October 1997, and subsequent updates, for an overview of the results of the household expenditure surveys undertaken by the Palestinian Central Bureau of Statistics in 1996-97.
}

liquidity difficulties, public consumption expenditures were compressed to below normal levels until later in the year and did not provide the economy with the envisaged boost.

The Palestinian Authority succeeded in containing the recurrent deficit at an estimated $\$ 50$ million, slightly less than the level targeted in the 1997 budget, despite the pressures induced by the two border closures (Table 5 and Figure 3). ${ }^{4}$ A tight stance with regard to both nonwage and wage expenditures allowed the containment of recurrent spending within the budgeted $\$ 866$ million. The Palestinian Authority maintained a restrictive employment policy throughout the year, while wage increases were limited to a 10 percent raise for teachers. Moreover, in contrast to the situation in 1996 when the

\footnotetext{
${ }^{4}$ The estimates of the fiscal outcome are preliminary, based on data available as of November 1997.
} 
Figure 1

West Bank and Gaza Strip: Selected Economic Indicators, 1992-97
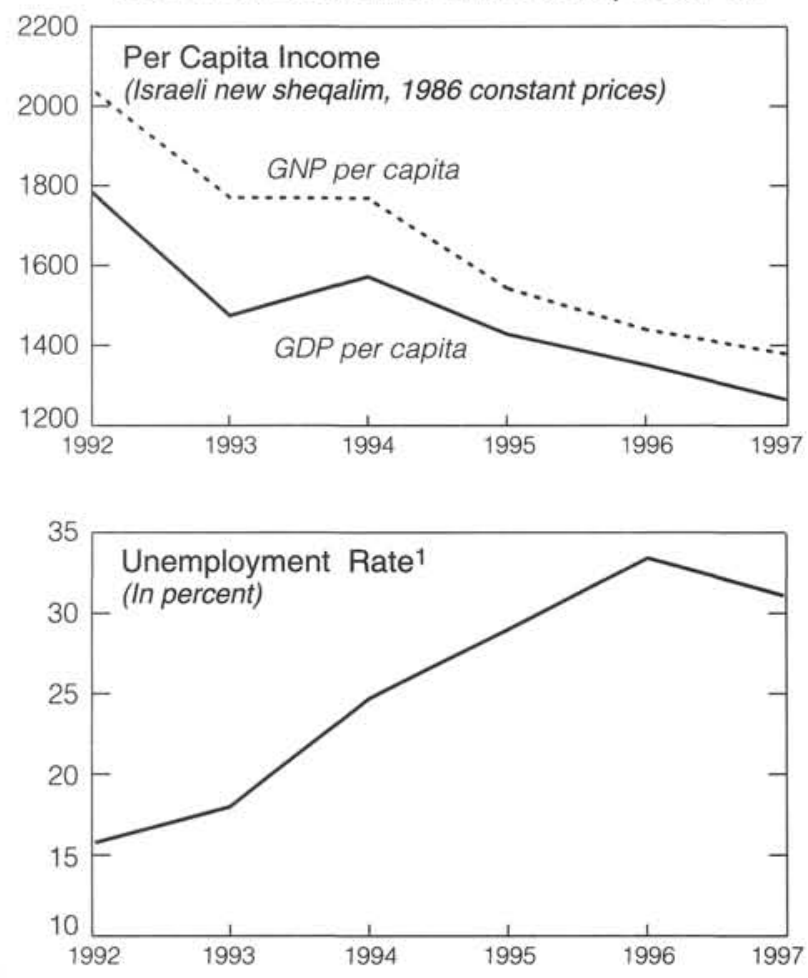

Sources: Palestinian and Israeli authorities; and IMF staff estimates and projections.

${ }^{1}$ Excludes underemployment.

Palestinian Authority had to implement a series of unforeseen measures to alleviate the effects of closures, in 1997 there were virtually no "emergency" or other unbudgeted expenditures. Palestinian Authority revenues, at an estimated $\$ 816$ million, were slightly above the amount envisaged in the budget, despite the weakerthan-anticipated economic activity. The effects of the slower economic growth, especially on revenue clearances from the value added tax, were offset by a sustained strengthening in revenue administration, especially in domestic tax collection and enforcement, and unexpected increases in clearances from customs duties, reflecting a shift from indirect imports via Israel to direct imports.

Despite the tight expenditure policy and the relatively favorable revenue developments described above, the Palestinian Authority continued to encounter significant liquidity difficulties throughout the year. These resulted in forced compressions of cash expenditures, an associated accumulation of arrears, as well as recourse to borrowing from the domestic banking system. Whereas in the past liquidity difficulties were induced by the diversion of petroleum and other excise revenue to accounts outside the control of the Ministry of Finance, in 1997 these problems were further compounded by the temporary withholding of clearance revenue transfers by Israel in August and September. This led to an increase in expenditure arrears to about $\$ 69$ million and in the net overdraft of the Ministry of Finance at domestic banks to about $\$ 100$ million by the end of September. ${ }^{5}$

The Palestinian Authority has continued to make steady progress in strengthening its capacity in revenue administration and expenditure management. With the basic structure of a modern tax system and administration in place, efforts in 1997 focused on improving revenue collection, especially from banks and large enterprises, on enforcement, and on the design of a tax audit strategy to address the underreporting of taxable income. The recruitment of qualified staff and the training of tax officers, in particular in the VAT and customs area, has also proceeded apace, and the efficiency of the revenue processing and information systems has been enhanced. In the area of expenditure management, oversight of ministries and public agencies by the Ministry of Finance has been improved through the implementation of a comprehensive set of financial regulations, and there has been a marked improvement in the budget preparation process, in particular through better coordination between the Ministry of Finance and other ministries. In contrast, efforts to improve the transparency of fiscal operations have been slow, with the full centralization of all revenues and expenditures under the control of the Ministry of Finance yet to be undertaken.

The expansion in banking system deposits and net foreign assets experienced a slowdown in 1997 , reflecting a tapering off in the rate of increase in the number of banks and bank branches throughout the West Bank and Gaza Strip (Table 6 and Figure 4). While the rate of growth of time and savings deposits remained largely steady at an

\footnotetext{
5The net overdraft of the Ministry of Finance at domestic banks was estimated at \$70 million at the end of 1996.
} 


\section{RECENT EXPERIENCE AND PROSPECTS}

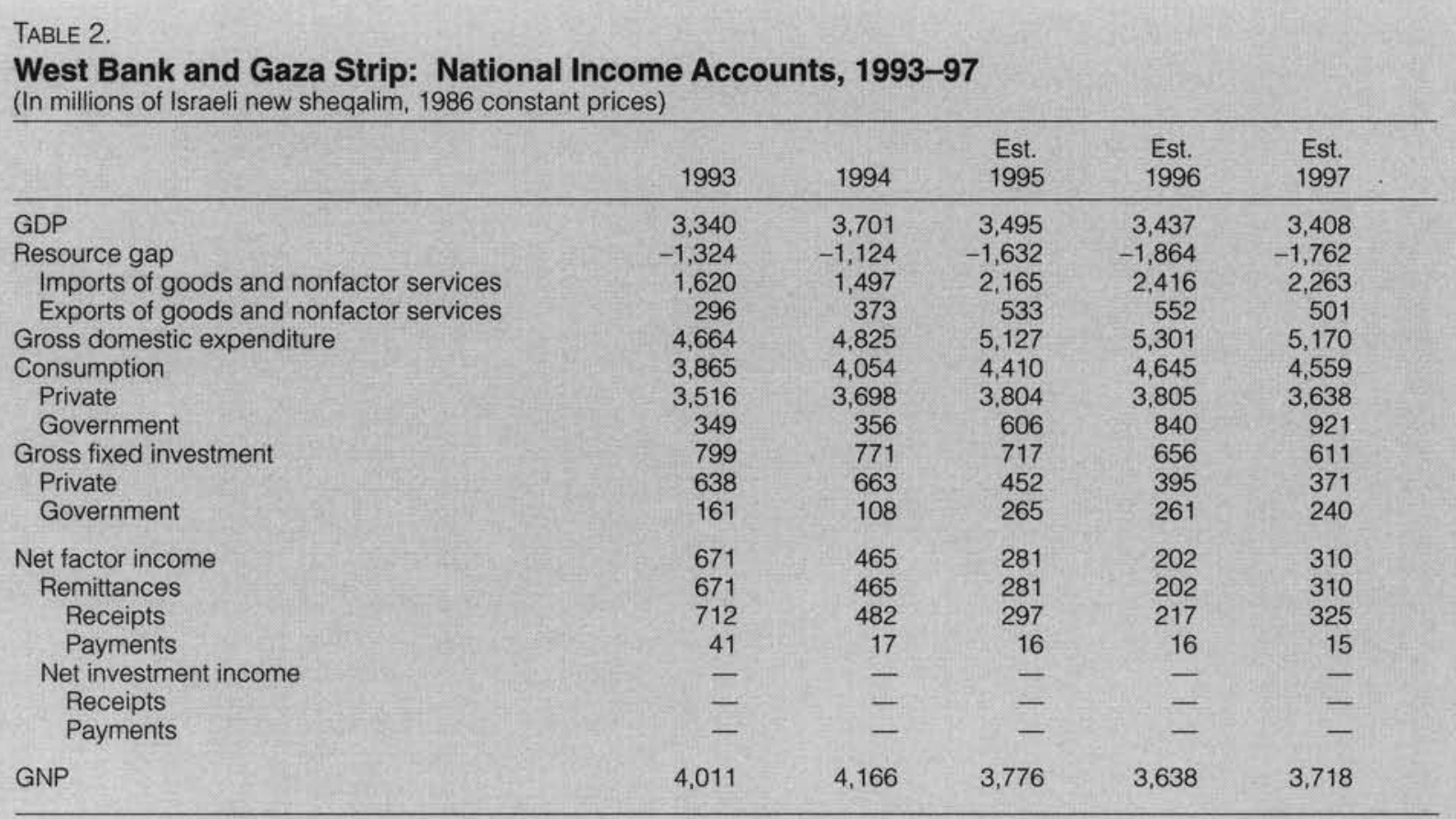

Sources: Palestinian and Israeli authorities; and IMF staff estimates.

TABLE 3.

West Bank and Gaza Strip: National Income Accounts, 1993-97

(In millions of U.S. dollars)

\begin{tabular}{lrrrrr}
\hline & & & Est. & \multicolumn{1}{c}{ Est. } & Est. \\
\hline GDP & 1993 & 1994 & 1995 & 1996 & 1997 \\
\hline Resource gap & 2,557 & 3,077 & 3,222 & 3,219 & 3,253 \\
$\quad$ Imports of goods and nonfactor services & $-1,088$ & -931 & $-1,435$ & $-1,655$ & $-1,657$ \\
$\quad$ Exports of goods and nonfactor services & 1,333 & 1,242 & 1,908 & 2,150 & 2,132 \\
Gross domestic expenditure & 245 & 312 & 473 & 495 & 475 \\
Consumption & 3,645 & 4,007 & 4,657 & 4,874 & 4,910 \\
$\quad$ Private & 3,021 & 3,395 & 4,062 & 4,318 & 4,376 \\
$\quad$ Government & 2,748 & 3,097 & 3,504 & 3,537 & 3,420 \\
Gross fixed investment & 273 & 298 & 558 & 780 & 866 \\
$\quad$ Private & 662 & 613 & 595 & 556 & 534 \\
$\quad$ Government & 529 & 527 & 375 & 334 & 324 \\
Net factor income & 133 & 86 & 220 & 221 & 210 \\
$\quad$ Remittances & 552 & 386 & 248 & 180 & 292 \\
$\quad$ Receipts & 552 & 386 & 248 & 180 & 292 \\
$\quad$ Payments & 586 & 400 & 262 & 194 & 306 \\
$\quad$ Net investment income & 34 & 14 & 14 & 14 & 14 \\
$\quad$ Receipts & - & - & - & - & - \\
$\quad$ Payments & - & - & - & - & - \\
GNP & -109 & 3,463 & 3,469 & 3,399 & 3,545 \\
\hline
\end{tabular}

Sources: Palestinian and Israeli authorities; and IMF staff estimates. 


\begin{tabular}{|c|c|c|c|c|c|}
\hline & 1993 & 1994 & $\begin{array}{c}\text { Est. } \\
1995 \\
\end{array}$ & $\begin{array}{c}\text { Est. } \\
1996 \\
\end{array}$ & $\begin{array}{l}\text { Est. } \\
1997\end{array}$ \\
\hline $\begin{array}{l}\text { Current account } \\
\text { Current account, excluding grants } \\
\text { Goods and services } \\
\text { Exports of goods and services } \\
\text { Imports of goods and services } \\
\text { Trade balance } \\
\text { Exports, f.o.b. } \\
\text { Of which: Israel } \\
\text { Imports, c.i.f. } \\
\text { Of which: Israel } \\
\text { Services (net) } \\
\text { Remittances (net) } \\
\text { Receipts } \\
\text { Payments } \\
\text { Public investment income (net) } \\
\text { Receipts } \\
\text { Payments } \\
\text { Nonfactor services (net) } \\
\text { Receipts } \\
\text { Payments } \\
\text { Unrequited transfers } \\
\text { Public } \\
\text { Private }\end{array}$ & $\begin{array}{r}-240 \\
-522 \\
-536 \\
831 \\
1,367 \\
-902 \\
236 \\
178 \\
1,138 \\
990 \\
366 \\
552 \\
586 \\
34 \\
\\
\\
-186 \\
9 \\
195 \\
296 \\
282 \\
14\end{array}$ & $\begin{array}{r}-154 \\
-530 \\
-545 \\
712 \\
1,256 \\
-798 \\
227 \\
204 \\
1,024 \\
920 \\
253 \\
386 \\
400 \\
14 \\
- \\
\\
- \\
-133 \\
85 \\
218 \\
391 \\
376 \\
15\end{array}$ & $\begin{array}{r}-679 \\
-1,210 \\
-1,227 \\
736 \\
1,963 \\
-1,327 \\
373 \\
345 \\
1,700 \\
1,521 \\
100 \\
248 \\
262 \\
14 \\
-1 \\
1 \\
-148 \\
100 \\
248 \\
548 \\
531 \\
17\end{array}$ & $\begin{array}{r}-959 \\
-1,459 \\
-1,476 \\
689 \\
2,165 \\
-1,617 \\
283 \\
242 \\
1,900 \\
1,633 \\
141 \\
180 \\
194 \\
14 \\
-1 \\
-1 \\
1 \\
-38 \\
212 \\
250 \\
518 \\
501 \\
17\end{array}$ & $\begin{array}{r}-917 \\
-1,343 \\
-1,361 \\
781 \\
2,142 \\
-1,593 \\
267 \\
212 \\
1,860 \\
1,463 \\
232 \\
298 \\
306 \\
8 \\
-2 \\
2 \\
-64 \\
208 \\
272 \\
444 \\
426 \\
18\end{array}$ \\
\hline $\begin{array}{l}\text { Capital account } \\
\text { Public Sector } \\
\text { Loans } \\
\text { Amortization } \\
\text { Other (incl. net errors and omissions) }\end{array}$ & $\begin{array}{l}240 \\
\cdots \\
240 \\
24\end{array}$ & $\begin{array}{r}154 \\
18 \\
18 \\
0 \\
136\end{array}$ & $\begin{array}{r}1,254 \\
22 \\
22 \\
0 \\
1,232\end{array}$ & $\begin{array}{r}1,237 \\
32 \\
57 \\
25 \\
1,205\end{array}$ & $\begin{array}{r}1,047 \\
37 \\
44 \\
8 \\
1,011\end{array}$ \\
\hline Overall balance & ... & ... & 575 & 279 & 130 \\
\hline Financing (commercial banks (net)) & ... & ... & -575 & -279 & -130 \\
\hline $\begin{array}{l}\text { Memorandum item: } \\
\text { External outstanding debt }\end{array}$ & - & 18 & 40 & 72 & 108 \\
\hline
\end{tabular}

average of about 1 percent per month, demand deposits stagnated, with periods of closures generally inducing temporary reductions in their level. The slower growth and sensitivity to closures of demand deposits reflect both the transient falls in private incomes and expenditures, which depress the transactions demand for money, as well as increases in the precautionary demand for cash during closures. The evolution of the private sector loans to deposits ratio shows an overall rising trend, from 21 percent in January 1996 to about 30 percent toward the end of 1997. While this trend has been interrupted and tempered by the recurrence of closures, it is clear that there exists a strong potential for the ratio to rise steadily during protracted closure-free periods, as witnessed in the period November 1996 to March 1997, and starting in September following the second episode of closures.

The Palestinian Monetary Authority has persevered in its efforts to strengthen its capacity in the area of bank supervision and regulation. The supervision department at the Palestinian Monetary Authority now requires all banks to submit on a regular basis information that would allow a comprehensive assessment of bank soundness, including an appraisal of the quality of banks' loan portfolios, liquidity, and earnings. $\mathrm{Al}$ - 
Figure 2

West Bank and Gaza Strip: Labor Market Indicators, 1992-97

(In thousands)

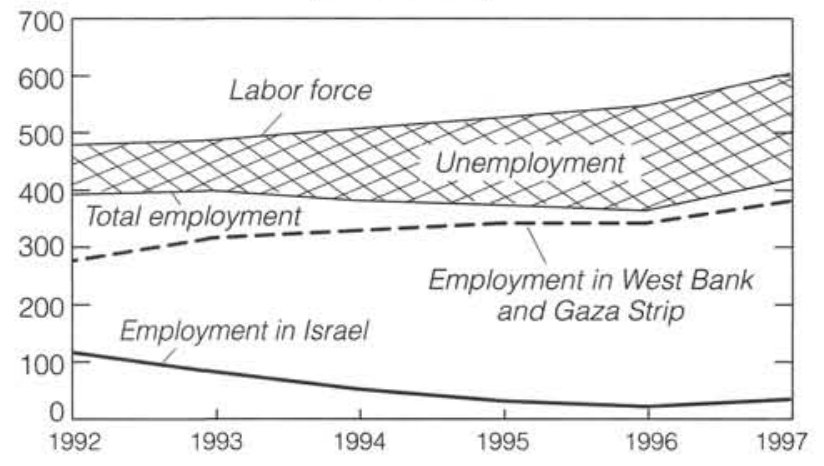

Sources: Palestinian and Israeli authorities: and IMF staff estimates and projections.

though the recurrence of border closures does not appear to have adversely affected public confidence in the banking system, some difficulties in the payment system during closures have been reported. In particular, some banks have temporarily been unable to clear checks due to the restrictions on the movement of bank employees and other bank physical resources, including currency. Although these disruptions have so far not had any serious consequences, in view of their temporary nature and the public's expectations of their removal in accordance with the cycle of closures, the Palestinian Monetary Authority is currently seeking to devise ways to minimize the induced costs.

An important objective of the Palestinian Monetary Authority continues to be the promotion of domestic lending and the stemming of what is viewed as the "export of funds" outside the West Bank and Gaza Strip. To help achieve this objective, the Palestinian Monetary Authority has issued guidelines requiring banks to satisfy the following two ratios by the end of 1997: a minimum loan-to-deposit ratio of 30 percent and a maximum ratio of foreign assets held abroad to total deposits of 90 percent. However, as such requirements may encourage unsound lending practices, a repeal of these guidelines and an increasing focus on indirect means to promote bank lending should be considered by the Palestinian Monetary Authority.

The recurrence of border closures has continued to weaken the linkages between changes in the consumer price index (CPI) in the West Bank and Gaza Strip and economic developments in Israel (Table 7). While the rate of inflation in the West Bank and Gaza Strip for the year as a whole averaged 6 percent, only slightly lower than that recorded in Israel ( 7 percent), the recurrence of closures resulted in important differences between the inflation rates in the two economies in the course of the year, in particular in the second and third quarters. The strong downward pressures on prices during closures, induced through the decline in remittances and other sources of income, were particularly strong following the imposition of the second blockade, as reflected in the steady fall in the monthly rate of increase in the CPI in the West Bank and Gaza Strip from 1.1 percent in July to an average of about 0.3 percent during August-October.

\section{The Palestinian Authority's Policy Stance in 1998 and Beyond}

The Palestinian Authority's medium-term economic approach is focused on developing the economy's domestic productive base and infrastructure, especially in the outward-oriented sectors, with the primary aim of reversing the declining trend in living standards and reducing the high unemployment rate. A key to achieving this objective would be the recovery of private investment from the currently depressed level of 10-11 percent of GDP toward the range of 15-20 percent of GDP that is characteristic of countries at similar levels of development. It is also important to step up the pace of implementation of the public investment program to take advantage of the sizable resources that have been committed by donors. It will not be easy to achieve these objectives, given the unfavorable "exogenous" factors faced by the Palestinian Authority, notably a particularly adverse trade environment due to the recurrence of border closures, a small domestic market, and a high population growth rate (including immigration) of about 5-6 percent per year (Table 8). Despite these challenges, the Palestinian Authority is persevering in the implementation of a broad range of policies and institution-building measures in the fiscal, regulatory, and external areas, geared primarily toward ensuring a stable 
TABLE 5 .

Fiscal Operations of the Palestinian Authority, 1996-97

(In millions of U.S. dollars, unless otherwise indicated)

\begin{tabular}{|c|c|c|c|}
\hline & Est. 1996 & $\begin{array}{l}\text { Draft Budget } \\
1997\end{array}$ & Est. 1997 \\
\hline $\begin{array}{l}\text { Revenue }{ }^{1} \\
\text { Domestic } \\
\text { Tax } \\
\text { Nontax } \\
\text { Clearance }\end{array}$ & $\begin{array}{r}684.2 \\
264.6 \\
178.8 \\
85.8 \\
419.6\end{array}$ & $\begin{array}{r}814.2 \\
301.1 \\
205.1 \\
96.0 \\
513.1\end{array}$ & $\begin{array}{l}816.0 \\
331.8 \\
209.8 \\
122.0 \\
484.2\end{array}$ \\
\hline $\begin{array}{l}\text { Current expenditure } \\
\text { Civil service wages } \\
\text { Police wages } \\
\text { Nonwage expenditure } \\
\text { Other expenditure? }\end{array}$ & $\begin{array}{r}780.1 \\
246.5 \\
156.5 \\
345.0 \\
32.0\end{array}$ & $\begin{array}{r}866.0 \\
296.0 \\
199.0 \\
371.0 \\
-\end{array}$ & $\begin{array}{r}866.0 \\
296.0 \\
199.0 \\
371.0 \\
-\end{array}$ \\
\hline $\begin{array}{l}\text { Current balance excluding foreign-financed } \\
\text { employment programs }\end{array}$ & -95.9 & -51.8 & -50.0 \\
\hline Foreign-financed employment programs & 49.2 & - & 8.6 \\
\hline $\begin{array}{l}\text { Current balance including foreign-financed } \\
\text { employment programs }\end{array}$ & -145.1 & -51.8 & -58.6 \\
\hline Capital expenditure 6 & ... & $\ldots$ & $\ldots$ \\
\hline Of which: Ministry of Finance financed & - & - & - \\
\hline Overall balance & $\ldots$ & ... & $\ldots$ \\
\hline $\begin{array}{l}\text { Financing } \\
\text { Domestic } \\
\text { Financing carried-forward } \\
\text { Foreign } \\
\text { Recurrent budget } \\
\text { Employment generation programs } \\
\text { Capital }\end{array}$ & $\begin{array}{r}\ldots \\
292.9 \\
83.7 \\
49.2 \\
\ldots\end{array}$ & $\begin{array}{l}\cdots \\
- \\
\cdots \\
\cdots \\
\cdots\end{array}$ & $\begin{array}{r}\ldots \\
- \\
34.4 \\
8.6 \\
\ldots\end{array}$ \\
\hline Financing gap & $\ldots$ & 51.8 & 15.6 \\
\hline $\begin{array}{l}\text { Memorandum items: } \\
\text { Revenue }^{3} \\
\text { Current expenditure } 3,4^{3} \text { Current balance }^{3,4} \\
\text { Payment arrears (end-period) } 5\end{array}$ & $\begin{array}{r}21.3 \\
24.3 \\
-3.0 \\
\end{array}$ & $\begin{array}{r}23.0 \\
24.5 \\
-1.5 \\
-\end{array}$ & $\begin{array}{r}25.3 \\
26.8 \\
-1.5 \\
\ldots\end{array}$ \\
\hline
\end{tabular}

Sources: Palestinian and Israeli authorities; and IMF staff estimates.

IOn cash basis, estimates of revenue include collections transferred to bank accounts outside the control of the Ministry of Finance.

2From accounts not directly under the control of the Ministry of Finance.

3in percent of GDP.

${ }^{4}$ Excluding foreign-financed employment programs.

5Payment arrears incurred in the second quarter of 1997 for civilian wages of $\$ 10$ million, pension contribution for police of $\$ 6$ million, and nonwage expenditure arrears of $\$ 5$ million; and in the third quarter for wages $\$ 3.9$ million, for police pension fund $\$ 13.2$ million, and for nonwage expenditures $\$ 51.4$ million.

While donors provide data on their total disbursements in the West Bank and Gaza Strip, only limited information is available on amounts spent by government agencies and ministries.

macroeconomic environment and encouraging a more prominent role for the private sector.

In the fiscal area, the Palestinian Authority is pursuing a prudent public expenditure policy with the objective of achieving increasing recurrent budget surpluses starting in 1998 while re- orienting the pattern of public expenditures toward the health and education sectors and physical infrastructural investments. The draft income tax law currently being discussed aims at ensuring a favorable business environment, in particular by avoiding excessive income tax rates. This ap- 


\section{RECENT EXPERIENCE AND PROSPECTS}

Figure 3

West Bank and Gaza Strip:

Fiscal Indicators, 1994-98

(In millions of U.S. dollars)

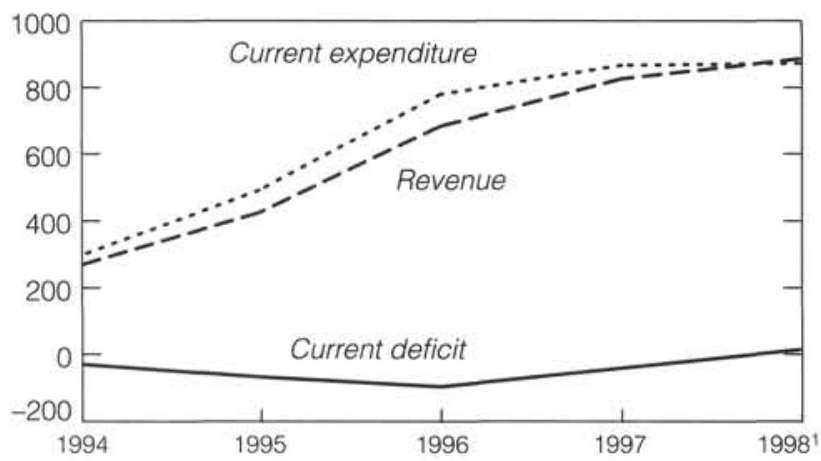

Sources: Palestinian and Israeli authorities; and IMF staff estimates and projections.

${ }^{1}$ According to 1998 budget.

proach is being supported by institution-building measures to further enhance the capacity of revenue administration, especially through improved tax collection and enforcement, and to increase the effectiveness of expenditure management, focusing in particular on enhancing fiscal transparency and accountability.

An increasingly active role is being taken by the Palestinian Authority in the planning and the implementation of the public investment program. Palestinian Authority capital expenditures under the program will henceforth be incorporated into the Palestinian Authority budget, starting with the 1998 budget, and the Palestinian Authority will be assuming increasing responsibility for financing such expenditures. The Ministry of Planning and International Cooperation, with some assistance from the World Bank, has prepared a detailed Palestinian Development Plan that presents a coherent strategy for public investment for the years 1998-2000. The plan envisages investment expenditures of $\$ 3.5$ billion over the three-year period, of which about $\$ 0.8$ billion are linked to ongoing or partially funded projects. In the Consultative Group meeting convened by the World Bank in Paris in December 1997, donors indicated their intention to commit $\$ 750 \mathrm{mil}$ lion in support of the proposed development plan, with \$500-600 million expected to be disbursed in 1998, considerably more than in earlier years.
Figure 4

West Bank and Gaza Strip: Selected Monetary Indicators
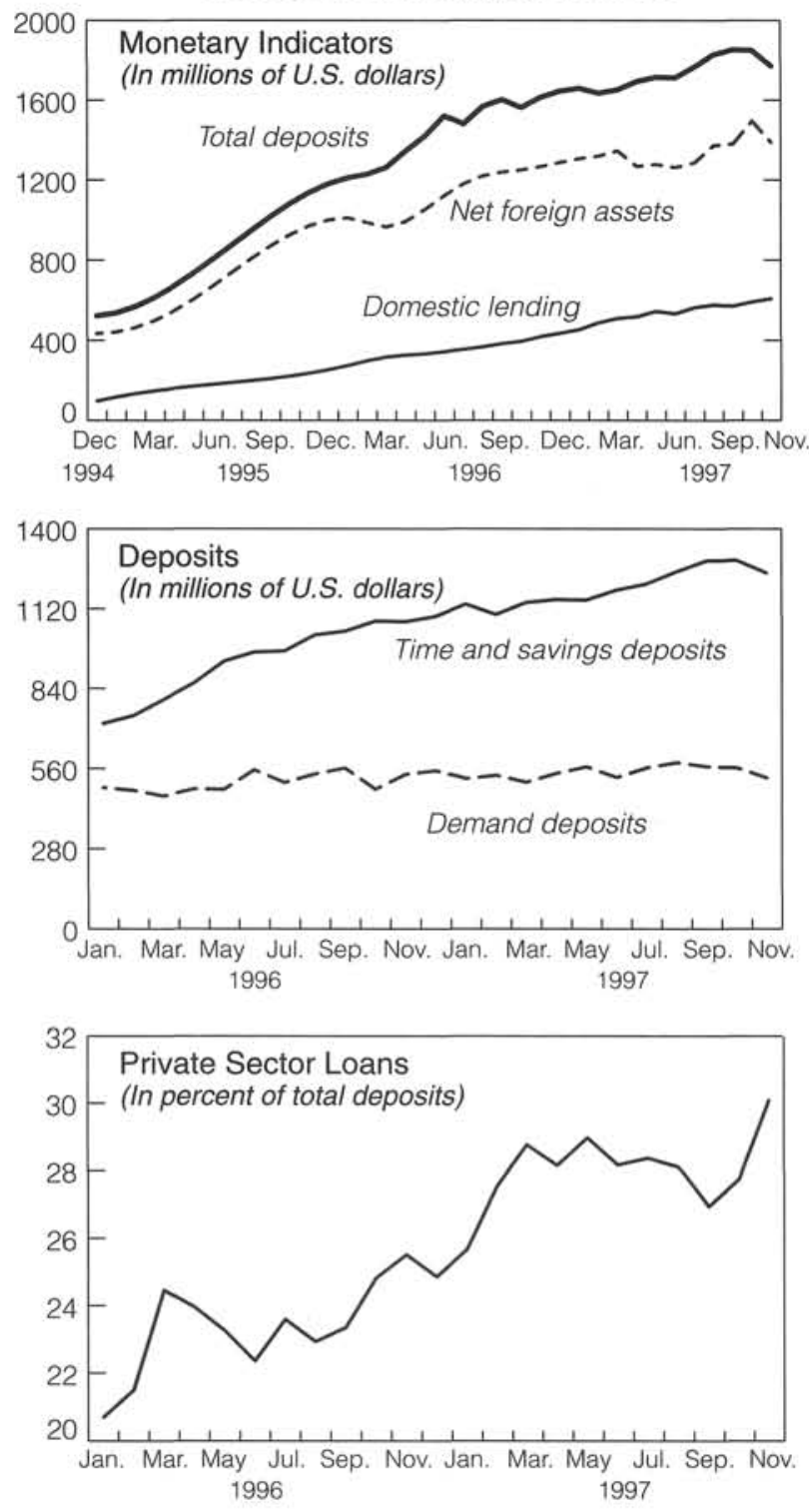

Source: Compiled from data provided by the Palestinian Monetary Authority.

The macroeconomic framework underlying the 1998 budgetary projections assumes only timid improvements in security and political conditions and in the external trade situation, the same average number of Palestinian workers in Israel as in $1997(35,000)$, and continued weak private investment, but some recovery in public investment, which reflects an envisaged higher pace of implementation. Under such conditions, real 
TABLE 6 .

West Bank and Gaza Strip: Consolidated Accounts of the Deposit Money Banks, 1994-971

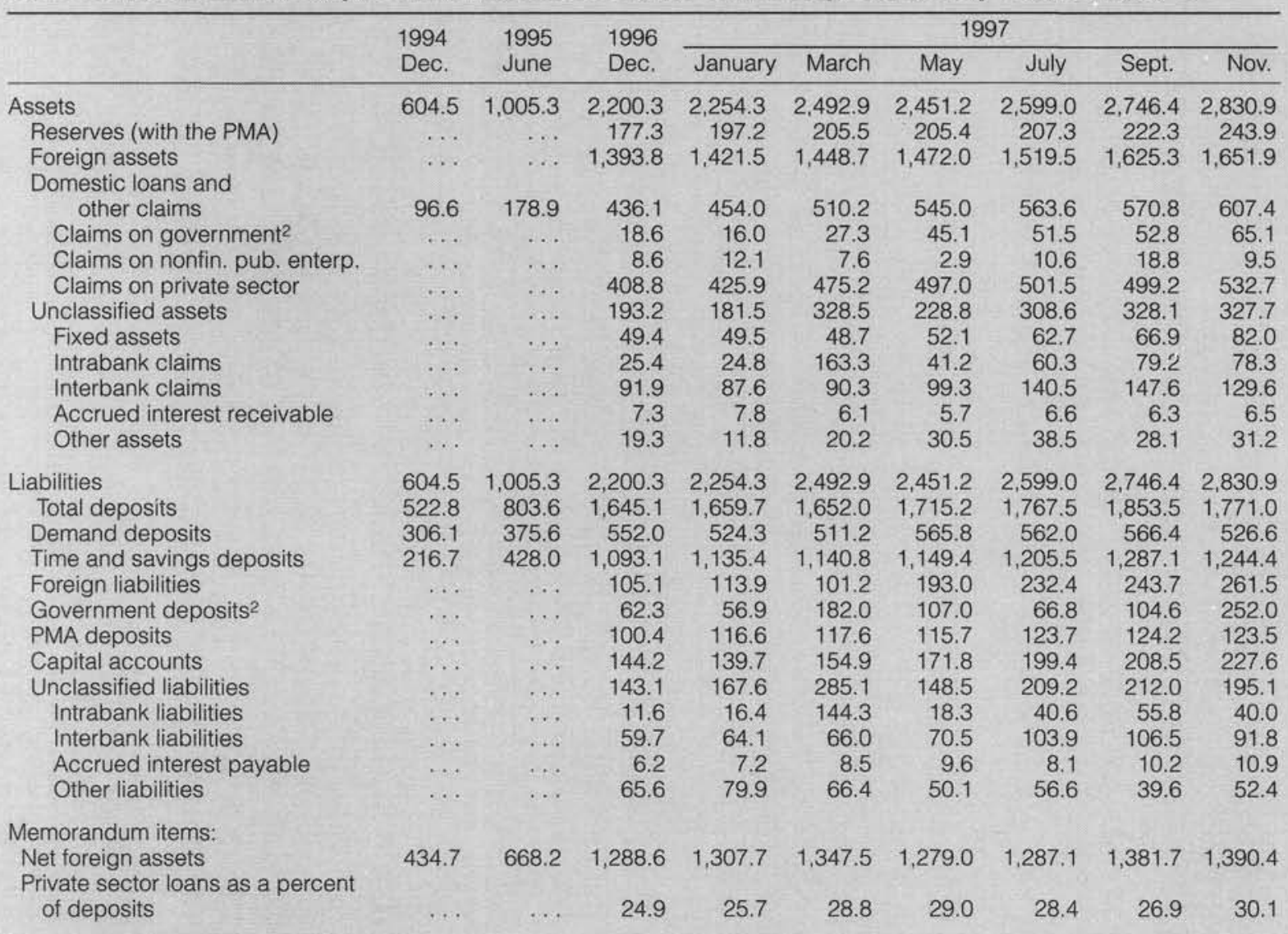

Sources: For 1996 and 1997, figures are from the Palestinian Monetary Authority (PMA). For 1994 and 1995, figures were compiled by the Palestinian Economic Policy Research Institute.

${ }^{1}$ Figures represent end-of-month balances.

${ }^{2}$ Data from the Bank of Palestine may be incomplete.

GDP is projected to rise by 2 percent and average unemployment to remain virtually unchanged at about 31 percent. The 1998 Palestinian Authority draft budget is based on a tight recurrent expenditure policy, aimed at the achievement of a small recurrent surplus, compared with an estimated deficit of $\$ 50$ million in 1997 ( 1.5 percent of GDP). ${ }^{6}$

The key factor underlying the expected improvement in the fiscal position in 1998 is the containment of recurrent expenditures at $\$ 872$

\footnotetext{
${ }^{6}$ Details of the 1998 budget will become available once the budget is approved by the Legislative Council.
}

million, close to the 1997 level, in particular through the absence of a general increase in Palestinian Authority wage rates, and the limiting of increases in Palestinian Authority employment to about 3 percent-consisting of a modest increase in the number of workers in the education and health sectors, with minimal increases in other sectors. Palestinian Authority revenues are prudently projected in the draft budget to increase roughly in line with GDP, on the basis of a continuation of the rising trend in customs revenues from clearances associated with the shift from indirect to direct imports and improved customs administration; and modest increases in the other revenue compo- 
TABLE 7.

West Bank and Gaza Strip: Inflation Rates (Based on Cost of Living Index), 1993-97 1

\begin{tabular}{|c|c|c|c|c|c|c|c|c|c|}
\hline & \multirow[b]{2}{*}{1993} & \multirow[b]{2}{*}{1994} & \multicolumn{7}{|c|}{ Estimated } \\
\hline & & & 1995 & 1996 & 1997:Q1 & $1997: Q 2$ & $1997: Q 3$ & 1997:Q4 & 1997 \\
\hline West Bank and Gaza Strip & 11.0 & 14.0 & 10.8 & 8.4 & 2.4 & 0.5 & 2.1 & 0.7 & 6.0 \\
\hline Israel & 11.3 & 14.4 & 8.1 & 10.6 & 2.6 & 2.3 & 1.3 & 0.6 & 7.0 \\
\hline Jordan & 4.8 & 3.6 & 4.2 & 2.5 & 0.8 & 1.1 & 1.3 & $\ldots$ & 4.7 \\
\hline
\end{tabular}

Sources: Palestinian Central Bureau of Statistics; and IMF staff estimates.

1 Inflation rates show percentage changes in (end-of-period) CPI. Figures shown for quarters show rates of increase over previous quarter.

\begin{tabular}{l} 
TABLE 8. \\
$\begin{array}{l}\text { West Bank and Gaza Strip: Population and Labor, 1993-97 } \\
\text { (In thousands, unless otherwise indicated) }\end{array}$ \\
\hline
\end{tabular}

nents, in line with the projected slow recovery in economic activity and assuming only gradual improvements in tax administration.

To ensure the attainment of the above budgetary targets, it is important that the Palestinian Authority perseveres in its efforts to further strengthen expenditure management and revenue administration. A key measure would be the full consolidation of all revenues and expenditures under the control of the Ministry of Finance, which will enhance fiscal transparency, increase the resources available to the budget, and help prevent the reemergence of liquidity problems. The successful implementation of the public investment program in 1998 hinges on reduced disruptions due to border closures, a continuation of efforts to improve coordination between the Palestinian Authority and donors, and a close follow-up by the Ministry of Planning and International Cooperation of implementation on a project-by-project basis. With regard to revenue administration, the focus should be on further strengthening VAT and income tax collection, especially from large enterprises, on enhancing en- forcement through the effective implementation of the audit strategy, and on raising the effective yield of trade taxes, notably through the creation of an import monitoring unit.

The Palestinian Authority is working closely with World Bank and IMF staff to strengthen the legal and regulatory framework with the aim of improving incentives faced by private investors and limiting the scope for discretionary interventions by the Palestinian Authority in private activities. Toward this end, several key laws are currently being revised, including the Investment Law, the Income Tax Law, and the Company Law. In the same spirit, as part of its general policy to minimize the distortion of incentives and avoid arbitrary interventions in private activities, the Palestinian Authority intends to consolidate all Palestinian Authority commercial operations, including import monopolies, under a fully transparent framework, before their complete elimination by the end of 1998 .

It is important that the steady expansion of the bank deposit base in the West Bank and Gaza Strip continues to be complemented by measures to 
strengthen bank regulation and supervision, with the aim of ensuring a stable financial system and the expansion of sound bank lending. This will be facilitated by the the Banking Law (expected to be enacted in early 1998) and the Palestinian Monetary Authority Law (enacted in late 1997), which establish a coherent legal framework for banking sector operations and provide a clear legal basis for the Palestinian Monetary Authority to enforce prudential regulations on banks and impose penalties in case of noncompliance. The Palestinian Monetary Authority intends to encourage domestic bank lending through measures to facilitate the use of collateral and improve the quality of information available on borrowers, as envisaged in the World Bank Financial Sector Development Program, including through the enactment of the Property Law, the Secured Lending Law and the Condominium Law, and the development of information systems for the registration of assets. The Securities Law is expected to be implemented by mid-1998, which will provide a framework for the regulation of the capital market's operations in line with international standards.
A key component of the Palestinian Authority's medium-term approach is the expansion of trade with the outside world, especially in view of the West Bank and Gaza Strip's small domestic market, the continual disruptions to trade flows with Israel, and the weakness of trade links with non-Israeli markets. The Palestinian Authority is working closely with the World Bank and the IFC in developing industrial zones in the West Bank and Gaza Strip that could be at least partially insulated from the effects of border closures through special security arrangements with Israel. The Gaza Industrial Estate is now nearly complete and is expected to be fully operational by end-1998. In the same spirit, the Palestinian Authority is according a high priority to improving the access of the West Bank and Gaza Strip to markets outside Israel through the development of seaports and airports, to strengthening transport links with Jordan and Egypt, and to tightening the economic integration of Palestinian territories through the establishment of a safe passage between the West Bank and the Gaza Strip. 


\title{
3. Private Investment Under Uncertainty in the West Bank and Gaza Strip
}

\author{
Oussama Kanaan
}

$\mathrm{T}$ here is a broad consensus that the weak private investment performance in the West Bank and Gaza Strip in recent years can be attributed largely to the unfavorable external environment and to adverse political developments, notably the general border closure imposed since 1993 , the intermittent total or "intensified" closures triggered by security incidents, and the uncertain prospects for progress in the peace process. At the same time, there is a growing recognition that, especially in view of what are perceived to be "political constraints" on liberalizing the West Bank and Gaza Strip's external trade environment, there is a need to formulate and implement appropriate economic policies and institution-building measures that would to some degree compensate for the effects of the trade-related constraints. This paper is structured as follows:

- The first section focuses on "the way it used to be" prior to the onset of the peace process, and makes clear the key role of the external trade environment in influencing both the magnitude as well as the composition and quality of private investment. The role of other important factors that have affected private investment, including the influence of the financial and institutional frameworks, is also examined.

- The next section assesses the potential of the economic system envisaged under the Oslo accords to relieve the constraints on private investment that hitherto existed, in particular by offering unprecedented opportunities for the implementation of measures to liberalize the extcrnal trade environment, to develop the financial sector, to improve the quality of infrastructural and institutional support to in- vestors, and to reduce uncertainties relating to the stability of incentives facing investors.

- The present key constraints on private investment in the West Bank and Gaza Strip are then examined, taking into account the important institutional weakness and other economic handicaps inherited from the period of military occupation, and employing the "peace as a turning point" scenario as a benchmark for an assessment of the "way it turned out."

\section{The Way It Used to Be}

\section{Key Features of Private Investment}

The evolution and composition of private investment in the West Bank and Gaza Strip has historically reflected to a large extent changes in the volume and pattern of trade in goods and services between the West Bank and Gaza Strip and Israel.

Following the Israeli occupation, the West Bank and Gaza Strip's external trade, which had been previously directed mostly toward neighboring countries of comparable wealth and level of development, was swiftly reoriented toward the economically more advanced Israeli economy, which had a GNP about 20 times as large. ${ }^{1}$ The opening of Israeli markets to Palestinian employment and, to a lesser extent, to commodity exports, was reflected in remarkably high rates of real GNP growth, which averaged 30 percent per year over the decade 1969-79. This high rate of

\footnotetext{
${ }^{1}$ For historical data for the period 1969-93 on GDP, GNP, and investment in the West Bank and Gaza Strip, see World Bank (1993) and Statistical Abstracts of Israel (1969-93).
} 


\section{Figure 1}

\section{West Bank and Gaza Strip: Gross Fixed Investment, 1969-97}
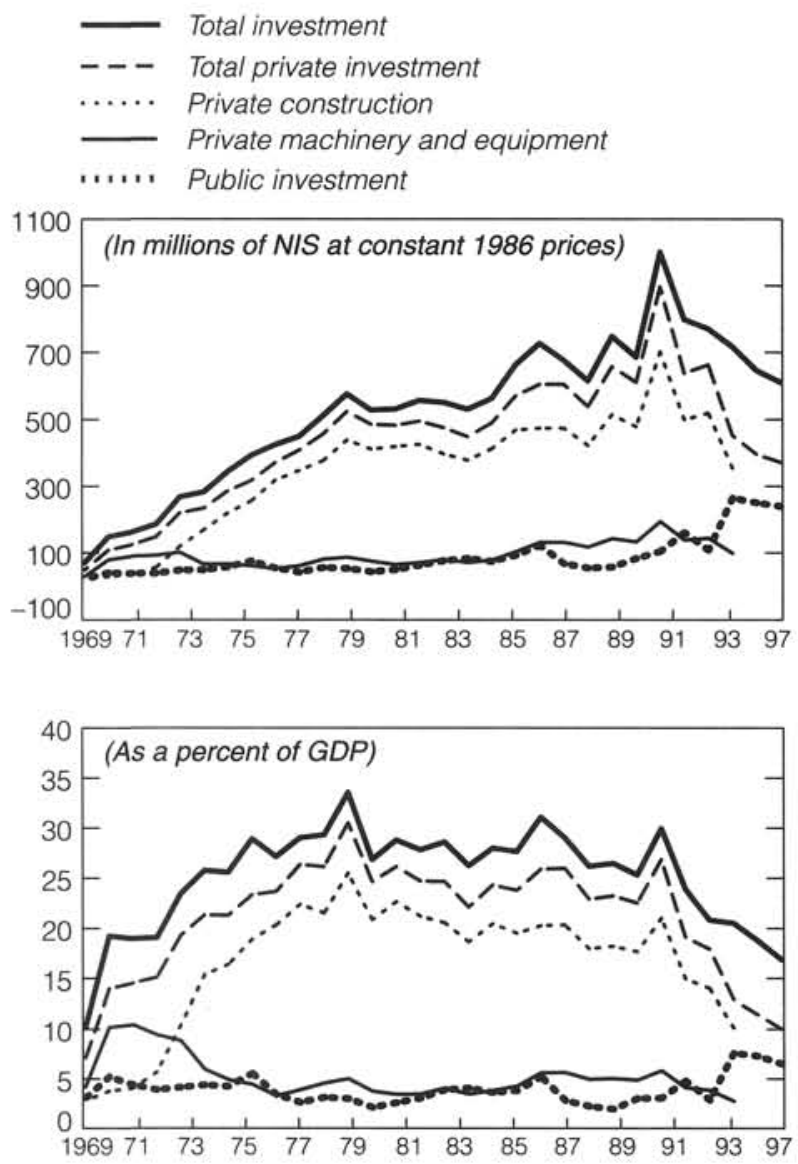

Sources: For years 1969-93, data are from the Statistical Abstracts of Israel (1969-93) and World Bank (1993); starting in 1994, data are IMF staff estimates and from IMF (1997).

income growth was accompanied by a rise in private investment as a share of GDP from about 14 percent in 1969 to 30 percent in 1979, with real private investment growing at an average of 25 percent per year (Figure 1).

Although this surge in private investment appears impressive, the composition of the increase in investment was heavily skewed in favor of investment in construction. The increase in private investment consisted almost entirely of increases in construction investment, largely in housing, which represented an average of 85 percent of total private investment over the period. In contrast, real investment in machinery and equipment grew by a yearly average of less than 1 percent, while as a share of GDP it fell steadily from about 10 percent of GDP in 1969 to 5 percent of GDP in 1979.

The concentration of private investment in residential construction, along with the virtual stagnation of investment in machinery and equipment, suggests that investment was being largely driven by growth, while making a relatively limited contribution as a potential source of growth for subsequent periods. ${ }^{2}$ Reflecting the limited "feedback effect" running from investment to growth, the tapering off of the initial boost to growth provided by the "integration effect," in particular the slowing of the pace at which labor shifted from low-productivity agriculture to higher-wage employment in Israel, resulted in a sharp deceleration of real GNP growth to a yearly average of about 5 percent in 1980-91. As a result, private investment was virtually stagnant during the latter period, growing at a yearly average of less than 1 percent, while its pattern remained heavily skewed in favor of residential construction.

The predominance of housing investment in overall private investment, and in particular the limited increase in investment in machinery and equipment, can be explained by a number of important factors. The first and key factor is the skewed pattern of trade between the West Bank and Gaza Strip and Israel, which suppressed the development of a large part of the domestic productive base, in particular of agriculture and industry, while encouraging services. Second, the absence of a developed system of financial intermediation reinforced the bias of the private investment pattern in favor of the housing sector and against the industrial and agricultural sectors. Third, the Israeli authorities provided little support to private investment in the form of public investment in infrastructure, nor did they create a favorable legal and regulatory environment. Fourth, the uncertainty with regard to political stability further stifled private investment in the productive sectors.

\section{The Key Role of the Trade Environment}

The trade regime with Israel was characterized by the absence of barriers to Israeli exports to the West

\footnotetext{
${ }^{2}$ Empirical evidence from developing countries on the contribution of different types of capital goods to economic growth strongly suggests that investment in machinery and equipment plays a key role as a source of growth. See for example De Long and Summers (1991) and Romer (1989).
} 
Bank and Gaza Strip, but with restrictions on Palestinian agricultural and industrial exports. ${ }^{3}$ This was reflected by large trade deficits in both agricultural and industrial products with Israel, ranging from about 25 to 30 percent of GDP since 1969 , financed to an important degree by the export of labor services. The asymmetries in the external trade environment resulted in an agricultural sector oriented largely toward domestic production, using mostly traditional techniques. Similarly, trade and licensing restrictions on industrial exports, along with the impact on labor costs of the demand-pull effect of employment opportunities in Israel, constrained the development of the industrial sector, which consisted largely of family-based microenterprises, with more than 90 percent of all enterprises employing eight or fewer workers. The share of industry in GDP stagnated in the range of 6-8 percent starting in 1969, well below the range of about 20 to 30 percent of other countries with comparable income levels. The asymmetric trade regime with Israel thus contributed to a strong bias in the composition of investment against agriculture and industry, representing the main potential outlets for investment in machinery and equipment, and in favor of investment in housing, which became the preferred vehicle for savings.

There were also other important factors, in addition to the key role of the trade environment, that tended to reinforce the skewed pattern of private investment.

\section{Absence of a Developed System of Financial Intermediation}

The financial sector in the West Bank and Gaza Strip prior to 1992 consisted of two or three banks offering a limited range of services, with low levels of domestic lending, operating alongside a wide system of moneychangers. There were no markets for equity, long-term debt, or government securities, and no instruments or vehicles for risk management. This absence of developed

\footnotetext{
${ }^{3}$ Restrictions on agricultural exports consisted of quotas on vegetable exports, while restrictions on industrial exports consisted of strict licensing requirements. In addition to these direct trade restrictions, the production of exportables was stifled by the Israeli policy of subsidizing Israeli agriculture and industry, including through subsidies on factors of production, credit at concessional rates, export finance, and minimum price supports through marketing boards. For a discussion of asymmetries in the external trade regime in the West Bank and Gaza Strip, see Nashashibi and Kanaan (1994).
}

formal channels of financial intermediation encouraged the channeling of savings toward investments that could more easily be self-financed or financed by a small group of savers through informal channels, in particular in residential construction, and away from investments in sectors that required longer-term risk capital, notably in modern farming and industry.

\section{Inadequate Infrastructural Support and Absence of a Supportive Legal and Regulatory Framework}

Public expenditure by the Israeli authorities in the West Bank and Gaza Strip consisted largely of military and security-related current expenditure, providing little in the way of infrastructural support for private investment. Public capital investment stagnated in the range of 3-6 percent of GDP throughout the 1969-91 period, well below levels in other developing countries (Figure 1). In the same vein, the Israeli authorities did little to provide a supportive legal and regulatory framework for private investment. Private investors were faced with a confusing amalgam of British Mandate, Jordanian, and Egyptian laws, periodically amended or suspended on an ad hoc basis by Israeli Military Orders. In effect, the framework provided strict controls on the entry of foreign funds, imposed strict restrictions on the repatriation of earnings and capital, and did not provide for adequate dispute resolution mechanisms. In addition, the authorities implemented a cumbersome and non-transparent system for the allocation of investment licenses. Such an environment encouraged household-based investments that required little infrastructural support, and that minimized the degree of interaction between investors and the authorities, an important attribute of nonentrepreneurial investments in residential construction and of investments in family-based microenterprises.

\section{Political and Economic Uncertainty Associated with the Military Occupation}

Insofar as private investors viewed the state of military occupation as a source of perpetual social and political tensions, they also perceived the overall political and economic environment associated with the occupation as inherently unstable. There 
was thus a "strategic" uncertainty with regard to the duration of the prevailing "status quo" (in particular with regard to the nature of economic relations between the West Bank and Gaza Strip and Israel and the West Bank and Gaza Strip's access to external markets) and to the corresponding structure of incentives affecting the profitability of investments. This uncertainty, which was especially high during the period of the Intifada, induced entrepreneurs to postpone investments in order to acquire key information on the structure and stability of incentives expected to prevail in the longer term. It tended in particular to discourage larger-scale investments in capital-intensive projects with significant "sunk" costs and long gestation periods. This uncertainty had a more limited adverse impact on smaller-scale, family-based investments, such as in housing and microenterprises, whose profitability was less vulnerable to market disruption.

\section{The Peace Process as a Potential Turning Point}

The peace accords signed in the early 1990s between the Israeli and Palestinian authorities promised an economic and political environment that had the potential to substantially relax or eliminate all of the constraints on private investment discussed above.

\section{The Liberalization of External Trade}

The Economic Protocol on Economic Relations signed in 1994 envisaged a trade regime for the West Bank and Gaza Strip in the interim period that was highly conducive to the expansion and reorientation of the economy's productive base toward agricultural and industrial export production, and that gradually reduced its dependence on the export of labor services. From the viewpoint of private investors, an important attractive feature of the Protocol lies in the envisaged removal of most restrictions on Palestinian commodity exports to the Israeli market, thereby increasing the profitability of investments in agricultural and industrial production. ${ }^{4}$ It also al-

\footnotetext{
${ }^{4}$ The only remaining restrictions would consist of quantitative restrictions on six agricultural products, which would be gradually reduced according to an agreed-timetable, and fully eliminated by 1998 .
}

lowed Palestinians more flexibility, albeit on a very limited scale, in determining their own import policies and tariff structure with regard to specific products and countries, including raw materials and capital goods from neighboring Arab countries, with potential favorable effects on investment costs.

Despite the advantages outlined above, the Economic Protocol still had certain limitations. In addition to the restrictive import policy, it did not address important disadvantages to the trade environment in the West Bank and Gaza Strip, in particular the absence of significant outlets to external markets, including of seaports and airports, and the prevalence of significant impediments to trade within Palestinian areas, in particular between the West Bank and the Gaza Strip. Nevertheless, although such key trade-related issues were postponed to later negotiations, high expectations were formed simply by such issues being placed on the negotiating table. Investors' expectations were further buoyed by the Palestinian Authority's stated resolve to minimize distortions in market incentives and to pursue a "private-sector led outward-oriented export promotion strategy" (a phrase cherished in official declarations) once it is granted powers over key economic spheres.

The peace process and the associated agreements, in addition to heralding a favorable trade environment to investors, had the potential to promote private investment opportunities by relaxing other important constraints.

\section{Development of the Financial Sector}

The dearth of banks in the West Bank and Gaza Strip during the period of occupation resulted in a large part of household savings being held in financial institutions outside the country, stored through informal domestic financial channels, or hoarded in cash. There was thus a large pent-up demand for formal financial channels of intermediation that would provide more profitable or convenient channels for such savings. The very rapid expansion of the banking sector and the fast rise in banking deposits even in the early stages of the peace process was a reflection of such conditions. At the same time, the absence of formal financial channels constrained access to finance by investors in need of long-term risk capital. There was thus an anticipation that, as an outcome of 


\section{PRIVATE INVESTMENT UNDER UNCERTAINTY}

the change in the trading environment and other favorable implications of the peace process, there would be a boom in domestic private investment demand that would offer lucrative domestic outlets to a large stock of financial savings.

\section{Substantial Infrastructural and Institutional Support}

The very low levels of public capital investment undertaken by the Israeli authorities during the occupation resulted in a dilapidated state of physical infrastructure, which increased an important component of investment costs, in particular those related to transportation. Such costs were expected to decline as a result of the implementation of the public investment projects, to which donors committed about $\$ 1.2$ billion for the period 1994-96 in the form of fixed capital investment, an important part of which were given in support of physical infrastructure. This represented a formidable increase compared to past public investment levels, which averaged $\$ 150$ million per year in 1990-93. Private investors also hoped for a supportive institutional framework, in particular a transparent legal and regulatory framework that would, in line with the Palestinian Authority's stated "market-friendly" stance, minimize the scope of government "meddling" in private sector activities. The productivity of private physical capital and the strength and quality of institutions (including the quality of public services) in the West Bank and Gaza Strip were also expected to benefit from an anticipated large inflow of human capital into the West Bank and Gaza Strip, embodied in a large pool of highly skilled Palestinians living in the diaspora, which would be attracted by the liberalization of the political and economic environment under Palestinian self-rule.

\section{Reduced Uncertainties Relating to the Overall Economic and Political Framework}

The rapid progress in the peace process at its earlier stages, and in particular the transfer of control over important economic spheres to the Palestinian Authority, signaled improved prospects for a stable political and economic environment and an associated stable structure of incentives facing investors. Although the "incremental approach" adopted in the peace accords, and in particular the postponement of key issues governing the nature of the trade environment to a later stage, maintained some degree of uncertainty for private investors, sources of social and political tensions appeared substantially diminished in the period immediately following the peace agreements.

\section{The Way It Turned Out}

The peace process thus had the potential to yield substantial welfare gains, largely through rapid growth in private investment and a reorientation of the investment pattern toward the economy's outward-oriented productive base. However, a look at the evolution of private investment since 1993 reveals a radically different and disturbing picture (Figure 1). In 1993-97 real private investment is estimated to have declined by an average of 10 percent per year, and private investment's share in GDP to have declined from 19 percent of GDP in 1993 to 10 percent of GDP in 1997. What went wrong?

\section{The External Trade Environment}

As we have seen earlier, the dominant role played by external trade in goods and services in the Palestinian economy makes the profitability profiles of investments especially vulnerable to changes in the external trade environment. The trade regime that prevailed in the West Bank and Gaza Strip since 1993 was characterized by the imposition since 1993 of strict controls at the borders, including stringent security requirements and procedures on goods and labor, and the recurrence of intermittent "total" or "intensified" closures that impose a transient state of virtual autarky of uncertain timing and duration. The regime of closures operated in the context of very limited access to markets outside Israel due to the absence of functioning seaports and airports.

Before looking closely at the effects of the regime of closures on investment incentives at the microeconomic level, it would be useful to first take a "bird's eye view" of the implications of the closures on production and investment at the economywide aggregate level. ${ }^{5}$

\footnotetext{
${ }^{5}$ See the Appendix for an illustration using the two-good trade theoretic model.
} 
The regime of closures and the corresponding trade restrictions induce a distortion of incentives faced by producers and consumers in the West Bank and Gaza Strip, which leads to reductions in the standard gains from trade and losses in the efficiency of resource allocation and social welfare. As the profitability of the export sector is reduced relative to that of other sectors, a "distorted" pattern of resource allocation and production emerges, with a corresponding shift in the composition of investment away from the "socially optimal" allocation. In the presence of adjustment costs and price rigidities, the regime of closures has a further depressing effect on aggregate investment induced by the adverse effects on aggregate income and demand. The demand for exports of goods and services is directly reduced by export barriers inherent in the regime of closures, whereas the demand for the output of other sectors is indirectly depressed due to aggregate income losses. The restrictions on the import of production inputs and factors of production, and the increase in transportation costs, induce an additional adverse effect on aggregate investment by raising production costs in all sectors. Finally, the "stop-go" cycles that characterize the regime of closures compound the adverse effects on investment of the changes in "average levels" of openness, aggregate and sectoral demand, and production costs.

The effects of the regime of closures could be more concretely revealed by examining the approach of an investor who is making decisions with the objective of maximizing profits, on the basis of an assessment of the profitability profiles of alternative investment projects. The "projects," defined broadly, could consist of capital investments to expand an existing enterprise or to establish a new enterprise. Insofar as the key variable influencing the investor's decisions is the net present value of the project under consideration, the investor needs to form expectations on the path of costs and revenues likely to be realized in the project's lifetime. ${ }^{6}$

\footnotetext{
${ }^{6}$ The net present value of a project is defined as the sum of the net income streams (revenues minus costs) expected in each period of the project's lifetime, discounted by a riskadjusted rate. The risk-factor in the discount rate reflects the uncertainty regarding the realization of the expected values of costs and revenues. One measure of the "risk" that reflects this uncertainty is related to the perceived variance of net income streams in future periods.
}

Figure 2
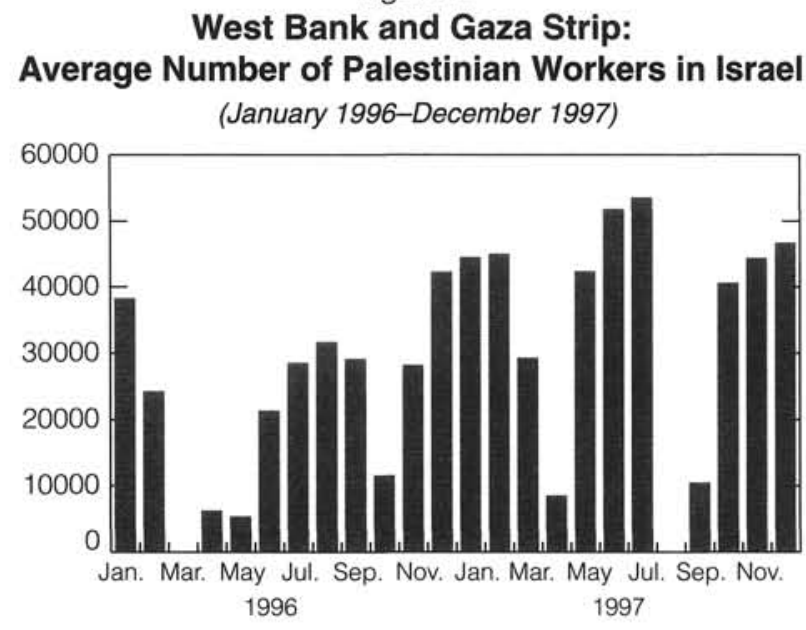

Sources: Palestinian authorities; and IMF staff estimates.

The regime of closures can potentially affect producers' revenues and costs both through its effect on the average levels of effective demand and production costs, and by sharply increasing the variability of demand and costs. This dual effect can be illustrated by considering the effects of the regime of closures on the effective demand for Palestinian labor services in Israel. Figure 2 shows the number of Palestinian workers in Israel in each month in 1996 and 1997. Two effects of the closures can be noted. First, the closures had an "average level" effect by reducing the number of Palestinian workers in Israel from an average of more than 100,000 prior to the regime of closures to an average of about 30,000 in 1996-97. Second, the closures introduced cyclical fluctuations in the effective demand for Palestinian labor in Israel, with the number of workers in Israel declining to a negligible level during periods of closures, then rising back to a peak level as closures are lifted, before dipping again as closures are reimposed. When examining the implications of the regime of closures on the path of costs and revenues, it is thus important to consider the extent to which the cycles introduced by the "stopgo" feature of closures compound the adverse effects on average levels.

\section{Impact on Expected Revenues}

From the point of view of the investor in the $e x-$ port sector assessing sales prospects over the project's time horizon, a key question that arises re- 
lates to the extent to which export sales forgone during periods of closures can be recouped during periods of open borders, and the effect of the "stop-go" cycle of closures on the permanent level of demand for exports. There are two characteristics of the West Bank and Gaza Strip export sector that tend to limit the degree of recoupment of export revenue losses and to make the sharp cyclical fluctuations in demand especially harmful. First, a large share of export activities is in the agricultural and horticultural sectors, whose output is highly perishable and thus involves high storage and inventory costs. ${ }^{7}$ Faced with such costs, farmers in the West Bank and Gaza Strip have often found it necessary to "dump" in the domestic market agricultural and horticultural products targeted at higher income consumers abroad, with adverse effects on prices and sales revenue. Second, whereas the orientation of the West Bank and Gaza Strip's export sector is heavily concentrated toward the Israeli market, with very limited access to other outlets, Israel's trade orientation is much less dependent on the West Bank and Gaza Strip markets, given its well established outlets and access to markets outside the West Bank and Gaza Strip. The costs to Israeli importers of an unanticipated interruption of supply during closures reduce the competitiveness of exports from the West Bank and Gaza Strip. These costs, given the flexibility of Israel's import orientation, is prone to induce a "permanent" decline in demand for exports from the West Bank and Gaza Strip, which could persist well beyond the downturns of the cycles of closures.

The effect of the regime of closures on demand for the output of the import-substitutes and nontradables tends to be less pronounced both in terms of the adverse effect on "average levels" as well as variability, since it operates indirectly through the effect on aggregate income. Aggregate income will be falling during the period of total border closures, and rising during the period of opening. The extent to which these fluctuations would be reflected in shifts in domestic consumer demand, and

\footnotetext{
${ }^{7}$ Data on the composition of exports from the West Bank and Gaza Strip are very limited. The most recent available data are from the bulletins of the Ministry of Planning's Statistics Department, which provide information on the composition of exports of goods from the Gaza Strip during the first six months of 1996. These show that out of a total of NIS 60 million exported during this period, about NIS 27 million, or 45 percent, is classified as either "citrus" or "fruits and vegetables." See CBS (1996).
}

thus in revenue from the sales of import-substitutes and nontradables, would depend on the extent to which consumers smooth their consumption patterns, in particular through saving/dissaving and recourse to credit markets. However, domestic sales revenue will unambiguously be adversely affected by the decline in "permanent" aggregate income, corresponding to the permanent reduction in the gains from trade compared with the pre-closures regime. The fluctuations in relative prices could induce a "substitution effect" corresponding to the shift in domestic demand from imports to domestically produced goods, which could temper the above "wealth effect."

\section{Impact on Expected Costs}

A key channel through which the regime of closures affects production costs is through the unanticipated disruption for uncertain periods of the importation of production inputs, in particular capital goods and raw materials. The recurrence of total closures would be expected to induce firms to raise their levels of inventories of production inputs to serve as buffer stocks in anticipation of closures. Although little data are available to allow the assessment of costs to producers of tying up resources in inventories of imported production inputs, these would be expected to be high on a priori grounds, in view of the high dependence on imported inputs of most commodity-producing activities in the West Bank and Gaza Strip, especially in the industrial and construction sectors. ${ }^{8}$ While the costs associated with the inability to import inputs are incurred only during periods of total closures, producers have witnessed since the imposition of generalized closures in 1993 a substantial rise in transportation costs as a result of very stringent security controls and delays at the borders. ${ }^{9}$ While such an increase in input costs affects virtually all

\footnotetext{
${ }^{8}$ Data on the composition of imports of goods to the Gaza Strip from CBS (1996) give some feel to the reliance of the economy on imported inputs. The data indicate that in the first six months of 1996, out of NIS 520 million in total imports, about 17 percent consisted of building materials, 9 percent of machinery and equipment, 9 percent of fuel products, and 4 percent of spare parts.

${ }^{9}$ For example, according to World Bank (1997a, chapter 3), the transportation costs for a truckload of goods between the West Bank and Gaza Strip increased from around NIS 500 in 1993 to NIS 1,500 in 1996.
} 
sectors, the export sector bears the additional burden of higher transportation costs on the output side, especially for perishable exports such as agricultural and food products.

The regime of closures can impose other types of production costs due to the unanticipated and pronounced shifts in demand associated with the stop-go cycle. First, firms are unable to fully adjust capacity and the level of inputs to match the cyclical fluctuations of demand, resulting in unused capacity and the retention by firms of unutilized inputs (including labor) during the periods of closures. Second, undertaking unexpected and large changes in production levels can involve substantial costs in cases where firms need to make binding decisions or "plans" with regard to future levels of production on the basis of anticipated demand conditions. ${ }^{10}$ To temper such cost effects, firms may resort to "production-smoothing" by accumulating inventories during periods of closures, which are then drawn down after borders reopen. ${ }^{11}$ Such production-smoothing itself involves the cost of tying up resources in inventories and of maintaining the quality of inventories. The costs of unanticipated demand shocks would be expected to be especially high for the large share of West Bank and Gaza Strip exports consisting of perishable agricultural and horticultural exports, because decisions on production levels have to be made well in advance of the time of export.

The adverse effects of the downturns of the regime of closures on the cash flows of firms are compounded by the high cost of and limited access to credit due to the important institutional weaknesses in credit markets in the West Bank and Gaza Strip and to induced credit-rationing, as will be examined closely below. Again, the "dual effect" inherent in the regime of closures is

\footnotetext{
${ }^{10}$ Miron (1996, chapters 4-5) reviews micro-level evidence from industrialized countries on the costs of changing production levels in response to changing demand conditions as well as evidence suggesting that unused capacity at the firmlevel tends to increase with the variability of demand. Van Ewijk (1997) discusses the costs in the form of productivity losses at the firm level when demand cycles involve severe downturns during which factors of production are not utilized. The losses in productivity occur as a result of the decay in skills and knowledge during periods of inactivity, in particular in the form of losses in labor skills as on-the-job "learning by doing" is interrupted.

${ }^{11}$ See Fair (1989) and Miron and Zeldes (1988) for discussions of the role of inventories in production-smoothing in response to demand cycles.
}

operative here. The "average degree" of credit rationing not only increases because of higher uncertainty during closures, but rationing is likely to become more severe during the downturn of the closures cycle, as banks perceive an increase in the lending risk. ${ }^{12}$ This "cycle effect" tends to further limit the producer's ability to offset the impact of the reduced net cash flows (as a result of lower sales and the higher production costs discussed above), thus raising the perceived risk of illiquidity and the expected costs associated with such illiquidity over the project's time-horizon.

In addition to the impact of the uncertainty with regard to the timing and duration of the total closures, there is a second source of uncertainty that could inhibit private investment. Investors do not view the current external trade regime as permanent, but one that is subject to change depending on the outcome of the Palestinian-Israeli negotiations, and in particular with regard to permanent status issues. This introduces a "strategic" uncertainty with regard to the duration of the current "status quo" for the external trade environment and the associated structure of incentives facing investors, in particular with regard to the continuation of the current regime of border closures, the size of the "domestic" market (as determined for example by the size of the areas in the West Bank and Gaza Strip under Israeli control relative to that under Palestinian control), and the extent of access to external markets. In the context of such strategic uncertainty, the existence of entry and exit costs could introduce an incentive to postpone investment in order to acquire additional information on the profile of costs and revenues expected to prevail in the medium and long term. ${ }^{13}$

There is one potentially favorable effect of the regime of closures on production costs. During periods of closures, the supply of labor in the domestic market in the West Bank and Gaza Strip increases as a result of the fall in the number of

\footnotetext{
${ }^{12}$ The increase in the degree of credit rationing during severe downturns of economic cycles is discussed in Stiglitz (1993).

${ }^{13}$ The existence of entry and exit costs to investment (partial or full irreversibility) induces investors to balance the value of waiting for new information affecting their profitability profile with the cost of postponing their investment in terms of profits forgone while waiting. See, for example, Abel et al (1996) and Ingersoll and Ross (1992) for a discussion of the implications on investment of strategic uncertainty in the presence of such costs.
} 
workers allowed in Israel, which could reduce labor costs to domestic producers. Available data from labor force surveys, however, show no significant variations in domestic wage rates commensurate with the wide fluctuations in the number of workers allowed in Israel. ${ }^{14}$ On a priori grounds the following two features may be at play. First, even in periods of open borders during which the number of workers allowed in Israel reaches its peak, the unemployment rate in the West Bank and Gaza Strip remains at more than 25 percent. This suggests that equilibrium domestic employment levels may be bound by constraints on the demand side of the labor market, thus limiting the effect of the greater supply of workers previously employed in Israel on domestic wage levels. Second, producers may find it more costly, ceteris paribus, to employ less "reliable" workers who are expected to abruptly revert to the more lucrative employment in Israel whenever borders reopen; this tends to limit the degree of competitiveness and "fungibility" of workers normally employed in Israel in relation to those of other domestic workers with similar skills.

\section{Summing Up: Implications for Profitability of Investments}

Viewed from the perspective of a private investor seeking to assess the profitability of projects in the West Bank and Gaza Strip, the regime of border closures has several features that could exert strong downward pressures on the projects' net present value (NPV). Producers' revenues are adversely affected by the decline in the average level of demand and the increase in its variability. Costs are raised through higher

\footnotetext{
${ }^{14}$ The results of four labor force surveys conducted by Palestinian Central Bureau of Statistics (1997) in 1996-97 show a 9 percent decline in real daily wages in the West Bank and Gaza Strip in the first quarter of 1997 compared with the average in 1996 (see, for example, UN (1997) for an overview). However, variations in the average daily net wage did not reflect the wide fluctuations in employment in Israel as a result of changing border restrictions. Thus, in the West Bank the daily wage remained stable in the range NIS $47-50$ while the share of the West Bank labor force employed in Israel and settlements varied widely between 11 percent and 21 percent; similarly, results for the Gaza Strip show that the daily wage rate remained at NIS $41-43$, while the share of the Gaza labor force employed in Israel and settlements varied between 4 percent and 14 percent.
}

transportation costs, disruptions of production due to difficulties in importing inputs, and through the adjustment costs incurred in adapting the level of output and capacity to fluctuating demand conditions. The institutional weaknesses in the credit market in the West Bank and Gaza Strip and the induced credit rationing has an adverse effect on the NPV by raising the cost of and limiting access to credit. The existence of strategic uncertainty with regard to the duration of the current "status quo," in particular with regard to duration and nature of the current external trade environment, in conjunction with entry and exit costs, has a further depressing effect on private investment. The only potentially beneficial side effect of the closures is the impact on labor costs, but even this effect appears to be tempered by the overall depressed demand conditions and the "on-off" cyclical feature of the regime of closures.

The adverse effects on the investments' net present value is especially strong in the export sector, where the effects on demand conditions are much more direct and pronounced than in other sectors. In the import-substituting and nontradables sectors, the downward pressures on the net present value are tempered by the change in relative prices in their favor induced by the shift in domestic demand from imports to domestically produced goods. The regime of closures thus has features that depress the profitability of investments in all sectors, with adverse effects on aggregate investment, and features that induce a shift in the composition of investment away from the export sector by changing the relative profitability of investments across sectors.

\section{Access to Sources of Finance}

As had been anticipated, a rapid expansion in the banking system in the West Bank and Gaza Strip has taken place, resulting in a rise in the banking sector deposit base from less than $\$ 500$ million in early 1993 to about $\$ 1.9$ billion by the end of 1997. Contrary to what was hoped for, however, less than a third of this base was lent to the domestic private sector. As we have seen above, the unfavorable external trade environment in the West Bank and Gaza Strip, in particular the regime of border closures, adversely affects private investment demand at the aggregate level by increasing risks and reducing expected returns. 
This would be reflected in a wide gap between bank lending capacity and credit to the private sector. At the same time, there are important institutional weaknesses characterizing the financial sector in the West Bank and Gaza Strip, which could potentially, when investment demand picks up, constrain access to, or increase the cost of, bank credit to creditworthy investors with profitable projects by inducing "credit rationing." 15

There are several key factors in the West Bank and Gaza Strip that could contribute to credit rationing: (1) the prevalence of imperfect information on the risk-return profiles of investors and on their ability to bear risk; (2) the absence of an adequate legal framework that would encourage the use of collateral in bank lending and thus reduce the high lending risk associated with imperfect information; and (3) the high liquidity risk of long-term lending, given the short-term nature of the bulk of deposits and the absence of markets for long-term debt in the West Bank and Gaza Strip.

\section{Imperfect Information}

In the West Bank and Gaza Strip the following sources of imperfect information have prevailed: (1) the virtual absence of banks for more than 25 years, and the consequent lack of experience of banks with lending in the specific conditions of the West Bank and Gaza Strip; (2) the large pool of potential borrowers with no previous experience in borrowing from banks, and no "track record" or bank credit history that can be used by banks to adequately assess a proposed investment project's prospects; and (3) the absence of a credit appraisal and rating system that would facilitate banks' assessment of the credit risk of borrowing enterprises.

A number of donor projects are currently being implemented, notably as part of the World Bank's Financial Sector Project and Microenterprise Project, that aim to alleviate such sources of imperfect information by: (1) assisting in the implementation of loan screening and monitoring systems; (2) providing technical assistance to mi-

\footnotetext{
${ }^{15}$ See Chapter 4 for a discussion of credit rationing in the West Bank and Gaza Strip and Chabrier and Kanaan (forthcoming) for a discussion of the links between economic policy, institutional weaknesses, and access to credit by the private sector.
}

croenterprises to help form basic skills in interacting and reporting to banks, including through the preparation of business plans; and (3) encouraging banks to lend to microenterprises by enhancing skills in cash-flow and character (or reputation)-based lending. This would help banks base their lending decisions on an assessment of borrowers' business prospects and on reputation, rather than only on the availability of acceptable collateral.

\section{Constraints on Collateral-Based Lending}

The consequences of imperfect information, in particular in the form of increased lending risk and induced credit rationing, can in principle be alleviated through collateral-based lending. However, this has been inhibited by: (1) difficulties in establishing a legal basis for ownership and registration of collateral; (2) uncertainty with regard to the effectiveness of the legal framework and judicial system for enforcing foreclosure; and (3) the rationing of credit to small-scale businesses through excessive collateral requirements. These weaknesses are currently being addressed through the strengthening of the legal framework to facilitate the use of collateral, and through the the development of information systems for the registration of assets. ${ }^{16}$

\section{Constraints on Long-Term Finance}

There are indications that banks tend to perceive a high liquidity risk in long-term lending due to the short-term nature of most bank deposits and the high uncertainty with regard to the stability of the deposit base. To help reduce this type of risk, several programs supported by the World Bank are being implemented to channel long-term funds from donors to banks, which would be on-lent for long-term investments (such as through subordinated debt facilities), and to establish facilities that would allow banks to refi-

\footnotetext{
16Important laws under preparation include the Property Law, which defines ownership rights and the recording of encumbrances; the Secured Lending Law, which allows banks to take security on movable property, and the Condominium Law, which establishes ownership rights for apartments. In the area of information systems, good progress has been made in developing a register for movable assets (including vehicles and machinery), although registers for fixed assets (including for land) are still inadequate.
} 
nance long-term loans, such as through the Housing Sector Project's secondary mortgage facility.

Although a market for equities currently exists in the West Bank and Gaza Strip, its contribution to the financing of investments is limited both by the depressed level of private investment demand, as well as the small-scale or "microenterprise" nature of most West Bank and Gaza Strip enterprises. Nevertheless, some steps to establish a strong legal foundation for the equity market are needed, including through the implementation of the Securities Law, which would provide a framework for the regulation of the equity market's operations in line with international practice, and establish adequate accounting and auditing standards for enterprises to enable a sound assessment of profitability. In the meantime, the IFC and other donors are playing an active role in promoting direct equity investments, most recently by helping to start up and partially finance the Peace Technology Fund, which will seek to channel funds from Palestinian and Israeli entrepreneurs into small- and medium-scale industries in the West Bank and Gaza Strip.

\section{Infrastructural and Institutional Support}

Private investors were disappointed with the limited public infrastructural support since 1994, especially in view of the formidable sums that had been committed by donors for public investment projects. The progress of implementation proceeded at a much slower pace than anticipated. Out of about $\$ 1.2$ billion committed by donors to public investment projects for the period 1994-97, only about $\$ 600$ million has been disbursed. More important, from the viewpoint of the private investor, the disbursements resulted in relatively limited investment in physical infrastructural projects that would have had the most favorable effects on the productivity of private capital investment. The implementation of public projects in the transportation sector was particularly slow, with the disbursement-to-commitments ratio in that sector averaging about 10 percent for 1994-97, compared to the overall ratio for the public investment projects of about 50 percent. ${ }^{17}$

\footnotetext{
${ }^{17}$ See Chapter 5 for a discussion of the implementation of the public investment projects.
}

\section{The Legal and Regulatory Framework}

With the advent of self-rule, the confusing array of laws that had prevailed under the occupation was expected to gradually give way to a transparent and supportive legal and regulatory framework. From the investors' viewpoint, a key component of the framework as it prevailed as of March 1998 was the Law on the Encouragement of Investment (the Investment Law). ${ }^{18}$ The Investment Law had several features that adversely affect the profitability of investments, especially by introducing a great deal of uncertainty with regard to costs. In particular, the Law granted considerable discretionary powers to the Palestinian Higher Agency for the Encouragement of Investment, including the approval of all investments through cumbersome and ill-defined procedures. The Investment Agency also had the power to cancel or suspend all licenses, with no possibility of recourse to the judicial system or to independent arbitration; the investor had recourse only to the President of the Palestinian Authority to dispute such decisions.

As part of efforts to strengthen the legal and regulatory environment, the IMF and the World Bank have been working with the Palestinian Authority on a new Investment Law designed to address the above shortcomings (the new law was approved by the legislature in April 1998). In the meantime, to allay investors' concern about the stability of the legal and regulatory framework, especially in the context of the high political uncertainty, donors are currently working on establishing a Guarantee Trust Fund for Private Investments (the "MIGA Project"). The Fund's purpose is to provide investors with guarantees against the risks of losses due to expropriation, to the breach or repudiation of contracts by the authorities, to the inability to transfer currency, and to damage to physical property due to politically motivated acts.

The drafting and adoption of laws and regulations, no matter the extent to which these are "in line with international standards and practice," would be viewed by investors as merely "pieces of paper" if they perceive that government actions, in particular those affecting private sector incen-

\footnotetext{
${ }^{18}$ Although the Law has not yet been approved by the Legislative Council, the Palestinian Authority views the Law as de facto applicable since its approval by the Cabinet of Ministers on April 30, 1995. For detailed assessments of the Law see Fidler (1996) and World Bank (1997a).
} 
tives, are not constrained by such laws and regulations. In view of the short track record of the Palestinian Authority in policymaking and implementation, investors currently have limited information on the basis of which to form expectations on the scope and nature of Palestinian Authority's future interventions in private sector activity. To reduce uncertainty with regard to the likelihood of unanticipated government interventions, it is important for the Palestinian Authority to establish a strong legal and regulatory framework, in particular by addressing the shortcomings of the Investment Law, and to build a solid track record, including through the abolition of import monopolies, which would demonstrate that government actions are delineated by such a framework, and avoid measures that would increase the perceived risk of future "government meddling" and of arbitrary interventions in private activities.

\section{Concluding Remarks}

What can be done to reverse the declining trend in private investment and to reduce the current distortion in its sectoral allocation against the export sector? This paper makes clear that a key to the improvement of investment incentives and to the achievement of a more balanced pattern of investment lies in the stabilization and liberalization of the external trade environment. The regime of border closures has a particularly adverse impact both because of the direct effect on investment incentives in the context of an already weak productive base and a small domestic market, and because the severe economic costs it imposes tend to slow or divert efforts by the Palestinian Authority and donors to alleviate the other significant impediments to private investment in the West Bank and Gaza Strip.

The prospects for an early lifting of the borderclosures regime and for the opening of outlets to external markets currently appear highly uncertain, given the slow progress in the peace process. In such a situation, ways should be found to at least partially insulate the economy from the current very restrictive trade environment. In this context, free-trade and industrial zones can play a positive role. By virtue of the concentration of production in a small area, the Israeli authorities might be more likely to offer a binding commit- ment to minimize security controls and other trade restrictions on the zones' exports and imports, thereby insulating part of the West Bank and Gaza Strip's external trade from the effects of both generalized and intermittent closures. Private investors would, in addition to the increased insulation from the effects of closures, benefit from (1) a favorable legal and regulatory framework that would be easier to develop and administer for a relatively small segment of the economy; (2) a faster pace of implementation of donor-supported public investment projects; and (3) lesser exposure to the weaknesses in credit markets in the West Bank and Gaza Strip (as the projects would initially be largely financed from external private sources).

The recovery of private investment, if it is to be sustained in the longer-term and on a large-scale throughout the West Bank and Gaza Strip, however, would depend largely on: (1) removal of trade restrictions and barriers both within the West Bank and Gaza Strip and between the West Bank and Gaza Strip and Israel; (2) unimpeded access of the West Bank and Gaza Strip to external markets, including through the development and operation of seaports and airports; (3) easier access by investors to credit through institution building in the financial sector; (4) acceleration in the implementation of the public investment program; and (5) strengthening of the legal and regulatory framework. It is clear that private investors' response will be shaped largely by a continual assessment of the actions of the Palestinian Authority, Israel, and the donor community in each of these areas.

\section{Appendix}

In this appendix we employ the two-good comparative statics neoclassical model to illustrate the economic implications of the regime of border closures examined earlier.

In Figure 3 we first depict an initial situation with a given stock of capital and labor and the associated Production Possibilities Frontier (PPF), represented by $\mathrm{AB}$. Under free trade, the economy would produce at point $\mathrm{F}$, the point of tangency of the free-trade price line with the PPF, which would maximize the value of domestic output at free-trade prices, and consume at a point yielding social utility UF. Under autarky, 


\section{Figure 3 \\ West Bank and Gaza Strip: Implications of the Regime of Border Closures}

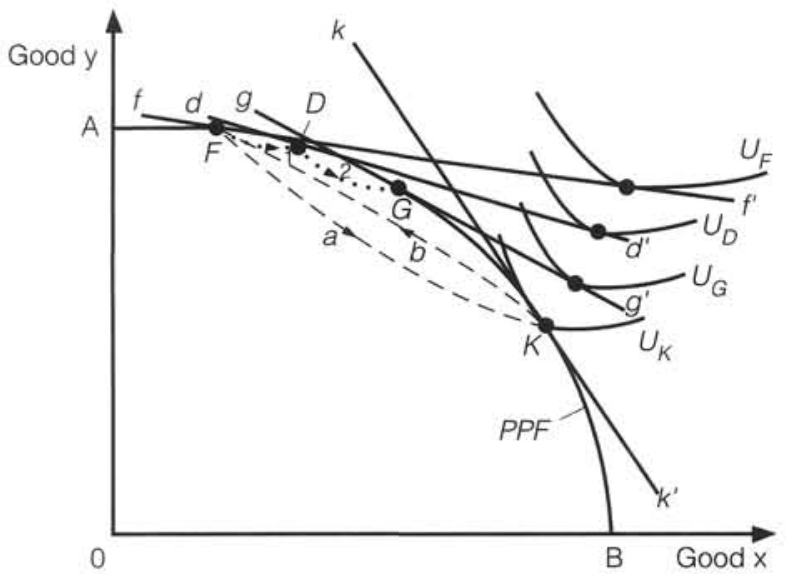

the economy produces and consumes at point $\mathrm{K}$, the point of tangency between the price line under autarky and the PPF, yielding lower social utility UK.

Consider first the implications of the "generalized" closures. In the context of the two-good model, we can represent the effect of generalized closures by making the "melting ice" assumption often used in the trade theoretic literature. ${ }^{19}$ This would be effectively reflected in a lowering in the economy's rate of transformation in trade, leading to a shift in the price line away from the free-trade price line and toward the autarky price line. In Figure 3, the effects of generalized closures have induced a rotation in the price line from the pre-1993 price line dd' to $\mathrm{gg}^{\prime}$, closer to the autarky equilibrium. Generalized closures have then led to a shift in the production pattern (path 2), corresponding to a decline in social utility in the West Bank and Gaza Strip depicted by the shift from UD, the utility prior to 1993 , to UG.

\footnotetext{
${ }^{19}$ Samuelson (1954) originally used the "melting ice" assumption in the two-good comparative statics model in which it is assumed that, in certain types of trade, part of the traded goods perishes, as if ice is being transported and is melting away in transit. This assumption was also used in an interesting two-good model by Bhagwati and Hansen (1973) of the effects of illegal trade, in which smugglers of goods across borders, in fear of detection, tend to mishandle and damage part of their merchandise. An analogous phenomenon may be occurring in the West Bank where traders tend to take advantage of the borders' porosity and opt for unusual passages to avoid the delays and stringent controls at checkpoints.
}

Let us now examine the case where the investor is assessing the impact on future income streams of intermittent shifts in the trade regime between free trade and autarky. Consider first the optimal policy response with the assumption of no production rigidities. If the economy is producing under free trade and a closure is imposed, the optimal policy would be to move instantaneously to the optimal autarky point $\mathrm{K}$ and remain there until the closures are lifted, after which the economy moves back to the free-trade production point F. Thus the economy oscillates between the two target points $\mathrm{F}$ and $\mathrm{K}$ in Figure 3 (paths $\mathrm{a}$ and $\mathrm{b}$ ).

Consider now the case of an economy with adjustment costs, as examined earlier in the chapter. It can be shown that in this case the optimal policy is characterized by movements between two target points $\mathrm{M}$ and $\mathrm{N}$, which lie in between the free trade optimal point $\mathrm{F}$, and the autarky optimal point $\mathrm{K}$ (Figure 4). ${ }^{20}$ The intuition behind this outcome is as follows: Since the policy objective is to maximize not only present levels of welfare but welfare levels in future periods, the optimal policy under open borders consists of balancing the gains of being close to the free-trade optimal point, with the future costs of shifting resources back toward the autarky equilibrium after the closure is reimposed. Thus, in the "open border" regime, the highest level of welfare and income that could be enjoyed by the economy, which corresponds to utility level UM associated with production at $M$, will be lower than utility UF under the free trade equilibrium. Similarly, with the border closed, the optimal policy is to balance the present gains from being close to the optimal autarky point, with the future costs of reallocating resources toward the free-trade equilibrium when the border reopens, thus leading to lower levels of aggregate welfare and income than under the optimal autarky point.

Even when borders are open, the economy does not enjoy free trade, but a situation of generalized closures. Because of the "melting ice" conditions that operate when borders are open, trade takes place at a lower rate of transformation, which effectively tilts the price line from the freetrade line $\mathrm{ff}^{\prime}$ and closer toward the autarky price

\footnotetext{
${ }^{20}$ For a proof of this dual solution in the context of "onoff" intermittent trade disruptions, see, for example, Cheng (1989). Other models of trade disruptions include Loury (1983), Arad and Hillman (1979), and the seminal contribution by Bhagwati and Srinivasan (1976).
} 


\section{Figure 4 \\ West Bank and Gaza Strip: Implications of the Regime of Border Closures with Adjustment Costs}

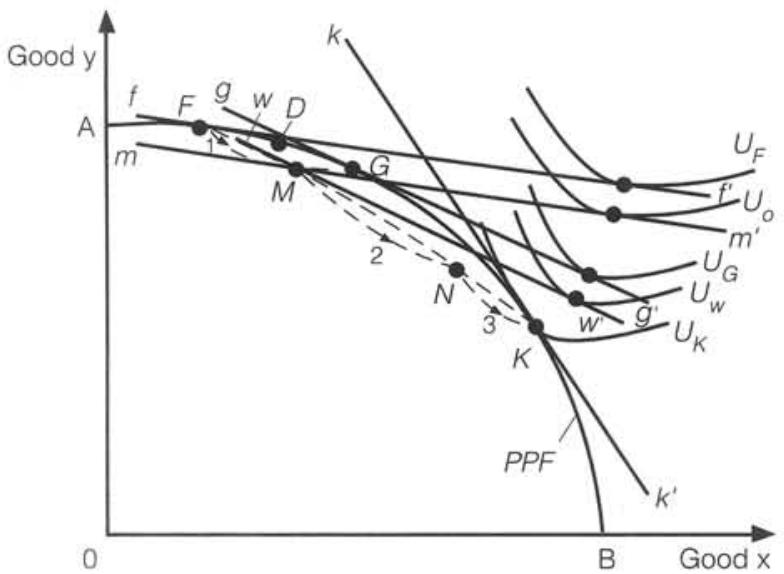

line. Thus when the economy is producing at M, it would not be able to attain the social utility level UO, as under the regime of oscillations between free trade and autarky, because it is forced to trade at a less favorable price line, such as ww', which yields a lower utility level UW.

The factors examined earlier in the chapter in the form of production rigidities and market imperfections, which induce a lowering of investment projects' net present value in all sectors, correspond to an inward shift in Figure 4 from production on the PPF toward the arc FK (dark dotted line) inside the PPF. The decline in the profitability of investments in the export sector relative to that in other sectors, in turn, induces a movement of factors of production away from the optimal allocation at $\mathrm{F}$ and toward the autarky allocation at $\mathrm{K}$.

\section{References}

Abel, A., A. Dixit, J. Eberly, and R. Pindyck, 1996, "Options, the Value of Capital, and Investment," Quarterly Journal of Economics, Vol. III, pp. 753-78.

Arad, R.W. and A.L. Hillman, 1979, "Embargo Threat, Learning and Departure from Comparative Advantage," Journal of International Economics, Vol. 9 (May), pp. 265-75.

Bhagwati, J.N. and B. Hansen, 1973. "A Theoretical Analysis of Smuggling." Quarterly Journal of Economics, Vol. 87, No. 12 (May), pp. 172-87.
Bhagwati, J.N. and T.N. Srinivasan, 1976, "Optimal Trade Policy and Compensation under Endogenous Uncertainty: The Phenomenon of Market Disruption," Journal of International Economics, Vol. 6 (November), pp. 317-36.

Chabrier, P. and O. Kanaan, forthcoming, "What Ought to Be the Role of the State in the Financial Sector?" In The Role of the State in a Changing Arab Economic Environment (Washington: International Monetary Fund).

Cheng, L.K., 1989, "Intermittent Trade Disruptions and Optimal Production," Journal of International Economics, Vol. 30, No. 4 (November), pp. 753-74.

Central Bureau of Statistics, Statistical Abstracts of Israel, yearly issues, 1969-93.

Central Statistics Department, 1996, Statistics Quarterly for Gaza Governorates, Vols. I and 2, Ministry of Planning and International Cooperation.

De Long, J.B. and L.H. Summers, 1991, "Equipment Investment and Economic Growth," Quarterly Journal of Economics, Vol. 106 (May), pp. 445-502.

Fair, R.C., 1989, "The Production Smoothing Model Is Alive and Well," Cowles Foundation for Research in Economics, Discussion Paper No. 896 (New Haven, Yale University).

Fidler, D., 1996, "An Analysis of the Law on the Encouragement of Investment in Palestine," Fordham International Journal, p. 529.

Ingersoll, J.E. and S. Ross, 1992, "Waiting to Invest: Investment and Uncertainty," Journal of Business, Vol. 65, (January) pp. 1-29.

International Monetary Fund, 1997, Recent Economic Developments, Prospects, and Progress in Institution Building in the West Bank and Gaza Strip, Middle Eastern Department (Washington).

Loury, G. C., 1983, "The Welfare Effects of Intermittent Interruptions of Trade," American Economic Review, Vol. 73 (Papers and Proceedings, May), pp. $272-77$.

Miron, J.E., 1996, The Economics of Seasonal Cycles, (Cambridge, MA: MIT Press).

Miron, J.E. and S.P. Zeldes, 1988, "Seasonality, Cost Shocks, and the Production Smoothing Model of Inventories," Econometrica, Vol. 56, No. 4 (July), pp. 877-908.

Nashashibi, K. and O. Kanaan, 1994, "Which Trade Arrangements for the West Bank and Gaza?" Finance and Development, Vol. 31, No. 3 (September).

Palestinian Central Bureau of Statistics, 1996-97, Labor Force Survey Report, Series No.1-4.

Romer, P., 1989, "Capital Accumulation in the Theory of Long Run Growth," Modern Business Cycle Theory, ed. By Robert Barro, Harvard University Press. 
Samuelson, P.A., 1954, "The Transfer Problem and Transport Costs: Analysis of Effects of Trade Impediments." Economic Journal, No. 254, pp. 264-89.

Stiglitz, J.E., 1993, "Endogenous Growth and Cycles", NBER Working Paper No. 4286 (Cambridge, Massachusetts: National Bureau of Economic Research).

United Nations, 1997, Economic and Social Conditions in the West Bank and Gaza Strip, Office of the Special Coordinator, Quarterly Report (October).
Van Ewijk, C., 1997, "Entry and Exit, Cycles, and Productivity Growth," Oxford Economic Papers, Vol. 49 (April), pp. 167-87.

World Bank, 1993, Developing the Occupied Territories: An Investment in Peace (Washington: World Bank).

1997a, "The Law on the Encouragement of Investment in Palestine" (mimeo; Washington: World Bank). 1997b, Development Under Adversity? The Palestinian Economy in Transition (Washington: World Bank and MAS, October). 


\section{Monetary Policy in the West Bank and Gaza Strip in the Absence of a Domestic Currency}

\section{Steven Barnett}

$\mathrm{T}$ he Palestinian Monetary Authority (PMA) was created following the declaration of principles signed in September 1993 between Israel and the PLO. Although the Palestinian Monetary Authority has many of the usual powers and functions of a central bank, it does not currently issue a domestic currency. Nonetheless, theoretical considerations suggest that by using its influence on the commercial banking sector, the Palestinian Monetary Authority might still be able to implement a monetary policy that stimulates real activity in the West Bank and Gaza Strip. However, based on an empirical evaluation of these theoretical considerations in the context of the West Bank and Gaza Strip economy, it is concluded that it is neither possible nor desirable for the Palestinian Monetary Authority to use monetary policy to promote short-run growth. The Palestinian Monetary Authority can, however, contribute to creating an economic environment conducive to sustainable growth by pursuing policies that maintain and enhance financial stability in the West Bank and Gaza Strip.

\section{Background}

The responsibilities and limitations of the Palestinian Monetary Authority are delineated in the Protocol on Economic Relations - Annex V, Article IV (Protocol), signed in April 1994. The Palestinian Monetary Authority's responsibilities include serving as lender of last resort; providing bank supervision and licensing in accordance with the principles of the "Basle Committee" and "Basle Concordat"; and acting as the Palestinian
Authority's sole financial agent. The Protocol also requires that the Israeli new sheqel (NIS) be one of the circulating currencies in the West Bank and Gaza Strip and that reserve requirements on new sheqel deposits be kept in line with those in Israel. The introduction of a Palestinian currency is mentioned in the Protocol as a future possibility and a topic for discussion by the Israeli-Palestinian Joint Economic Committee (also established in the Protocol).

Under the Palestinian Monetary Authority law, enacted in late 1997, "the objective of the PMA is to secure the stability of the banking and monetary systems, which will encourage the economic development in the areas under Palestinian jurisdiction." The Palestinian Monetary Authority is given broad authority over the means appropriate for achieving its objective and is designated as an independent entity.

\section{Banking Sector Developments}

Since the signing of the declaration of principles there has been considerable growth in the banking sector. $^{1}$ The number of banks operating in the West Bank and Gaza Strip grew from 2 banks in 1989 to 20 banks in June 1997. The banks, 8 of which are Palestinian, maintain a total of 78 branches in the West Bank and Gaza Strip. Even with this growth, the banking sector remains relatively concentrated, with roughly 80 percent of deposits being held at the three largest banks.

${ }^{1}$ See Chapter 3 and IMF (1997) for recent developments. 


\section{MONETARY POLICY IN THE ABSENCE OF A DOMESTIC CURRENCY}

\section{Figure 1 \\ Claims on the Private Sector to Deposit Ratios, January 1996-August 1997 (In percent)}

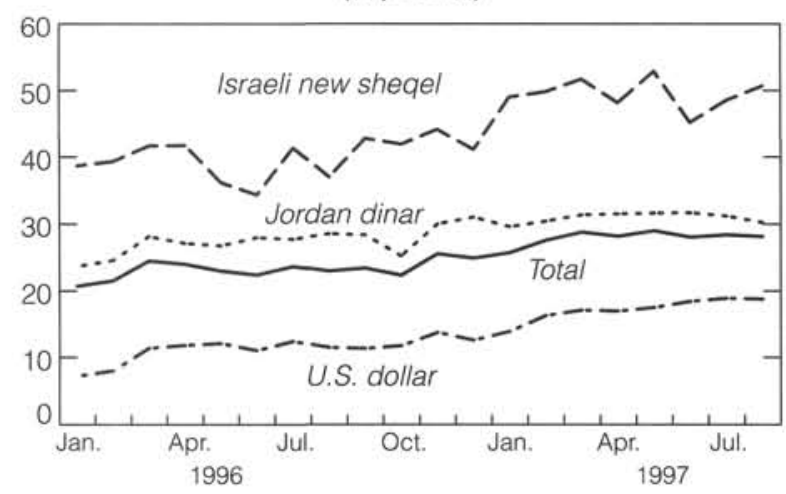

Source: Palestinian Monetary Authority.

The banking sector has also grown rapidly in terms of assets, deposits, and claims on the private sector. From January 1996 to November 1997 total assets in the banking sector grew by 65 percent to $\$ 2.8$ billion, deposits increased by 46 percent to $\$ 1.8$ billion, and claims on the private sector more than doubled, increasing by 112 percent to $\$ 533$ million.

Despite the rapid growth in claims on the private sector, public dissatisfaction with the private sector credit to deposit ratio has been evident. There is a perception that banks are pursuing a deliberate policy of transferring the West Bank and Gaza Strip's wealth abroad, and that the banking sector's unwillingness to lend domestically is contributing to the economic difficulties in the West Bank and Gaza Strip. Despite its significant growth since January 1996, the claims on the private sector to deposit ratio is still relatively low and stood at just under 30 percent in August 1997 (Figure 1). ${ }^{2}$ Indeed, the growth in this ratio has done little to reduce pressure on the Palestinian Monetary Authority to take action.

As shown in Figure 1, there are also significant differences between the currencies. The claims on the private sector to deposit ratios for the Israeli new sheqel and Jordan dinar, 51 and 30 percent

\footnotetext{
${ }^{2}$ For comparison, as of December 1996 claims on the private sector as a share of deposits (demand, time, savings, and foreign currency) was 42 percent in Lebanon, 55 percent in Egypt, 89 percent in Jordan, and 96 percent in Israel (data are from the IMF's International Financial Statistics). Please note that data on the currency composition of private sector credit and deposits are only available through August 1997.
}

respectively in August 1997, are considerably higher than the 19 percent for the U.S. dollar. The low dollar claims on the private sector to deposit ratio is especially noteworthy since, as shown in Figure 2, the U.S. dollar is also the most popular currency for deposits. The preferred currency for deposits is therefore the least likely to be lent domestically. The U.S. dollar, however, has also been growing in popularity for borrowing, but at over 40 percent in August 1997, the Jordan dinar still accounts for the largest share of claims on the private sector (see Figure 3). Figures 2 and 3 also show that commensurate with the movement toward using the U.S. dollar, the deposit and claims on the private sector shares for both the Jordan dinar and Israeli new sheqel have declined since January 1996.

\section{Policy Objectives}

A consensus has emerged, in academic and policy circles, around the belief that monetary stability (i.e., low inflation) should be the primary goal of a monetary authority. However, in the West Bank and Gaza Strip, without the recourse of a domestic currency, inflation remains largely outside the control of the Palestinian Monetary Authority. Nonetheless, the related goal of promoting financial stability, through the maintenance of a healthy banking sector, is an objective that the Palestinian Monetary Authority needs to pursue and one that could contribute significantly to creating an environment conducive to achieving sustainable growth.

As a result of the recent economic conditions prevailing in the West Bank and Gaza Strip-declining income and very high unemploymentexpanding output and investment are high on the list of short-term Palestinian Monetary Authority objectives. In the long run, however, the development and stability of the financial sector are crucial for improving growth prospects. ${ }^{3}$ Given the preeminence placed on improving current economic conditions, the ability of the Palestinian Monetary Authority to boost short-run

\footnotetext{
${ }^{3}$ The Palestinian Monetary Authority is also responsible for prudential supervision and regulation of the banking sector. These responsibilities, while extremely important for maintaining a stable financial environment, are beyond the scope of the present analysis.
} 
Figure 2

\section{Currency Compositic.l of Deposits \\ (In percent of total deposits)}

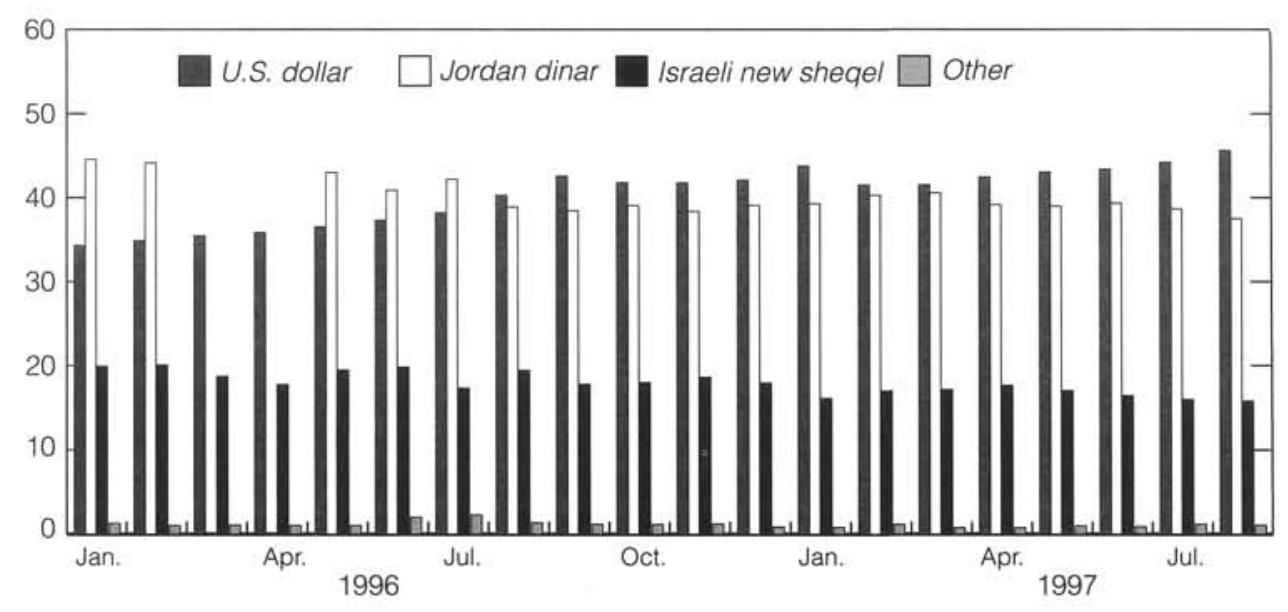

Source: Palestinian Monetary Authority.

Figure 3

Currency Composition of Claims on the Private Sector (In percent of claims on the private sector)

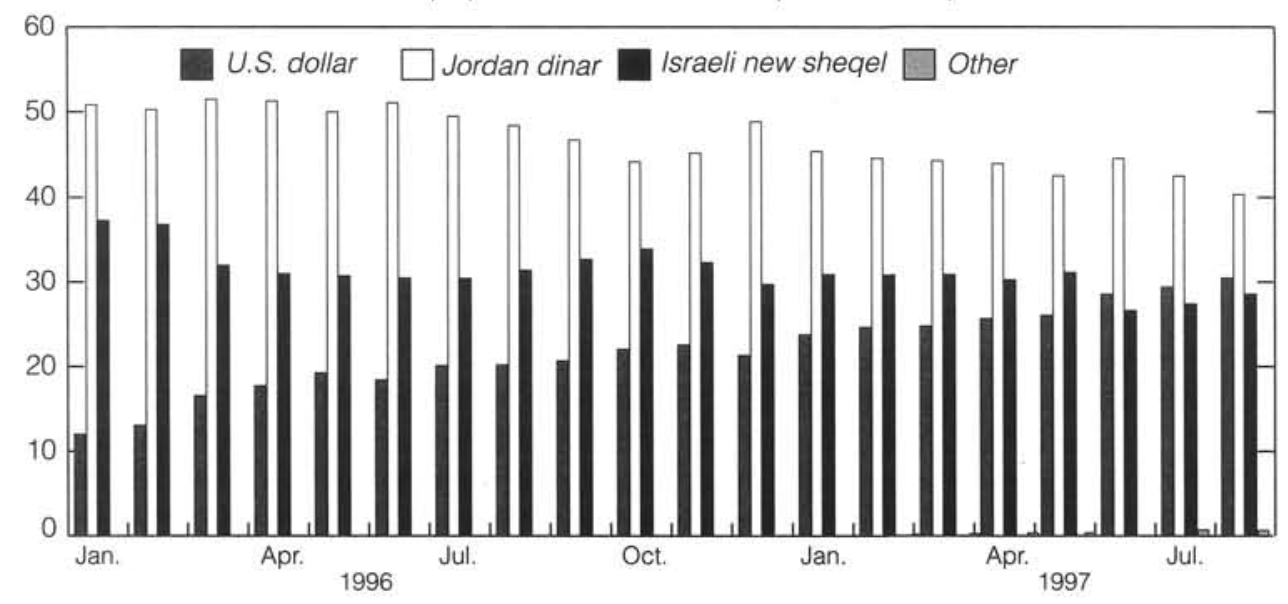

Source: Palestinian Monetary Authority.

growth, as well as the implications of such policies for financial stability, is a major issue.

\section{Monetary Instruments}

Most of the conventional indirect monetary instruments are not available to the Palestinian Monetary Authority. Since there is not a domestic currency, the Palestinian Monetary Authority does not have control over a domestic money supply. Furthermore, the lack of government debt or a similarly tradeable security precludes the use of open market operations. In fact, without a domestic interbank market or market-based central bank credit facility, there is not even a benchmark West Bank and Gaza Strip interest rate for the Palestinian Monetary Authority to influence.

The main indirect instruments currently available to the Palestinian Monetary Authority are related to reserve requirements. The Palestinian Monetary Authority determines the reserve requirements for each of the currencies in circula- 


\section{MONETARY POLICY IN THE ABSENCE OF A DOMESTIC CURRENCY}

tion, consisting primarily of Jordan dinars, Israeli new sheqalim, and U.S. dollars. In addition to setting the specific reserve requirement rates, other tools available to the Palestinian Monetary Authority include the determination of the amount of remuneration on reserves, placement of reserves, and possible imposition of multiple reserve requirements. In its capacity as bank regulator, the Palestinian Monetary Authority also has recourse to several direct monetary instruments. The Palestinian Monetary Authority has already issued guidelines placing a ceiling on foreign assets and a floor on the claims on the private sector to deposit ratios (see Chapter 2). Given the paucity of alternative monetary instruments, the use of such direct measures may be especially tempting.

Finally, the Palestinian Monetary Authority also has the option of establishing some of the indirect measures commonly used by other central banks. This would encompass not only creating the particular instrument, but also contributing to the development of the requisite market institutions. The merits, as well as the viability, of establishing the various indirect instruments are considered below.

\section{Credit Channel: Theory and Evidence}

The lack of a domestic currency, small size, and openness of the West Bank and Gaza Strip economy suggest that most common monetary transmission mechanisms - such as the interest rate, exchange rate, and asset prices-are unlikely to play a significant role in the monetary transmission process. However, monetary policy could operate, via the banking sector, through the credit channel. ${ }^{4}$ By altering the banking sector's willingness to supply credit, monetary policy may be able to influence aggregate demand and therefore real economic activity. The magnitude of the increase in real activity depends on the degree to

\footnotetext{
${ }^{4}$ See Mishkin (1995) for a synopsis of the various transmission mechanisms and Bernanke and Gertler (1995) for a more comprehensive analysis of the credit channel. The credit channel in general encompasses both a "balance sheet" and "bank lending" effect. The former focuses on the transmission of policy through the impact on the balance sheet of individual firms. The bank lending channel, which is described in this analysis, is more relevant for the West Bank and Gaza Strip.
}

which any policy-induced increases in bank lending actually finance extra consumption and investment. Since there is not a corporate bond market and the stock exchange is nascent and still relatively small, the banking sector is the primary formal source of business and household credit; this suggests that additional bank credit may indeed finance expenditures that would have otherwise not taken place. Alternatively, to the extent that any additional bank credit is used as a substitute for informal sources, such as self-financing, then there would only be small changes in consumption and investment, and thus a minimal change in output.

The effectiveness of monetary policy in increasing growth, through the credit channel, therefore depends on three factors: (1) how the given policy affects the supply of credit; (2) how the change in the supply of credit affects domestic borrowing; and (3) how the change in domestic borrowing influences the macroeconomy.

\section{West Bank and Gaza Strip Credit Markets}

In order for the credit channel to serve as the conduit of monetary policy, supply factors would have to play the dominant role in determining the credit market equilibrium. In other words, if the low claims on the private sector to deposit ratios are a product of supply considerations, then policy-induced changes in credit supply have the potential to increase output via the credit channel. Conversely, if a lack of credit demand is responsible for the low claims on the private sector to deposit ratios, then there is little scope for an expansionary monetary policy, which works by increasing credit supply, to affect domestic lending and therefore growth.

Credit supply is determined by a combination of the banking sector's portfolio decisions and its lending capacity (i.e., assets in the banking sector that are highly liquid and readily available for domestic lending). The Palestinian Monetary Authority can therefore increase credit supply by pursuing policies that either expand the banking sector's lending capacity or alter its portfolio decisions. Examples of the former include policies such as lowering reserve requirements, extending central bank credit, and redepositing reserves. Palestinian Monetary Authority policies may also have an indirect effect on lending capacity; for example, a decrease in reserve requirements or re- 
muneration of reserves, which lower the effective tax that banks pay for holding deposits, may induce banks to raise deposit interest rates and thus attract more deposits.

For a given lending capacity, portfolio considerations dictate the amount of credit to supply domestically. In light of the generally high risks that prevail in the current political environment in the West Bank and Gaza Strip, the banking sector's preference for foreign assets relative to domestic lending is not surprising. Nonetheless, even though there is a significant amount of foreign assets in the banking sector's portfolio, the domestic credit market could still be effectively supply constrained. The coexistence of low claims on the private sector to deposit ratios and a supply constrained credit market can be explained using an extension of the imperfect information model of Stiglitz and Weiss (1981). ${ }^{5}$ A key premise is that a bank is unable to obtain adequate information about the default risks of potential loans, a situation that is particularly applicable in the West Bank and Gaza Strip. For example, the lack of credit screening methods and the absence of other institutions or practices to assist banks in assessing the riskiness of a given loan are often cited as contributors to the low claims on the private sector to deposit ratios. Moreover, the informational problems are compounded by the fact that many potential applicants do not have experience preparing credit applications; do not possess a formal credit history; and do not use standard accounting procedures and other practices that would facilitate the conveyance of information relevant for determining creditworthiness (see Chapter 3 ).

As a consequence of imperfect information, the credit market equilibrium could be subject to credit rationing (i.e., the demand for credit exceeds the banking sector's willingness to supply it) despite the fact that banks have plenty of liquidity. In the absence of other indicators, the lending interest rate itself serves as a signal of the riskiness of a loan. At higher interest rates, only the entrepreneurs with the riskier projects-projects with a high probability of failure but that also pay a large return if successful-are willing to borrow. From the bank's perspective, this implies that there is a profit maximizing lending interest rate that serves

\footnotetext{
${ }^{5}$ See Barnett (1998) for a detailed exposition.
}

as an effective interest rate ceiling. ${ }^{6}$ Credit rationing may occur because, above the effective interest rate ceiling, the lending interest rate does not adjust to clear the credit market.

\section{Empirical Analysis}

The primary objective of the empirical analysis is to assess whether credit to the private sector is constrained by supply considerations. Credit to the private sector in the West Bank and Gaza Strip consists primarily of overdrafts and loans. Overdrafts, which account for 60 percent of claims on the private sector (August 1997), effectively serve as a line of credit. This means that the dominant form of private sector credit is most likely not being used to finance fixed investment. Loans, which account for 33 percent of claims on the private sector (August 1997), correspond more closely to the type of credit considered in the theoretical section. To determine if the credit market is supply constrained, regressions using both claims on the private sector and loans were evaluated for each of the currencies in circulation. In addition, the sensitivity of deposits to interest rates, which is used in the subsequent section, was also measured. The regressions are discussed in the Appendix; the main results are summarized below.

Overall, there is some evidence to suggest that supply considerations affect the equilibrium quantity of credit. The Jordan dinar and Israeli new sheqel loan markets display characteristics consistent with credit rationing. However, while being the theoretically appropriate measure, loans account for only a small share of credit. Therefore, even though these loan markets appear to be supply constrained, the small quantities involved could disguise an overriding lack of credit demand, which would ultimately limit the ability of the Palestinian Monetary Authority to increase output through the credit channel. In other words, as in-

\footnotetext{
${ }^{6} \mathrm{An}$ increase in the lending interest rate affects the expected return on a loan in two opposing directions: (1) the higher interest rate increases the expected return by raising the amount of interest payments a bank would receive if the loan is repaid, and (2) the higher interest rate decreases the expected return by lowering the probability that the loan would be repaid. Thus, the expected return on a loan is a concave (and initially increasing) function of the lending interest, which is maximized at the point at which the above two effects exactly offset each other.
} 


\section{MONETARY POLICY IN THE ABSENCE OF A DOMESTIC CURRENCY}

creases in supply eliminate the excess demand for credit (i.e., credit rationing), an underlying lack of credit demand could be revealed that would prevent further expansions in credit supply from increasing credit and therefore output. Furthermore, these results are also consistent with there being significant segments of the market that are not subject to credit rationing but nonetheless do not desire credit. ${ }^{7}$ If this is the case, then the low claims on the private sector to deposit ratios are fundamentally the product of demand considerations. Therefore, even if the evidence in favor of supply constraints was stronger, the existence of supply constraints-while necessary for Palestinian Monetary Authority policy to influence outputdoes not preclude the possibility that the low claims on the private sector to deposit ratios are ultimately the result of a lack of credit demand. Finally, and most important, the broader measure of credit (claims on the private sector), while responding to supply considerations, does not appear to be subject to credit rationing.

\section{Policy Options}

The following analysis of the Palestinian Monetary Authority's policy options examines the effectiveness of available indirect instruments in increasing short-run growth; the consequences arising from the enactment of various direct measures; and the merits of creating or utilizing alternative indirect instruments.

\section{Existing Instruments}

The instruments most readily available to the Palestinian Monetary Authority are related to reserve requirements. These include ( 1 ) determination of reserve requirement rates, (2) remuneration of reserve deposits, (3) placement of reserves, and (4) institution of differentiated reserve rates based on the composition of a bank's assets (dual or multiple reserve requirements). In

\footnotetext{
7For example, there could be a pool of potential borrowers to whom the banks would be willing to extend credit (i.e., are not subject to the imperfect information problem), but who choose not to borrow for business reasons. See Chapter 3 for an analysis of the factors discouraging investment, and therefore the need for credit financing, in the West Bank and Gaza Strip.
}

order to put an upper bound on the efficacy of using these instruments, the broader measure of credit (claims on the private sector), for all three currencies, is assumed to be subject to credit rationing. Since this is actually in contrast to the empirical evidence, which suggests that only the narrow measure of credit (loans) is potentially subject to credit rationing, the actual magnitude of the effect on growth is likely to be substantially smaller than what is reported below.

Three policy options are evaluated for each currency: (1) placement of $\$ 10$ million in the domestic banking sector; (2) a one percentage point decrease in the reserve requirement rate; and (3) full remuneration of reserves at the existing international deposit interest rates. The maximum quantitative impact of these policies is displayed in Table 1 , which is calculated as follows. ${ }^{8}$ First, the policy's initial impact on lending capacity, which consists of direct and indirect effects, is measured. For example, the direct effect of lowering reserve requirements refers to the funds that banks formerly deposited with the Palestinian Monetary Authority as reserves that would be made available for lending by the reduction in reserve requirements. The indirect effect of a decrease in reserve requirements, which lowers the banks' costs and thus allows them to increase deposit interest rates, refers to the growth in deposits following from the increase in deposit interest rates. The total change in claims on the private sector is calculated using a money multiplier formula appropriate for the West Bank and Gaza Strip. Finally, assuming that the price level is not affected, the change in real GDP is derived by multiplying the increase in the domestic money supply by West Bank and Gaza Strip velocity.

The results in Table I show that even the most effective of these policies is not likely to result in even a .25 percent increase in annual real GDP. For example, placing $\$ 10$ million in all three currencies (for a total of $\$ 30$ million) would generate less than $\$ 13$ million in new output-implying a multiplier that is actually less than one. The total stock of reserves available for placement is not large enough to overcome the small impact that domestic placements have on growth.

\footnotetext{
${ }^{8}$ See Barnett (1998) for a more detailed description of the methodology used to construct Table 1 .
} 
TABLE 1.

Maximum Impact of Different Palestinian Monetary Authority Policies

\begin{tabular}{|c|c|c|c|c|c|c|c|c|}
\hline \multirow[b]{4}{*}{ Policy } & \multirow[b]{4}{*}{ Currency } & \multirow{2}{*}{\multicolumn{3}{|c|}{ Initial Increase in Lending Capacity }} & \multicolumn{4}{|c|}{ Total Change } \\
\hline & & & & & \multirow{3}{*}{$\begin{array}{l}\text { US\$ } \\
\text { Claims } \\
\text { on the } \\
\text { private } \\
\text { sector }\end{array}$} & \multirow[b]{3}{*}{ GDP } & \multicolumn{2}{|c|}{ Growth in percent } \\
\hline & & \multicolumn{2}{|c|}{ US\$ millions } & \multirow{2}{*}{$\begin{array}{c}\begin{array}{c}\text { Percent } \\
\text { of lending } \\
\text { capacity }\end{array} \\
\text { Total }\end{array}$} & & & $\begin{array}{l}\text { Claims } \\
\text { on the } \\
\text { private }\end{array}$ & \\
\hline & & Direct & Indirect & & & & sector & GDP \\
\hline Placement of $\$ 10$ million & $\begin{array}{l}\text { JD } \\
\text { NIS } \\
\text { US\$ }\end{array}$ & $\begin{array}{l}10.00 \\
10.00 \\
10.00\end{array}$ & $\begin{array}{l}0.00 \\
0.00 \\
0.00\end{array}$ & $\begin{array}{l}1.50 \\
3.67 \\
1.51\end{array}$ & $\begin{array}{l}3.66 \\
6.98 \\
1.90\end{array}$ & $\begin{array}{l}3.49 \\
7.12 \\
1.90\end{array}$ & $\begin{array}{l}1.73 \\
4.52 \\
1.47\end{array}$ & $\begin{array}{l}0.11 \\
0.22 \\
0.06\end{array}$ \\
\hline $\begin{array}{l}\text { Lower reserve requirements } \\
\text { by one percentage point }\end{array}$ & $\begin{array}{l}\text { JD } \\
\text { NIS } \\
\text { US\$ }\end{array}$ & $\begin{array}{l}0.00 \\
2.93 \\
7.37\end{array}$ & $\begin{array}{l}1.00 \\
1.27 \\
0.63\end{array}$ & $\begin{array}{l}0.15 \\
1.54 \\
1.21\end{array}$ & $\begin{array}{l}0.37 \\
2.92 \\
1.52\end{array}$ & $\begin{array}{l}0.35 \\
2.95 \\
1.50\end{array}$ & $\begin{array}{l}0.17 \\
1.89 \\
1.18\end{array}$ & $\begin{array}{l}0.01 \\
0.09 \\
0.05\end{array}$ \\
\hline Fully remunerated reserves & $\begin{array}{l}\text { JD } \\
\text { NIS } \\
\text { US\$ }\end{array}$ & $\begin{array}{l}0.00 \\
0.00 \\
0.00\end{array}$ & $\begin{array}{r}14.05 \\
10.16 \\
0.00\end{array}$ & $\begin{array}{l}2.11 \\
3.73 \\
0.00\end{array}$ & $\begin{array}{l}5.14 \\
7.07 \\
0.00\end{array}$ & $\begin{array}{l}4.84 \\
7.13 \\
0.00\end{array}$ & $\begin{array}{l}2.43 \\
4.57 \\
0.00\end{array}$ & $\begin{array}{l}0.15 \\
0.22 \\
0.00\end{array}$ \\
\hline
\end{tabular}

Sources: Palestinian Monetary Authority; and IMF staff estimates.

Note: See the text for an explanation of the direct and indirect increase in lending capacity.

Table 1 also shows that lowering reserve requirements by one percentage point produces an even smaller increase in output. In fact, fully eliminating reserve requirements on any given currency would not even yield a 1 percent increase in GDP. Since Jordan dinar reserves are already fully placed back into the banking sector, the effect of reducing dinar reserve requirements is partially offset by the need for the Palestinian Monetary Authority to make a commensurate reduction in domestic placements. Since U.S. dollar deposits are already remunerated, this policy option is only applicable to Israeli new sheqalim and Jordan dinars. Even full remuneration of these reserves would not significantly impact GDP or claims on the private sector.

Hamed (1996, Section 6.5.3) proposes that the Palestinian Monetary Authority could increase domestic lending by lowering reserve requirements on the portion of money lent domestically (i.e., dual reserve requirements). However, an upper bound on the effectiveness of this policy is the negligible impact resulting from a complete elimination of reserve requirements. In addition, dual reserve requirements may affect domestic lending through an induced change in the relative cost of different assets. In this case, a policy of dual reserve requirements closely resembles, and is for the most part equivalent to, offering a subsidy for domestic lending or imposing a tax (such as an increase in reserve requirements) for the portion of funds placed abroad. Such policies would alter banks' desired portfolio causing a change in the credit supply curve. However, given the limited resources of the Palestinian Monetary Authority, it is unlikely that a subsidy could offer sufficient incentives to significantly affect lending. Likewise, a tax on other bank assets would decrease bank profits, reduce deposit interest rates, and risk disintermediation.

In a study of reserve requirements Hardy (1993) identifies four primary functions of reserve requirements: (1) tool for monetary control, (2) policy instrument, (3) revenue source, and (4) safeguard of bank liquidity. The above analysis focused on the second of these objectives and the first one, without a domestic currency to control, is not applicable to the West Bank and Gaza Strip. However, the policy options considered also have ramifications for the other reserve functions as well as the more general monetary objectives.

Reduction in reserve requirement rates, remuneration, and, to a lesser degree, dual reserve requirements each have negative consequences for Palestinian Monetary Authority revenue. Indeed, reserve requirements are implicitly the Palestinian Monetary Authority's major source of finance. The above policies, with the exception of place- 
ments, would be quite expensive in terms of lost revenue; for example, full remuneration at market rates or flat-out elimination of reserves would completely close down this source of revenue.

The liquidity safeguard role of reserves is jeopardized by policies such as reducing reserve requirements and placing reserves in the domestic banking system. This is a potentially serious consideration as the practice of placing reserves may exacerbate a liquidity shortage. In order to meet its obligations during a liquidity crisis, the Palestinian Monetary Authority itself would be forced to withdraw deposits from the banking system and thus potentially contribute to a further deterioration of the situation. A localized (i.e., at one or a few banks) liquidity problem could thereby be spread to other parts of the banking system. However, provided that they are sufficiently liquid, the banks' large holding of foreign assets would be a good safeguard against a liquidity shortfall.

As described above, the Protocol sets strict guidelines for reserve requirement rates for deposits of Israeli new sheqalim. This limits the scope for the Palestinian Monetary Authority to adjust the actual new sheqel rates directly but does not preclude the use of remuneration or placements. By depositing a portion of new sheqel reserves with the bank of origin without accepting interest the Palestinian Monetary Authority can effectively skirt the reserve requirement restrictions. Adjusting Jordan dinar reserve requirement rates, although not in violation of any formal agreements, may elicit a negative response from the Jordanian financial community.

In summary, the empirical evidence suggests that reserve requirements are not an effective tool for achieving the Palestinian Monetary Authority's monetary policy objectives of promoting growth or increasing lending to the private sector. Moreover, using reserves as a policy instrument could generate adverse consequences ranging from a significant decline in Palestinian Monetary Authority revenue to the possibility of aggravating any nascent liquidity crisis. In light of these factors-ineffectiveness, costs, and potential risks - there is essentially no scope for reserves to be used as an instrument of policy.

\section{Direct Measures}

The Palestinian Monetary Authority has already turned to direct instruments in an effort to support economic growth. A rule has been issued limiting foreign assets to 90 percent of a bank's total assets, as well as one requiring each bank to maintain a minimum claims on the private sector to deposit ratio of 30 percent. With foreign assets accounting for only 60 percent of total assets and the claims on the private sector to deposit ratio at just less than 30 percent, compliance with these rules should, in the aggregate, require only minor (if any) changes in the banks' portfolios. Nonetheless, recourse to such direct measures is counter to the prevailing international trend toward indirect instruments and away from direct ones.

These policies are unlikely to noticeably increase domestic lending, promote growth, or contribute to financial stability. In fact, use of the above direct instruments is actually likely to have deleterious consequences. By instituting distortionary quantitative restrictions, such policies impede the development of a vigorous banking sector and may therefore lead to disintermediation. Furthermore, these policies signal a general willingness to resort to such direct interference in the market, which may inhibit potential market participants and thereby interfere with the formation of deeper financial markets. ${ }^{9}$ A more direct repercussion is that in order to comply, banks may be forced to make inappropriate lending and portfolio decisions and thus jeopardize the soundness of individual banks, as well as the banking sector as a whole. Finally, these policies also create an incentive for the banks to employ creative accounting practices in an effort to satisfy the quantitative restrictions. Not only does this contribute to the regulatory burden of the Palestinian Monetary Authority, but such accounting practices may also undermine the overall quality of reported data.

\section{Developing Indirect Instruments}

Despite the lack of a domestic currency, there are circumstances in which use of domestic market-based (i.e., indirect) instruments would be advantageous. For example, there is likely to be sufficient demand to support the establishment of domestic liquidity management facilities if trans-

\footnotetext{
9See Chabrier and Kanaan (forthcoming) and Alexander, Baliño, and Enoch (1995) for a more detailed discussion of government intervention in the financial sector.
} 
action and other costs of operating in foreign markets are higher than in a local one; if some, perhaps smaller, banks in the West Bank and Gaza Strip do not have ready access to foreign markets; and if political crises periodically impede or preclude banks in the West Bank and Gaza Strip from effectively managing their liquidity abroad.

Currently, there is not a transparent and efficacious method for the Palestinian Monetary Authority to address localized liquidity shortages. Opening a discount window (i.e., Lombard or overdraft facility) is preferable to the current discretionary and opaque practice of placing reserves. ${ }^{10}$ The creation of such a facility offers several distinct advantages: it is transparent; easy to create; available at the initiative of the banks; and could actually increase Palestinian Monetary Authority revenues while simultaneously contributing to the development of an interbank market. For example, by setting an interest rate above the market rate, only banks that do not have ready access to alternative (i.e., cheaper) sources of credit would choose to borrow from the Palestinian Monetary Authority. This in turn might encourage interbank lending to occur at an equivalent, if not more competitive, interest rate.

In operating such a discount window, the Palestinian Monetary Authority would have to be especially prudent in its monitoring of borrowing banks. The window should only be used to alleviate temporary liquidity shortfalls. Banks with more fundamental problems and whose solvency may be in doubt should not be allowed to use the window. Another potential problem is that the Palestinian Monetary Authority may not have sufficient resources, based on its holding of reserves that would represent the ultimate constraint on borrowing, to effectively manage the window. To address this problem, the Palestinian Monetary Authority could create a deposit taking window using the interest rate to attract liquidity as needed. The Palestinian Monetary Authority would then essentially be serving as the market maker in a nascent interbank market. Not only would the Palestinian Monetary Authority gain experience in using interest rates as a policy tool,

\footnotetext{
10The Palestinian Monetary Authority uses the following criteria to determine the amount of reserves to deposit and the recipient bank: compliance with Palestinian Monetary Authority regulations; capital adequacy; conformity with Basle accords; liquidity ratio; and extent of domestic lending.
}

but it would also contribute to the development of a new domestic financial market with the potential to increase the efficiency of the West Bank and Gaza Strip banking sector.

Hamed (1996) and the Palestinian Economic Policy Research Institute and World Bank (1997), as well as Chapter 3, propose several structural, rather than monetary, measures directed at increasing domestic lending. For example, improving property registration, enhancing the legal system, and facilitating the credit application and approval process have been mentioned. Structural measures such as these would potentially improve the functioning of the credit market, lower the lending interest rate, and increase lending to the private sector whether or not credit rationing is present. However, to the extent that investment (and therefore the need for credit financing) is constrained by demand considerations (see Chapter 3 ), the low claims on the private sector to deposit ratios may be reflecting economic considerations largely unrelated to the market for credit.

\section{Conclusion}

Is monetary policy capable of boosting output, at least in the short run, in the West Bank and Gaza Strip? Despite the lack of a domestic currency, the Palestinian Monetary Authority may conduct monetary policy using the credit channel transmission mechanism; thus, in principle this question may be answered in the affirmative. However, the effectiveness of the credit channel depends on the degree to which credit markets are constrained by supply considerations. Even though West Bank and Gaza Strip banks have sufficient liquidity, as demonstrated by the share of foreign assets in their portfolios, the domestic credit market could in theory still be subject to credit rationing, and therefore effectively be supply constrained. In order for the Palestinian Monetary Authority to have the potential to influence real activity using indirect monetary instruments, domestic lending to the private sector must be predominantly constrained by supply considerations.

Overall, the empirical evidence does not indicate that domestic lending to the private sector is primarily constrained by supply considerations. While the empirical evidence for the narrow mea- 


\section{MONETARY POLICY IN THE ABSENCE OF A DOMESTIC CURRENCY}

sure of domestic lending to the private sector (loans) appears to show that Jordan dinar and Israeli new sheqel loans, but not U.S. dollar loans, are subject to credit rationing, the broader measure of private sector credit (claims on the private sector) does not appear to be subject to credit rationing. Moreover, even assuming that the broader measure of credit is subject to credit rationing, the empirical exercises indicate that Palestinian Monetary Authority policies would have, at best, only a negligible impact on real GDP. Furthermore, the use of reserves as a policy instrument, aside from being ineffective, could be expensive in terms of lost revenue and be destabilizing to the banking sector.

Although not able to influence short-run growth, there is a constructive role for the Palestinian Monetary Authority to play in the development of the West Bank and Gaza Strip economy. The Palestinian Monetary Authority can pursue policies that create a stable financial environment, consisting of a sound and thriving banking sector, and thereby contribute to the long-run growth prospects in the West Bank and Gaza Strip. Specifically, this can be accomplished by eliminating recently enacted rules (i.e., direct instruments); refraining from using direct instruments in the future; diligently fulfilling its prudential supervisory and regulatory responsibilities; and contributing to the development of the financial sector, including establishing a credit window and facilitating the creation of a West Bank and Gaza Strip interbank market. The existence of wellfunctioning financial markets would also increase the ability of the Palestinian Monetary Authority to manage, using indirect monetary instruments, a Palestinian currency in the event that one is issued. In essence, the Palestinian Monetary Authority is best able to serve the economy of the West Bank and Gaza Strip by closely adhering to its legally defined objective: "to secure the stability of the banking and monetary systems, which will encourage the economic development in the areas under Palestinian jurisdiction."

\section{Appendix: Domestic Credit and Deposit Regressions}

In order to test for the presence of credit rationing (or more generally the importance of lending capacity in determining the amount of credit to the private sector), regressions were run on the following equation,

$$
c=l c \beta_{c}+W \beta_{w}+X \beta+u
$$

where $c$ and $l^{c}$ are, respectively, the natural logarithm of credit and lending capacity, $W$ is the average number of workers in Israel, $X$ is a matrix of other explanatory variables (such as a time trend, constant, or interest rate), $u$ is a vector of residuals, and the $\beta s$ are coefficients to be estimated. Under credit rationing, the elasticity of credit with respect to lending capacity should be unitary $\left(\beta_{c}=1\right)$ and credit should be independent of demand factors $\left(\beta_{w}=0\right)$ as proxied for by the number of workers in Israel. ${ }^{11}$ More generally, $\beta_{c}>0$ is a prerequisite for the Palestinian Monetary Authority to be able to increase credit by enhancing the banking sector's lending capacity. Alternatively, if the credit market equilibrium is primarily determined by demand considerations, then lending capacity would not influence credit $\left(\beta_{c}=0\right)$ while changes in demand would be accommodated $\left(\beta_{w} \neq 0\right)$. However, the number of workers in Israel may not be a good proxy for credit demand. Business investment, which in general (although not in the West Bank and Gaza Strip) is a major source of credit demand, is dependent on a firm's expectations of future profits. These expectations are based on many factors (see Chapter 3, which examines the ones pertinent for the West Bank and Gaza Strip), and may only respond moderately, if at all, to the transitory and periodic fluctuations in the number of workers in Israel. Nonetheless, in the absence of a viable alternative measure of credit demand, it is used in the subsequent analysis.

The results for the regressions using loans as the explanatory variable are presented in Table 2 . The positive and significant coefficients on lending capacity, for the Jordan dinar and the Israeli new sheqel, are supportive of the credit rationing hypothesis. Whereas both are significantly different from zero at the 10 percent level, neither is statistically different from 1 . In contrast, the negative and insignificant coefficient on lending capacity for the

\footnotetext{
${ }^{11}$ If credit is constrained by supply factors, then changes in credit demand should not have a measurable effect on the equilibrium (i.e., $\beta_{w}=0$ ). The reasoning underlying the unitary elasticity (i.e., $\beta_{c}=1$ ) is that since portfolio considerations determine the share of lending capacity banks' allocate to credit to the private sector, to preserve this share the quantity of credit to the private sector would have to rise in proportion with the growth in the banks' overall portfolio.
} 


\section{Appendix: Domestic Credit and Deposit Regressions}

TABLE 2.

Loans as a Function of Lending Capacity ${ }^{1}$

\begin{tabular}{lccc}
\hline & \multicolumn{3}{c}{ Currency } \\
\cline { 2 - 4 } Parameter & $\begin{array}{c}\text { Jordan } \\
\text { dinar }\end{array}$ & $\begin{array}{c}\text { Israeli new } \\
\text { sheqel }\end{array}$ & $\begin{array}{c}\text { U.S. } \\
\text { dollar }\end{array}$ \\
\hline Constant & -1.61 & $-10.85^{\star * *}$ & $5.39^{* *}$ \\
& $(2.97)$ & $(5.55)$ & $(2.65)$ \\
Time trend & 0.007 & 0.03 & $.06^{\star}$ \\
& $(.011)$ & $(.02)$ & $(.01)$ \\
Lending capacity & $.89^{* * *}$ & $2.25^{\star *}$ & -0.31 \\
R-squared & $(.48)$ & $(1.00)$ & $(.43)$ \\
& 0.54 & 0.37 & 0.93 \\
\hline
\end{tabular}

*Significant at 1 percent; **significant at 5 percent; *** significant at 10 percent.

Source: Palestinian Monetary Authorities.

Notes: Dependent variable is the natural log of loans. Standard errors are in parentheses. Monthly data from January 1996 to August 1997.

1Parameters are estimated via Seemingly Unrelated Regressions (SUR); the US\$ equation includes an adjustment for serial correlation.

U.S. dollar suggests that U.S. dollar loans are not constrained by supply considerations. ${ }^{12}$

On balance, this evidence is supportive of the hypothesis that the loan markets for Israeli new sheqel and Jordan dinar are supply constrained, whereas the U.S. dollar one is not. However, these results should be interpreted somewhat cautiously. Although efficiency was enhanced by running the equations as a system, a larger sample would contribute to the precision of the estimates and, therefore, improve the reliability of the results. In addition, given the scarcity of monthly data series, it is difficult to rule out the possibility that the positive relationship between lending capacity and loans is not due to an omitted variable. For example, deposits (the primary component of lending capacity) and loans may each respond positively to overall perceptions concerning the future prospects for

\footnotetext{
${ }^{12}$ These results are relatively robust to the incorporation of other explanatory variables. When included, neither the contemporaneous nor the lag of the number of workers in Israel is ever significant at the 10 percent level. Moreover, the qualitative features of the coefficients on lending capacity are the same as above, with the only exception being that when the lag of workers is included the coefficient on Jordan dinar lending capacity is no longer significant. The addition of the deposit interest rate, which proxies for a bank's opportunity cost of funds, did not substantially affect the results and the corresponding coefficients are never statistically significant at the 10 percent level.
}

TABLE 3.

Claims on the Private Sector Regressions ${ }^{1}$

\begin{tabular}{|c|c|c|c|}
\hline \multirow[b]{2}{*}{ Parameter } & \multicolumn{3}{|c|}{ Currency } \\
\hline & $\begin{array}{l}\text { Jordan } \\
\text { dinar }\end{array}$ & $\begin{array}{c}\text { Israeli new } \\
\text { sheqel }\end{array}$ & $\begin{array}{l}\text { U.S. } \\
\text { dollar }\end{array}$ \\
\hline Constant & $\begin{array}{r}3.07^{*} \\
(1.05)\end{array}$ & $\begin{array}{l}4.33^{*} \\
(.95)\end{array}$ & $\begin{array}{r}5.18^{*} \\
(1.51)\end{array}$ \\
\hline Time trend & $\begin{array}{l}0.018^{*} \\
(.004)\end{array}$ & $\begin{array}{l}0.025^{*} \\
(.004)\end{array}$ & $\begin{array}{r}.077^{*} \\
(.008)\end{array}$ \\
\hline Lending capacity & $\begin{array}{l}.31^{\star \star \star} \\
(.17)\end{array}$ & $\begin{array}{l}.04 \\
(.17)\end{array}$ & $\begin{array}{l}39^{* *} \\
(.18)\end{array}$ \\
\hline Workers in Israel & $\begin{array}{c}-0.014^{\star \star \star *} \\
(.007)\end{array}$ & $\begin{array}{c}-0.007 \\
(.010)\end{array}$ & $\begin{array}{r}-.036^{\star} \\
(.012)\end{array}$ \\
\hline Interest rate & $\begin{array}{c}\text { Not } \\
\text { included }\end{array}$ & $\begin{array}{c}\text { Not } \\
\text { included }\end{array}$ & $-.70^{\star}$ \\
\hline R-squared & 0.87 & 0.86 & 0.96 \\
\hline
\end{tabular}

*Significant at 1 percent; ${ }^{* \star}$ significant at 5 percent; *** significant at 10 percent.

Sources: Palestinian Monetary Authorities; International Financlal Statistics; and IMF staff estimates.

Notes: Dependent variable is the natural log of claims on the private sector. Standard errors are in parentheses. Monthly data from January 1996 to August 1997.

1 Parameters are estimated via Seemingly Unrelated Regressions (SUR); the Israeli new sheqel equation includes an adjustment for serial correlation.

the West Bank and Gaza Strip. As prospects improve, expectations of higher profits increase the demand for credit, while confidence about future conditions encourages people to deposit their money inside the West Bank and Gaza Strip banking system.

The results of regression using the broader measure of credit, claims on the private sector, are presented in Table 3 and are not supportive of the credit rationing hypothesis. ${ }^{13}$ Although the coefficient on lending capacity is statistically significant (10 percent level) for the Jordan dinar and U.S. dollar, the hypothesis of a unitary elasticity may be rejected. Furthermore, in each of these cases the demand variable is statistically different from zero at the 10 percent level. For the Israeli new sheqel, neither the demand nor supply variable is statistically different from zero.

\footnotetext{
${ }^{13}$ The specifications used for loans are repeated for claims on the private sector. The actual specification reported in Table 3 most broadly captures the nature of the relationships as indicated by the many regressions examined. Nonetheless, the combination of a small sample, relatively large number of explanatory variables, and specification search suggests that these results should be interpreted with a good degree of caution.
} 
TABLE 4.

\section{Deposit Regressions ${ }^{1}$}

\begin{tabular}{lccc}
\hline & \multicolumn{3}{c}{ Currency } \\
\cline { 2 - 4 } Parameter & $\begin{array}{c}\text { Jordan } \\
\text { dinar }\end{array}$ & $\begin{array}{c}\text { Israeli new } \\
\text { sheqel }\end{array}$ & $\begin{array}{c}\text { U.S. } \\
\text { dollar }\end{array}$ \\
\hline Constant & $6.24^{*}$ & $5.07^{\star}$ & $5.78^{*}$ \\
Time trend & $(0.04)$ & $(.17)$ & $(.43)$ \\
Interest rate & $0.007^{\star}$ & $0.010^{\star}$ & $.024^{\star}$ \\
& $(.001)$ & $(.002)$ & $(.007)$ \\
R-squared & $0.024^{*}$ & $0.033^{*}$ & 0.084 \\
& $(.006)$ & $(.011)$ & $(.083)$ \\
\hline
\end{tabular}

*Significant at the 1 percent level.

Sources: Palestinian Monetary Authorities; and International Financial Statistics.

Notes: Dependent variable is the natural log of deposits. Standard errors are in parentheses. Monthly data from January 1996 to August 1997.

1Parameters are estimated via Seemingly Unrelated Regressions (SUR), adjusted for first order serial correlation.

These results indicate that the credit market, as defined by claims on the private sector, operates differently than that defined by loans. The Jordan dinar and U.S. dollar markets resemble a "normal" credit market, with the equilibrium responding to both supply and demand considerations. The statistical significance of the demand terms, regardless of the magnitude of the supply coefficients, suggests that demand factors are a pertinent determinant of credit; therefore, the market is not subject to credit rationing. Moreover, consistent with the above discussion of overdrafts, the negative coefficient on workers in Israel indicates that credit to the private sector actually increases when there is a negative shock. This means that rather than financing new fixed investment, borrowing occurs to offset any temporary income shortfalls resulting from the reduction in income from workers in Israel. Finally, the negative coefficient on the U.S. dollar interest rate implies that banks' redistribute their portfolio away from domestic lending to the private sector and toward (safer) foreign assets as the return on the latter increases.

The sensitivity of deposits to interest rates is also used to measure quantitative impact of Palestinian Monetary Authority policies on growth. The regression results in Table 4 show that deposits are positively related to interest rates for each of the currencies, with the U.S. dollar coefficient being the only one that is not statistically significant at conventional levels. Israeli new sheqel deposits are the most sensitive to interest rates, with the point estimate indicating that a 1 percentage point increase in the deposit interest rate would precipitate a 3.3 percent increase in new sheqel deposits. Including either the contemporaneous or the lag of the number of workers in Israel did not substantially affect the estimate of the interest rate sensitivity.

\section{References}

Alexander, William E., Tomás J.T. Baliño, and Charles Enoch, 1995, The Adoption of Indirect Instruments of Monetary Policy, IMF Occasional Paper No. 126 (Washington: International Monetary Fund).

Barnett, Steven, 1998, "Monetary Policy in the West Bank and Gaza in the Absence of a Domestic Currency," Mimeo. (Washington: International Monetary Fund).

Bernanke, Ben S. and Mark Gertler, 1995, "Inside the Black Box: The Credit Channel of Monetary Policy Transmission," Journal of Economic Perspectives, Vol. 9, No. 4, pp. 27-48.

Chabrier, Paul and Oussama Kanaan, forthcoming, "What Ought to Be the Role of the State in the Financial Sector?" in The Role of the State in a Changing Arab Economic Environment, International Monetary Fund.

Hamed, Osama, 1996, "The Palestinian Banking System: Reality and Potential," Palestinian Economic Policy Research Institute (MAS).

Hardy, Daniel C., 1993, "Reserve Requirements and Monetary Management: An Introduction,” IMF Working Paper 93/35 (Washington: International Monetary Fund).

International Monetary Fund, 1997, Recent Economic Developments, Prospects, and Progress in Institution Building in the West Bank and Gaza Strip, Middle Eastern Department (Washington: International Monetary Fund).

International Monetary Fund, 1998, International Financial Statistics, January CD-ROM.

Mishkin, Frederic S., 1995, "Symposium on the Monetary Transmission Mechanism," Journal of Economic Perspectives, Vol. 9, No. 4, pp. 3-10.

Palestine Economic Policy Research Institute (MAS) and the World Bank, 1997, Development Under Adversity? The Palestinian Economy in Transition (Ramallah and Washington).

Stiglitz, Joseph E. and Andrew Weiss, 1981, "Credit Rationing in Markets with Imperfect Information," American Economic Review, Vol. 71, No. 3, pp. $393-411$. 


\title{
5. Fiscal Policy and Its Impact on Private Sector Activity
}

\author{
Dale Chua
}

$I^{n}$ $\mathrm{n}$ the absence of a national currency, fiscal polI icy is the main policy instrument available for macroeconomic management in the West Bank and Gaza Strip. Consequently, the soundness of fiscal policies has far-reaching implications for achieving a high level of sustainable economic growth. In addition to its impact on aggregate demand, the composition of government expenditures and the efficiency of the tax system will affect total factor productivity in the economy and private sector investment and growth in particular.

Since its establishment in 1994 the Palestinian Authority has made considerable progress in establishing a fiscal administration and in financing recurrent expenditures from its own revenues. Indeed, in 1998 a small recurrent surplus is budgeted compared with a deficit of \$96 million in 1996. Revenues, in particular, have risen sharply as a result of improvements in tax administration. Following the sharp increase in recurrent expenditures in 1994-97, the early years of forming the Palestinian Authority administration, the growth of recurrent expenditures is expected to level off in 1998, aided in particular by a restrictive recruitment and wage policy. Despite efforts to stabilize the fiscal position, however, the overdraft and arrears of the Palestinian Authority have been increasing due to the diversion of some revenues to accounts outside the control of the Ministry of Finance.

In parallel with the improvement in the fiscal position, there is an increasing recognition within the Palestinian Authority that fiscal policy needs to be used to lay the ground for private sector growth, especially under the difficult conditions of border closures that have been outlined in Chapter 3. Thus, this chapter will concentrate on two areas in which the fiscal policy of the Pales- tinian Authority can have the strongest impact on private sector activity in the West Bank and Gaza Strip: the tax system and the expenditure policy of the Palestinian Authority.

\section{The Tax System}

A good market-based tax system must balance efficiency, equity, and simplicity in a way that raises adequate revenue for financing an appropriate level of government expenditures while promoting a high level of private sector investment. At the same time, with increased capital mobility and globalization, a sound tax system must also remain competitive vis-à-vis those in neighboring countries. In the case of the West Bank and Gaza Strip, the Protocol on Economic Relations with Israel has placed some restrictions on the design of the tax system. Nevertheless, the scope for improving the tax system in support of private sector activity remains considerable.

\section{Existing Constraints and Reform Priority}

Under the Protocol on Economic Relations, the major trade and purchase taxes in the West Bank and Gaza Strip cannot be modified significantly. Indeed, the Protocol also limits any permissible deviation of the value added tax (VAT) rate in the West Bank and Gaza Strip to no more than 2 percentage points below that of Israel. However, the Protocol provides for unilateral changes in the West Bank and Gaza Strip income tax laws (individual and corporate) and in a small number of customs duties on certain goods.

The fact that tax reform must be confined to direct taxes is not too limiting because the indirect 
tax system is relatively well designed. In contrast, the income tax is dated and inefficient. Thus, in the short term, the priority should be to make the income tax more efficient and supportive of growth.

\section{Current Income Tax System}

The current income tax is in need of fundamental overhaul. ${ }^{1}$ Partly a vestige of history and partly a result of years of general neglect, the income tax is outdated, costly to administer, and imposes high compliance costs on taxpayers. In addition, the system is not uniform. In the West Bank, for example, the legal base for the income tax is rooted in the Hashemite Kingdom of Jordan Income Tax Law No. 25 of 1964 (as amended), while in the Gaza Strip the legal base originates from the British Mandate Income Tax Ordinance No. 13 of 1947 (as amended). While the tax in the West Bank is based on the territorial principle, that in the Gaza Strip is based on the residence principle. The corporate tax rates are also not uniform- 38.5 percent in the West Bank and 37.5 percent in the Gaza Strip-and are high by regional and international standards. In addition, all agricultural incomes in the West Bank are free from tax while similar incomes are taxed in the Gaza Strip.

Other weaknesses in the present income tax include a complex and inadequate system of depreciation allowance for capital investments, the lack of clear rules for inventory valuation, and restrictive carrying forward of losses. At the same time, tax exemptions are widespread. For example, under the current investment promotion code, income tax holidays ranging from $2-5$ years are available depending on a project's paid-up capital, ${ }^{2}$ on the number of permanent Palestinian workers employed, ${ }^{3}$ and on its duration. Furthermore, wide unspecified discretionary power to grant additional and exceptional exemptions to large projects, defined as exceeding $\$ 5$ million in paid-up capital and employing at least 50 permanent Palestinian workers, is also present.

On the personal income tax, deductions are prevalent. For example, standard deductions for

\footnotetext{
${ }^{1}$ This section focuses mainly on the corporate income tax as it has the most direct bearing on private sector activity.

${ }^{2}$ Enterprises with a paid-up capital of more than $\$ 100,000$ receive a two-year tax holiday; more than $\$ 150,000$, three years; and more than $\$ 500,000$, five years.

${ }^{3}$ Businesses employing at least 10 workers are granted a two-year exemption; at least 15 workers, three years; and at least 25 workers, five years.
}

self, spouse, children, and parents are generous while nonstandard ones such as wage/salary, education, and medical deductions are distortive. In particular, because the wage/salary deduction at the personal level is treated as an expense at the company level, a well-defined stream of income is effectively not taxed. In addition, the personal income tax has too many brackets, and marginal rates are steeply progressive reaching 48 percent for income above $\$ 49,000$.

The weak income tax law, coupled with a nascent tax administration, has undermined revenue collection from personal incomes and business profits. Income tax revenues are relatively insignificant, amounting to only 10 percent of total revenue in 1997. However, the low yield presents an opportunity for revamping the income tax without major risks to the budget. Indeed, a modern income tax law can partially compensate for some other disadvantages faced by the Palestinian private sector. In this regard, a new draft income tax law and investment promotion code will be presented to the Legislative Council soon.

\section{A Competitive Income Tax System}

A tax system that is designed to encourage private sector activity and to attract capital investment must be business-friendly and competitive, while avoiding the use of cost-ineffective incentives. Such a system should contain the following general characteristics. ${ }^{4}$

First, the corporate tax should have a low rate that is set at, or at about, the same rate as the lowest corporate tax rate in the region. Therefore, the corporate tax in the West Bank and Gaza Strip should be set at a unified rate, preferably at 25 percent for all sectors of the economy, including the financial sector.

Second, a generous and simple system of depreciation charges should be a prominent feature. For administrative simplicity, the Palestinian Authority should adopt a simple system of pool account depreciation where there are no more than 4-5 asset groups. A declining balance approach should be used as it allows for the pooling of all assets with the same depreciation rate in one group for which the only record of relevance would be the undepreciated balance.

\footnotetext{
4The IMF has provided detailed technical assistance to the Palestinian Authority on this issue. This section summarizes the main conclusions.
} 
Third, a system of well-targeted investment tax credits should be introduced in lieu of current tax holidays if it is politically infeasible to withdraw completely all incentives. This would limit revenue losses to the ceiling offered by the tax credits. However, all holidays that have already been provided should be honored.

Fourth, generous personal income tax deductions (as noted above) that are poorly targeted should be eliminated in favor of personal tax credits. This should improve tax equity while providing maximum flexibility for the reduction in tax rates. The top individual income tax rate should also be set at the same level as, or be as close as possible to, the corporate tax rate.

Last, but not least, any discordant parts of the tax systems in the West Bank and in the Gaza Strip should be removed.

\section{Expenditure Policy}

An appropriate expenditure policy can support macroeconomic stability, promote equity, and enhance growth. Concerning its impact on growth, public spending has two opposing characteristics. On the one hand, public expenditures that need to be locally financed may crowd out private investment and reduce private sector activity. On the other hand, some spending programs will complement private sector activity and, over time, increase its productivity in the West Bank and Gaza Strip. Government spending should center on health and education to enhance human capital accumulation, and on public investment in basic infrastructure to support a buildup of nonmilitary capital stock. ${ }^{5}$ These areas are the focus of discussion in the remainder of this section.

\section{Budget Allocation for Health and Education}

The analysis below suggests that substantial increases in real terms in spending on health and ed-

\footnotetext{
${ }^{5}$ See, for example, W. Baumol, 1986, "Productivity Growth, Convergence, and Welfare: What the Long-Run Data Show," American Economic Review, Vol. 76, pp. 1072-85; R. Barro, 1991, "Economic Growth in a Cross Section of Countries," Quarterly Journal of Economics, Vol. 106, pp. 407-43; and X. Sala-i-Martin, 1996, "Regional Cohesion: Evidence and Theories of Regional Growth and Convergence," European Economic Review, Vol. 40, pp. 1325-52.
}

ucation will be required to maintain the present high level of services in these areas. ${ }^{6}$ If these requirements are not to put excessive pressure on the fiscal position over the medium term, the Palestinian Authority will need to resort to increased cost sharing and private sector participation, as well as strict prioritization in these sectors.

\section{Health}

The Palestinian health system consists of four service providers: the Palestinian Authority, UNRWA (for those in refugee camps), nongovernment organizations (NGOs), and the private sector. ${ }^{7}$ While complex, this integrated health care system has so far produced an admirable standard of health care service compared to other countries with a similar level of economic development. In some instances, it approaches those of newly industrialized Asian countries. For example, life expectancy in the West Bank and Gaza Strip at 71.7 years is much higher than that of several Middle East and North Africa (MENA) countries such as Egypt, Jordan, and Tunisia, and it is comparable to South Korea ( 72 years), but lower than Israel (77 years) (see Table 1). Infant mortality at 28 per 1,000 is much lower than that of the MENA countries, although it is more than twice as high as that of South Korea, and more than thrice that of Israel. In addition, malnutrition is rare. Equally important, access to primary and secondary level health care services is generally adequate and affordable even for the poor, although tertiary health services are more scarce. However, of some concern is the high fertility in the West Bank and Gaza Strip, which at 6.2 is the highest in the region and more than three times that of South Korea (1.8).

While health care services are generally adequate for now, the pressure to maintain current standards is enormous owing to several factors. On the demand side, the high rate of population growth in recent years (estimated at 4.5 percent in 1996) will give rise to unprecedented demand

\footnotetext{
6In 1995 and 1996, budgetary expenditures on health and education represented about a third of total recurrent expenditures (in the range of 5-6 percent of GDP).

7This section has benefitted from information contained in a discussion paper by the Palestine Economic Policy Research Institute (MAS), Health in Palestine: Potential and Challenges, March 1997, and in Chapter 12 of a World Bank draft paper, Development Under Adversity? The Palestinian Economy in Transition, May 1997.
} 


\begin{tabular}{|c|c|c|c|c|c|c|}
\hline Indicator & $\begin{array}{c}\text { West Bank } \\
\text { and } \\
\text { Gaza Strip }\end{array}$ & Egypt & Israel & Jordan & Tunisia & $\begin{array}{c}\text { Republic } \\
\text { of } \\
\text { Korea }\end{array}$ \\
\hline Life expectancy (years) & 71.7 & 62 & 77 & 70 & 68 & 72 \\
\hline Infant mortality rate (per 1,000 ) & 28 & 52 & 8 & 32 & 40 & 12 \\
\hline Total fertility rate & 6.2 & 3.5 & 2.4 & 4.8 & 5.2 & 1.8 \\
\hline
\end{tabular}

for health care services in the near future. On the supply side, the gradual but steady cutback in recent years of NGO-provided health care services (resulting from reduced funding to such organizations because of a diversion of international financial assistance away from NGOs to the Palestinian Authority) has reduced access to basic care in the health care system for many poor Palestinians. In addition, the eventual withdrawal of UNRWA health care services to the refugee population in the near future could further reduce the supply of health services in the West Bank and Gaza Strip and impose further demands on Palestinian Authority-provided health care.

Successfully meeting the demands for quality health care services in a financially viable way requires the Palestinian Authority to adjust its current health care priority, as well as taking measures to address the health-care-related financial burden on its budget. In addition, to strengthen the health care system, the Palestinian Authority should also encourage further private sector participation, particularly at the tertiary care level in order to enhance the present integration of public and private care.

\section{Prioritization}

To control escalating costs that can be expected to accompany a higher level of demand, the Palestinian Authority needs to prioritize its health care expenditures. As basic care is instrumental in providing a growing child with the minimal level of care that ensures its proper development, a health care system that emphasizes adequate primary care will in the long term be more costeffective than one that allocates its resources mainly to secondary and tertiary care. In fact, the relatively good health indicators in the West Bank and Gaza Strip today are a reflection of a sound system of health care that in the past has stressed basic care.

In the near future, the Palestinian Authority will need to devote more resources to basic health care services. This is because of two recent developments. First, as noted, NGO-provided primary care has been curtailed, resulting in a diminished level of care generally as well as reduced access in remote areas. Second, in recent years, the Palestinian Authority has increasingly devoted a fairly significant share of its health resources to two areas that are outside the ambit of basic care, namely, hospital care ${ }^{8}$ and increasing hospital capacity. ${ }^{9}$ The combined effect of these developments has shifted the emphasis from basic care to tertiary care. In particular, it is vital that the high level of access to primary care of the recent past is maintained and greater attention be paid to remote villages in view of the sharp reduction of services in those areas. To ensure the adequacy of tertiary care as resources of the Palestinian Authority are shifted toward basic care, the Palestinian Authority should make greater private sector provision in tertiary-level care one of its main health care policy goals (see below).

\section{Cost-Sharing}

Because providing a quality care service in the face of rapidly increasing demand will impose a high financial burden on the Palestinian Author-

\footnotetext{
${ }^{8}$ For example, in the West Bank, the Ministry of Health currently spends about two-thirds of its budget allocation on hospital care and one-third on primary care.

9While the Palestinian Authority has contributed to increasing the bed capacity and developing more care units in some hospitals, the building of new hospitals is largely funded by international donors who seem to prefer this type of support.
} 
ity, new sources of financing health care must be explored. This challenge can be met by increased cofinancing. The policy options for achieving this are the reform of the Palestinian Authority health insurance system and the expansion of cost recovery programs.

In 1996, general tax revenues provided financing for more than 60 percent of the Ministry of Health budget while health insurance contributions accounted for about a quarter, and user fees, the remainder. ${ }^{10}$ While existing direct contributions (health insurance premiums) and user fees may already be burdensome to the poor, they are relatively low in comparison to the level of benefits that are offered. For example, on direct contributions, government employees pay only 5 percent of their basic salary per month, up to a maximum of $\$ 20$, to enroll in the health insurance system while nongovernment employees who choose to join the health insurance system pay approximately \$11 per month for a single individual or \$20 for a nuclear family, regardless of size.

For those insured, outpatient visits to a Palestinian Authority clinic or hospital cost approximately a token $\$ 1$ for each item of medication prescribed regardless of the type of treatment received. Inpatient visits to Palestinian Authority hospitals are free. For those without health insurance, fees for outpatient visits are only somewhat higher (according to a less heavily subsidized cost schedule depending on treatment) while inpatient visits may be charged up to $\$ 200$ per day for intensive care. For both insured and uninsured, referral services costing up to about $\$ 6,500$ to non-Palestinian Authority hospitals are also available. However, because referrals are expensive to the Palestinian Authority, access is controlled. In addition, all treatment for children below the age of 3 is free. ${ }^{11}$

This pricing system is inefficient. For those insured, not only does it not discriminate against the type of care provided for outpatient services, it also does not create the right incentives for inpatient visits by allowing free admission. For the uninsured, the price of outpatient treatments, which are heavily subsidized (although less so compared to those insured), also provide no in-

\footnotetext{
${ }^{10}$ Data provided by staff of the Ministry of Health.

${ }^{11}$ Data provided by officials of the Ministry of Health, and World Bank draft paper, Chapter 12, pages 10-12 (see footnote 7 ).
}

centive for them to join the health insurance system. Thus, the pricing structure is in need of reform to allow a more efficient allocation of medical services.

With current low insurance premiums and user fees, the expected increase in demand for health services in the near future will exert a disproportionally high burden on the budget. This is because the share of cost recovery (premiums and fees) in the overall funding of the Ministry of Health budget can be expected to fall with increased demand if no adjustments are made to the present system. Thus, to reduce or slow the increase of this burden on the Palestinian Authority budget, the system of financing health care needs to be modified. In fact, the combined funding from health insurance premiums and user fees in 1996, at less than 40 percent of the Ministry of Health budget, is low compared to more than 60 percent in the past (in part, a result of a recent Palestinian Authority decision to lower the insurance contribution premiums).

A target to raise this level to 60-65 percent of the Ministry of Health budget in the medium term may be appropriate, as this was the range of the pre-1994 funding level. This can be achieved by reducing the general level of implicit subsidy by increasing and broadening the coverage of insurance premiums and by increasing user fees for both outpatient and inpatient visitations. In addition to recovering costs in the short term, these adjustments should also improve the pricing structure of medical services, which should provide the proper incentives to users, thus, assisting the Ministry of Health to control costs in the long term. To ensure that the poor are not denied access to a minimum level of health care as a result of these rate adjustments, the Palestinian Authority could consider introducing a system of targeting for the poor.

\section{Private Sector Participation}

To supplement its provision and enhance the current mix of Palestinian Authority and nonPalestinian Authority providers, the Palestinian Authority should encourage private sector participation at all levels of health care services and, particularly, in tertiary care services involving expensive advanced medical technology. This strategy should be developed in line with the objective to reduce the high reliance on hospitals outside the 
West Bank and Gaza Strip, which are very costly. For example, in 1996, the cost of overseas treatment of admitting Palestinian patients to hospitals in Israel, Jordan, and Egypt amounted to slightly less than 20 percent of the Ministry of Health budget. ${ }^{12}$ With more local private hospitals, and the newly established European and Japanese hospitals, considerable cost saving can be expected from not sending Palestinians to overseas hospitals, thus freeing some of the Ministry of Health health resources that would have been allocated for overseas treatment.

The potential for attracting greater private sector participation in providing quality care appears good. The recent strong interest in forming large Palestinian-owned private health care companies that is supported by many well-trained physicians is indicative that a viable private sector care industry can develop in the West Bank and Gaza Strip.

\section{Education}

Like the health sector, joint provision is a hallmark of the education system in the West Bank and Gaza Strip, with the Palestinian Authority, UNRWA, and the private sector, including NGOs, providing complementary schooling from basic to university education. ${ }^{13}$ The Ministry of Education has overall responsibility for basic and secondary schools and the Ministry of Higher Education is responsible for the development of higher education, which is financed mostly by non-Palestinian Authority entities.

The Palestinian Authority dominates the provision of schooling for children between the ages of $6-17$, operating up to 70 percent of all basic schools (for 6-12 years old in primary schools and for 13-14 years old in preparatory schools) and up to 85 percent of all secondary schooling (for those in the 15-17 years age group). UNRWA complements the Palestinian Authority by concentrating its efforts on the schooling of children in refugee camps up to the basic level. It funds and administers about a quarter of all basic schools in the West Bank and Gaza Strip and a small number of preschools for toddlers below the age of 6 . Strongly reinforcing UNRWA's ef-

\footnotetext{
${ }^{12}$ Data obtained from the Ministry of Health.

${ }^{13}$ This section is based on information and data from the World Bank paper (see footnote 7), Chapter 11, and from a background paper by Berryman, The Education Story, 1996.
}

forts in the schooling of younger children, the private sector, including NGOs, operates up to 95 percent of all preschools. At the same time, the private sector, supported by the European Union (EU), is the sole provider of universitylevel education, funding all eight universities, as well as running a small, but significant, number of basic schools ( 5 percent) and secondary schools ( 15 percent).

Despite the diversity in provision, the coverage and quality of the school system in the West Bank and Gaza Strip is relatively good, although there is still much room for improvement. In general, the population and the labor force are fairly well-educated by regional standards. Social indicators in education for the West Bank and Gaza Strip compare favorably against those of its neighbors. For example, the literacy rate for those in the 15-19 age group is 97 percent in the West Bank and Gaza Strip, which is comparable to Israel and much higher than that of the MENA region (79 percent) (see Table 2). For those above 15 years of age, the literacy rate is 84 percent relative to a rate of 57 percent in the neighboring countries. In addition, school enrollments in primary and preparatory schools in the West Bank and Gaza Strip for both males and females are high (more than 90 percent), while those in secondary schools are moderately high (less than 70 percent).

These indicators have been translated into a relatively well-educated workforce that should bode well for the Palestinian economy as it begins to participate more fully and compete more actively in the regional and world markets. To ensure that this level of advantage over its neighbors is maintained over the long term, the Palestinian Authority should continue to stress the importance of education. In particular, it should improve the current level of access up to the secondary level and enhance the quality of its education services.

\section{New Challenges}

While the need to improve the education system is always present, the ability of the Palestinian Authority to maintain even the current standards will come under mounting pressure. Three largely unrelated factors emerge as being particularly significant. First, the high fertility rate, which has averaged more than 6 percent in recent years, will soon place a very high demand on the Palestinian Au- 


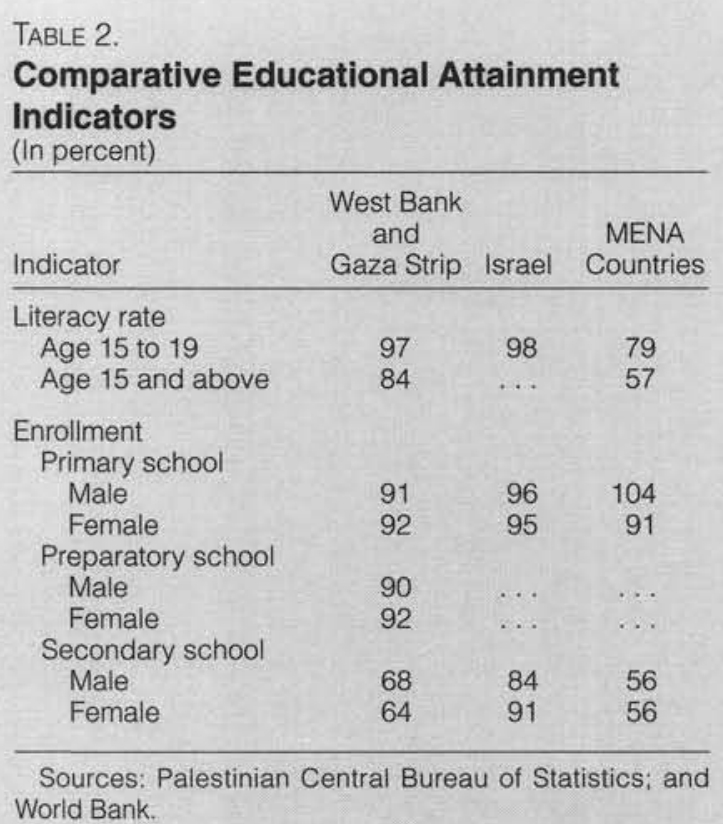

thority to absorb the growing number of children into the system. This would call for devoting substantially more resources to building new schools and for training and employing a large number of new teachers, as well as increasing the supply of teaching materials. Second, following years of general neglect in school maintenance under the Israeli Civil Administration, many existing schools are now in need of major repairs. Third, the eventual withdrawal of UNRWA's support for basic education in the near future will place an additional significant burden on the Palestinian Authority.

In the presence of these emerging pressures, a broad strategy for managing the education system must become one of the highest priorities for the Palestinian Authority in order to preserve its standing in education in the region and to promote a high level of learning in its future workforce. The Palestinian Authority needs to set long-term educational objectives covering developmental plans, governance, finance, and management.

\section{Maintaining High Access to Primary and Secondary Education}

More schools will have to be built and old schools rehabilitated. It has been estimated that over the period 1995 to 2025 , all else equal, the number of spaces in basic schools must be increased by 95 percent, in preparatory schools by 115 percent, and in secondary schools by 125 percent, in order to meet the needs of the rapidly growing population in the West Bank and Gaza Strip. ${ }^{14}$

If a doubling of the student population translates into a doubling of schools, then the number of schools will need to be doubled to 2,700 in the education system by the year 2020 . From today to the year 2000,330 more primary schools would have to be built. At the same time, as school maintenance was given a low priority in the past, many schools are now in need of urgent major repair work. All these factors imply that the investment budget for schools will have to be increased considerably over the next few years. To the extent that donors are willing to continue funding the building and rehabilitation of schools, the financial pressure on the Palestinian Authority will be greatly reduced. If not, the Palestinian Authority would have to explore new ways of paying for an increasing number of schools (see below).

In parallel with the rehabilitation of run-down schools and building of new schools, school facilities should also be used intensively. While threeshift schools should be changed to double-shift ones, moving to universal single-shift schools does not appear appropriate because it would greatly increase the demand for resources for more schools. Although double-shift schools may be less conducive for learning for some students, a system of single-shift schools should not be a high priority for the Palestinian Authority at this moment. In fact, many Asian countries with higher income levels still adopt a double-shift school system because of the high cost of singleshift schools.

A large number of quality teachers will need to be employed to meet the rising demand for basic and secondary education of a growing population. Assuming that the current teacher to student ratio of $1: 46$ is maintained, the number of

\footnotetext{
${ }^{14}$ See Education Statistics in the West Bank and Gaza Strip, Palestinian Central Bureau of Statistics, Current Status Report Series No. 5, August 1995, Tables 7.23 and 7.24, pages 138-139; World Bank Population Projections; and The Demographic Survey in the West Bank and Gaza Strip, Palestinian Central Bureau of Statistics, preliminary report, March 1996, page 89.
} 


\section{FISCAL POLICY AND ITS IMPACT ON PRIVATE SECTOR ACTIVITY}

teachers will need to be increased from about 16,500 in 1996 to 33,000 in $2020 . .^{15}$

\section{Encouraging Diversity in the Provision of Education Services}

The Palestinian Authority should strive to maintain a mix of providers of schools. Diversity in the provision of education encourages competition and strengthens the education system. Thus, the present mix of private and public schools up to the secondary level should be preserved. While to a lesser extent this principle may also be extended to university education, numerous competing demands for limited Palestinian Authority resources at the moment suggest that the provision of university education in the West Bank and Gaza Strip is best left to the NGOs, which have been the traditional source of funding for university education, and the private sector.

However, in view of recent developments concerning the funding for universities, the Palestinian Authority would need to formulate new financing options for higher education. The EU has recently expressed its intention of cutting direct funding to universities in the West Bank and Gaza Strip. In the absence of other donors stepping in to fill the gap, the most likely short-term impact would be a higher burden on the Palestinian Authority, while in the longer term, competition at the university level may be reduced if the Palestinian Authority financed all universities. Neither of these outcomes is desirable. Thus, in anticipation of the eventual withdrawal of funding by the EU, the Palestinian Authority should begin to invite other international NGOs and well-endowed Arab institutions to accept the funding responsibility for universities in the West Bank and Gaza Strip.

The option of replacing donors' funding with Palestinian Authority budgetary sources should be avoided, except possibly for a temporary period. Accepting funding responsibility for universities will most likely involve a trade-off such as curtailing or postponing other education projects

\footnotetext{
${ }^{15}$ Data obtained from discussions with Ministry of Education staff and from the World Bank report, Development Under Adversity? The Palestinian Economy in Transition, May 1997, Chapter 11, page 6. Although the teacher to student ratio is relatively low, it is not completely unacceptable by international standards.
}

at the more basic schooling level. This is not recommended, as the social rate of return on higher education while positive is not as high as that of lower levels of education. ${ }^{16}$

In addition, regional experience has shown that public funding of higher education may be extremely inefficient in the long run. In the face of high youth unemployment, students are admitted to publicly funded universities to provide a oneshot respite for the authority grappling with high youth unemployment. To make matters worse, some countries have also guaranteed government jobs to university students on graduation, resulting in a bloated civil service. In the event the Palestinian Authority is left with no option but to fund higher education, it should ensure that its financing role is kept limited. To achieve this, it should introduce fees to maximize cost recovery.

\section{Physical Infrastructure}

In addition to investment in social infrastructure, adequate public investment in physical infrastructure is also important for promoting growth. Indeed, several empirical studies have found strong correlation between private sector productivity and spending on nonmilitary public capital stock. ${ }^{17}$

The West Bank and Gaza Strip suffers from a deficient and unreliable infrastructure owing to years of neglect and under investment. Large parts of the infrastructure stock are unused because of system losses or disrepair. Virtually all the major roads were constructed before 1967 and received minimal or no maintenance. In the early 1990s, the West Bank and Gaza Strip had only 80 meters of paved roads per 100 people compared with 170 meters in Jordan and 266 meters in Israel. ${ }^{18}$ International transportation (ports and airports) was almost entirely under Israeli control. Moreover, even though the bulk of West Bank and Gaza Strip households had electricity connections, such connections did not necessarily denote adequate or steady supply of

\footnotetext{
16Psacharopoulos, George, 1993, "Returns to Investment in Education: A Global Update," World Bank Policy Research Working Paper, No. 1067.

${ }^{17}$ Levine and Renelt (1992), "A Sensitivity Analysis of Cross-Country Growth Regressions," American Economic Review, Vol. 82, pp. 942-63.

${ }^{18}$ These and the following infrastructure comparison figures are based on data for the years 1992-94 and are from the World Bank report (see footnote 7).
} 
electricity. Indeed, electricity supply was estimated to be 13 kilowatts per 100 people in the West Bank and Gaza Strip while it was 25 kilowatts in Jordan and 82 kilowatts in Israel. Electric power system losses in the West Bank and Gaza Strip were 30 percent, while in Jordan they were 19 percent and in Israel they were only 4 percent. Another severe impediment to growth was restricted access to telecommunications, though this is being partially overcome through the mobile telephone network. Furthermore, although more than 90 percent of West Bank and Gaza Strip households were connected to the water supply, water consumption per head in the West Bank and Gaza Strip was less than 90 liters per day, compared to 140 liters in Jordan and 280 liters in Israel. Also, water quality in the West Bank and Gaza Strip was steadily deteriorating. Of even greater concern, only about 25 percent of West Bank and Gaza Strip households were connected to sewage networks, compared to 100 percent in both Jordan and Israel and 50 percent in Egypt. Sewage collection, treatment, and disposal were growing, major problems.

Recognizing these deficiencies in the infrastructure, during 1994-September 1997 donors committed to the West Bank and Gaza Strip almost $\$ 3$ billion in assistance, out of which \$1.1 billion was, in descending order of magnitudes, for investment projects in eight social and physical infrastructure sectors: water and sanitation, multiple sectors, education, housing, transportation, health, energy, and solid waste (Table 3). ${ }^{19}$ Commitment for physical infrastructure sectors (i.e., excluding education, health, and housing) amounted to $\$ 754$ million. At the first Consultative Group meeting for the West Bank and Gaza Strip in December 1993 it was agreed that the public investment program was to emphasize infrastructure and human resource development. The focus of the program was initially on upgrading, repairing, and maintaining existing facilities, as well as gradually undertaking new construction. Human resource development aimed to maintain essential services, while initiating insti-

${ }^{19}$ Ministry of Planning and International Cooperation, MOPIC's 1997 Third Quarterly Monitoring Report of Donor Assistance, November 28, 1997. These figures represent the status prior to the December 1997 Consultative Group for the West Bank and Gaza Strip. The sectoral breakdown is according to MOPIC's classification. Multiple sectors include projects that have components relevant in various sectors, such as World Bank projects and cofinancing for such projects by donors. tutional, policy, and structural reforms. This orientation remained to a large extent intact at the subsequent donor meetings.

Disbursements for public investment projects and, in particular, infrastructure, were significantly less than envisaged, however. Out of the $\$ 1.8$ billion disbursed by donors during 1994-September 1997 , only $\$ 544$ million was for public investment projects in the eight sectors cited above, with those for physical infrastructure amounting to only $\$ 355$ million. Multiple sectors received the largest amount of investment, followed by water and sanitation, housing, education, health, transportation, solid waste, and energy. The disbursement ratios (disbursements relative to commitments) for these sectors varied widely. In particular, housing had the highest disbursement rate (69 percent) while transportation and energy had the lowest rates (10 percent and 3 percent, respectively).

Public investment disbursements to implementing agencies for these eight sectors accounted on average during the period 1994-September 1997 for only about 4.6 percent of GDP. For physical infrastructure (energy, multiple sectors, solid waste, transportation, and water and sanitation) investment disbursements were less than 3 percent of GDP. ${ }^{20}$ Such investment levels are significantly inadequate when account is taken of the poor initial state of the infrastructure and that developing countries on average spend 4 percent of GDP on basic infrastructure (i.e., transportation, electricity, communications, and water). It must, moreover, be noted that in rapidly growing economies, infrastructure investment levels amounting to 6 to 8 percent of GDP are common.

The lack of interest in the infrastructure in the West Bank and Gaza Strip was due not only to the vacillations in the peace process, which have on occasion resulted in shifting donor focus from investment projects and barriers to project implementation, but also lack of coordination between the Palestinian Authority and Israel. In particular, border closures caused shortages in materials and impediments to the movement of local and international personnel involved in project implementation. In addition, donors often focused more

${ }^{20}$ The ratios were 2.1 percent of GDP in $1994,2.5$ percent in 1995 , and 2.8 percent in 1996 . For 1997 , taking into account the first three quarters, the ratio was 4.9 percent. Regarding the latter, however, it must be noted that the disbursements were to implementing agencies so that by year end the ratio probably declined. 


\begin{tabular}{|c|c|c|c|c|c|}
\hline & \multirow{2}{*}{ 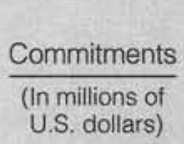 } & \multirow{2}{*}{$\begin{array}{c}\begin{array}{c}\text { Disburse- } \\
\text { ments }\end{array} \\
\text { (In millions of } \\
\text { U.S. dollars) }\end{array}$} & \multirow{2}{*}{$\begin{array}{l}\text { Disburse- } \\
\text { ment Ratio } \\
\text { (In percent) }\end{array}$} & \multicolumn{2}{|c|}{ Disbursements } \\
\hline & & & & $\begin{array}{l}\text { (In percent } \\
\text { of total) }\end{array}$ & $\begin{array}{l}\text { (In percent } \\
\text { of GDP) }\end{array}$ \\
\hline Agriculture & 18.3 & 5.5 & 30.2 & 0.9 & 0.0 \\
\hline Education & 133.6 & 70.6 & 52.8 & 11.7 & 0.6 \\
\hline Energy & 26.4 & 0.7 & 2.7 & 0.1 & 0.0 \\
\hline Environment & 0.2 & 0.0 & 0.0 & 0.0 & 0.0 \\
\hline Health & 79.3 & 44.2 & 55.8 & 7.3 & 0.4 \\
\hline Housing & 108.7 & 74.5 & 68.6 & 12.4 & 0.6 \\
\hline Industrial development & 30.3 & 5.8 & 19.2 & 1.0 & 0.0 \\
\hline Institution building & 80.3 & 31.4 & 39.1 & 5.2 & 0.3 \\
\hline Multiple sectors & 290.9 & 171.4 & 58.9 & 28.4 & 1.4 \\
\hline Police & 13.2 & 11.5 & 87.1 & 1.9 & 0.1 \\
\hline Solid waste & 15.1 & 9.8 & 64.9 & 1.6 & 0.1 \\
\hline Tourism and culture & 6.6 & 2.5 & 37.8 & 0.4 & 0.0 \\
\hline Transportation & 99.1 & 10.1 & 10.2 & 1.7 & 0.1 \\
\hline Undefined & 15.3 & 0.2 & 1.1 & 0.0 & 0.0 \\
\hline Water and sanitation & 322.9 & 162.9 & 50.4 & 27.0 & 1.4 \\
\hline Women & 3.1 & 2.0 & 66.3 & 0.3 & 0.0 \\
\hline Total & $1,243.4$ & 603.2 & 48.5 & 100.0 & 5.0 \\
\hline
\end{tabular}

Source: MOPIC, MOPIC's 1997 Third Quarterly Monitoring Report of Donor Assistance, November 28, 1997.

on short-term feasibility studies and technical assistance rather than on major infrastructure projects. Other aspects of Israeli-Palestinian relations (such as security considerations) also affected the implementation of major infrastructure projects, such as airport and port projects. Furthermore, in the early phase, weaknesses in official Palestinian institutions contributed to limited infrastructure investment projects. During most of 1994-97 Palestinian institutions and the Palestinian $\mathrm{Au}-$ thority were being set up and there was a limited sense of Palestinian ownership of public investment programs.

Recently, at the December 1997 Consultative Group meeting, the Palestinian Authority presented a $\$ 3.5$ billion Palestinian Development Plan for the years 1998-2000, with 49 percent allocated for infrastructure and natural resource management, 25 percent for human resource and social development, 17 percent for productive sectors (such as agriculture and industrial development), and 9 percent for institution capacity building. Among infrastructure and natural resource management projects almost 50 percent (\$831 million) is allocated for water and wastewater and 25 percent ( $\$ 414$ million) for trans- portation. The Palestinian Development Plan is novel in that its development objectives and priorities were identified and project selection criteria set in the context of a highly deliberative and participatory process involving all Palestinian Authority organs, as well as private sector representatives. Moreover, its preparation was carried out within an institutional framework involving collaboration both within the Palestinian Authority and between the Palestinian Authority and the donor community, especially the World Bank. The Palestinian Development Plan has also a medium-term orientation and places emphasis on the ongoing nature of the planning exercise. At the conclusion of the 1997 Consultative Group meeting, donors indicated their intention to commit about $\$ 750$ million toward development activities in the West Bank and Gaza Strip in 1998, and a further $\$ 150$ million in the form of guarantees for private investment. Even more important, the Palestinian Authority is in the process of instituting better, home-grown project follow-up mechanisms for the Palestinian Development Plan. Although these recent developments give encouragement to future disbursements for infrastructure projects, such improvements will require time. 


\section{The Trade System}

Nur Calika for the near- and short-term for the West Bank and Gaza Strip to improve its allocative efficiency and enhance its economic growth.

\section{Current Status of the Trade Regime}

Owing to historical developments, the trade pattern of the West Bank and Gaza Strip is highly oriented toward the Israeli market. Indeed, based on most recent data, the West Bank and Gaza Strip is estimated in 1996 to have had a trade deficit of $\$ 1.6$ billion, of which about 86 percent, $\$ 1.4$ billion, was with Israel. The West Bank and Gaza Strip's exports to Israel in 1996 were \$242 million and consisted mainly of stone, textiles, and agricultural products. Its exports of $\$ 40$ million to the rest of the world, mainly Jordan, consisted of fruits, stone products, and foodstuffs. Its imports from Israel were \$1.6 billion and from the rest of the world only about $\$ 265$ million. The latter were mainly from the European Union (EU), which is estimated to have accounted for about 66 percent of non-Israeli imports, followed by those from Egypt (about 16 percent of nonIsraeli imports), Jordan (14 percent), and other countries (4 percent). Of the non-Israeli imports, it is estimated that consumption goods accounted for 60 percent, capital goods for 33 percent, and raw materials for 7 percent.

\section{Protocol on Economic Relations and Other Agreements with Israel}

The 1994 Protocol on Economic Relations (incorporated subsequently in the Interim Agreement of September 1995) defines the rules that are to govern economic relations between the Palestinians and Israelis during the interim period 


\section{THE TRADE SYSTEM}

(i.e., until 1999). The proposed trade regime is very close to a customs union for the West Bank and Gaza Strip and Israel-under the Agreement, the Palestinian Authority is given some options to modify the prevailing customs union.

The trade regime of Israel is highly complex. It has more than 85 different ad valorem, specific, combined, and alternative tariff rates, with import duties ranging from zero percent to 100 percent, with an average of about 8 percent. ${ }^{1}$ Duty-free treatment is afforded to about 40 percent of tariff positions. In general, Israeli tariff rates on processed items are higher (average of about 10 percent) than those levied on semi-processed items (7 percent average), which in turn are higher than those levied on raw materials (about 2 percent). Israel is unilaterally committed to reducing its tariffs on imports from countries with which it does not have free trade agreements. Import licensing and quotas exist for a limited number of products.

Under the Interim Agreement, for goods other than those in Lists A1, A2, and B (see below), the Palestinian Authority has to apply, at minimum, the same level of customs and other duties and charges as in Israel. ${ }^{2}$ In addition, the Palestinian Authority is allowed to conduct in almost total freedom the exchange of commodities (the main exception being quotas on six agricultural products that are to be phased out by 1998) between the West Bank and Gaza Strip and Israel, and all customs revenue and fees levied on imports have to be distributed between Israel and the West Bank and Gaza Strip on the basis of the place of final destination.

The Palestinian Authority is given under the Interim Agreement some limited options to modify the prevailing customs union with Israel. These include, for certain clearly defined goods, the right to determine the rates of customs and other import taxes. The applicable goods are certain goods produced in Jordan, Egypt, and other Arab trading partners (List Al items), certain basic foodstuffs (List A2 items) from other countries, and certain tools and equipment related es-

\footnotetext{
${ }^{1}$ Excludes preferential tariff rates under free trade arrangements. Most imports from the United States, the EU, and the European Free Trade Association (EFTA) benefit from preferential duty-free status.

${ }^{2}$ There are also exemptions from tariffs and purchase taxes (and specifications) with respect to imported vehicles registered in the West Bank and Gaza Strip and petrol derivatives. The Palestinian Authority, however, has not utilized these options.
}

sentially to the development of the West Bank and Gaza Strip (List B items). The quantities of Lists $\mathrm{Al}$ and $\mathrm{A} 2$ items have to be in accordance with the Palestinian market need as agreed by Israeli and Palestinian authorities. For these agreed quantities of $\mathrm{A} 1$ and $\mathrm{A} 2$ goods, Israeli standards (including quality, licensing requirements, classification, etc.), country origin requirements, and customs and other import taxes do not apply. As the situation has evolved, the Palestinian Authority has only marginally implemented these trade options. In particular, it has not set the rates of customs and other import taxes for goods in Lists $\mathrm{A} 1, \mathrm{~A} 2$, and $\mathrm{B}$, with the minor exception of some goods that are included in Palestinian Authority's trade agreement with Jordan. ${ }^{3}$

An important feature of this Interim Agreement for the West Bank and Gaza Strip is that it bestows the West Bank and Gaza Strip with one of the least protectionist trade regimes in the region. Even more important, it provides the West Bank and Gaza Strip with tariff-free access to the large Israeli market as well as to the markets of the countries with which Israel has free trade arrangements (see below).

The Agreement, however, from the Palestinian perspective, has shortcomings related to the disposition of trade revenues, policy independence toward third parties, and the West Bank and Gaza Strip's access to Israeli and other foreign markets. With respect to trade taxes, the Agreement does not provide for the Palestinian Authority to receive customs and purchase taxes on indirect imports, that is, goods imported from third countries when the final destination of the good is not clearly defined as being the West Bank and Gaza Strip. This flaw has contributed to the Palestinian Authority encouraging direct imports from abroad.

The second weakness of the Agreement is attributed to its severe limits on the trade policy independence of the West Bank and Gaza Strip with respect to third countries. According to the Agreement, the West Bank and Gaza Strip cannot lower its tariffs on most of its imports to below those in Israel, and the West Bank and Gaza Strip has to observe quality standards that may not be consistent with the Palestinian level of income. ${ }^{4}$

\footnotetext{
${ }^{3}$ Under this agreement with Jordan, customs duty rates are set at zero for specified goods.

${ }^{4}$ Technical and nontechnical standards, sanitary and veterinary conditions, as well as packing and labeling specifications
} 
The West Bank and Gaza Strip has no say in formulating Israeli trade policy and, indeed, the Palestinian Authority has to conduct essentially the same trade policy as Israel, including with respect to having trade relations with third countries. ${ }^{5}$ Furthermore, the trade policy options in the Agreement are highly restrictive. These relate to the allowable tariff rates and quantity limits on goods for which tariffs could be set. In particular, for many of the items in lists $\mathrm{A} 1, \mathrm{~A} 2$, and $\mathrm{B}$, the Israeli tariff rates are already nil or very low. The option to set tariff rates above those in Israel is of no practical consequence since it would ensure imports leaking from one area into the other in the absence of customs borders. Additionally, the highly restrictive quantity limits on Lists $\mathrm{Al}$ and A2 items also severely limit the ability of the Palestinian Authority to determine its own tariff rates because on quantities in excess of these limits, Israeli customs rates have to be utilized. The quantities of items in Lists $\mathrm{Al}$ and $\mathrm{A} 2$ have only once been increased since the inception of the Agreement but are expected to be increased shortly through agreement with Israel.

The final shortcoming of the Agreement is viewed as the nature of access it provides to the respective Israeli and Palestinian markets. Under the Agreement, trade advantages are given to the respective parties relative to other trade partners. As formulated, the West Bank and Gaza Strip benefits from the Agreement because Israeli tariffs are relatively high in the sectors where the West Bank and Gaza Strip has strong export potential-agriculture and labor intensive manufacturing, such as shoes, garments, furniture, etc. The Israeli exports to the West Bank and Gaza Strip reflect the Israeli tariff structure (in the case of reexports) and/or Israeli domestic prices (in the case of goods originating in Israel). To the extent that these prices are higher than those from other sources, the West Bank and Gaza Strip would be in a disadvantageous position. ${ }^{6}$ Given the substantial trade deficit of the West Bank and Gaza Strip with Israel, the

of imported goods are important elements of Israeli trade policy. Israel has faced complaints against the use of such standards as a means to protect local products and discriminate against imports. Israeli quality standards employed with respect to food items are very rigid.

5 The West Bank and Gaza Strip cannot (with the exception of List A1 and A2 countries) conduct trade with those countries with which Israel does not have relations. This has curtailed the West Bank and Gaza Strip's trade relations with the majority of Moslem countries. advantages accorded to Israel by the West Bank and Gaza Strip would appear to be more significant than vice versa. This has been further enhanced by border closures and security measures, which have affected the West Bank and Gaza Strip's access to the Israeli market-closures affect the exports of West Bank and Gaza Strip more severely than its imports from Israel.

\section{Trade Relations with Countries Other Than Israel}

The Palestinian Authority has trade agreements with various countries, such as the United States, the EU, and Jordan. Some of these agreements are outgrowths or parts of Israeli trade agreements with third countries, while others are recently concluded agreements between the Palestinian Authority and the countries concerned. The West Bank and Gaza Strip's trade agreements with countries other than Israel have to be in compliance with the Israeli trade regime. The Palestinian Authority cannot offer any different import concessions than those applicable under the Israeli trade regime. So far, these agreements have had a relatively insignificant effect on the West Bank and Gaza Strip's trade regime and trade patterns, as is evident from the continuing high concentration of Palestinian trade with Israel.

In February 1997, the Palestinian Authority signed an Interim Association Agreement with the EU. Before this Agreement, Palestinian trade with the EU was conducted under the Israeli-EU Association Agreement. With this new Agreement, which is similar to other Euro-Mediterranean accords in terms of structure and content, the Palestinian Authority has become a full participant in the Euro-Mediterranean partnership and has its own quotas of agricultural exports to the EU. The aim of the Interim Association Agreement is the creation of an EU-Palestinian free trade area by the end of 2001. This liberalization process is to supplement and provide a formal setting for the commercial arrangements currently taking the form of autonomous trade concessions that the European Commission has conferred in the past for farm and industrial goods.

Despite the signing of trade agreements, the West Bank and Gaza Strip's trade with Egypt,

\footnotetext{
${ }^{6}$ Negative effects of trade diversion can be reduced by having the tariffs in the West Bank and Gaza Strip be lower than those in Israel.
} 
Jordan, and other Arab countries has so far not developed much because of the strong trade ties of West Bank and Gaza Strip to Israel and to the lack of competitiveness of Palestinian goods in Jordan and Egypt. The Palestinian Authority has a trade agreement with Jordan, signed in January 1995 , that calls for free trade in about 60 items. With Egypt, in January 1994 a technical and economic cooperation accord was signed by the Palestinian Authority to stimulate trade and give Palestinian goods access to world markets. Under this agreement, Egypt and the Palestinian Authority agreed to preferential trade status for some goods. The agreement stipulated practical steps to facilitate trade between the two entities, such as setting up a free zone for transit and easing of border restrictions, certificate of origin procedures, and the use of Egyptian ports and airports. This agreement, however, is a protocol and has not yet been implemented due to the above cited reasons. Currently the Palestinian Authority is seeking ways to establish a free trade zone at the Egyptian-Palestinian border, with the objective of getting Palestinian exports to other markets.

With the United States, the Palestinian Authority concluded in November 1996 a preferential treatment and duty-free access agreement, similar to the one the United States has with Israel. ${ }^{7}$ Under this agreement, the United States has abolished customs duties on all products imported from the West Bank and Gaza Strip, bestowing the same benefits on Palestinian products as those enjoyed by Israeli imports. The West Bank and Gaza Strip also benefits from the free trade agreement of the EFTA with Israel. In December 1996 the Palestinian Authority and EFTA signed a declaration of economic cooperation; the cooperation is to include the creation of a free trade area with preferential treatment. The final agreement, however, is awaiting the conclusion of a series of consultations between the Palestinian Authority and EFTA.

\section{Security Considerations and Trade}

The greatest influence on the trade patterns and volumes of the West Bank and Gaza Strip has been the restrictions imposed by the Israelis in connection with security considerations, which

\footnotetext{
7The United States Congress does not recognize this agreement and regards it as part of the agreement with Israel.
}

have raised costs and slowed the flow of goods substantially and thus undermined considerably the competitiveness of the Palestinian economy. These restrictions have impacted not only trade between the West Bank and Gaza Strip and Israel, between the Gaza Strip and the West Bank, and on occasion even among Palestinian cities in the West Bank, but also the Gaza Strip's access to third countries because under the Interim Agreement Israel is allowed to control all international passages. To conduct trade through Israeli territory (between the Gaza Strip and the West Bank, between the West Bank and Gaza Strip and Israel, and between the West Bank and Gaza Strip and third countries) travel permits and transport vehicle permits are required. Moreover, there is different treatment of Israeli trade with the West Bank and with the Gaza Strip. In the case of the West Bank, Israeli trucks conduct trade. However, in the case of the Gaza Strip, goods have either to be transferred to Israeli trucks (licensed) before they could enter Israel or else the convoy system has to be utilized. Under the circumstances, at checkpoints between the Gaza Strip and Israel, trade is conducted through "back to back operations" (involving the transfer of goods from Palestinian trucks to Israeli trucks or vice versa) or convoys. The latter involves convoys of Palestinian trucks accompanied by Israeli security.

These methods are used to conduct all Palestinian trade because, at present, the West Bank and Gaza Strip does not have independent access to the outside world through airports or seaports. The airport in the Gaza Strip is completed but has not become operational. The Israeli authorities want to have joint control of the airport in order to deal with their security concerns as well as to ensure customs duty collection. Construction of a seaport in the Gaza Strip has not yet started. The Israeli authorities regard the port of Ashdod as providing the Gaza Strip with the necessary access to the rest of the world. Under these circumstances, Palestinian goods have to be transported to Israeli ports and airports and to borders with Jordan and Egypt using the above-cited transportation methods, which increase significantly the costs of Palestinian trade. For example, it is maintained that the utilization of both Israeli and Palestinian trucks may increase transportation costs almost five-fold. ${ }^{8}$

\footnotetext{
${ }^{8}$ According to Israeli authorities, the use of an Israeli truck costs about NIS 2,000 per day, while a Palestinian truck in
} 
The West Bank and Gaza Strip have two passage points with Egypt and Jordan and at both highly complicated security procedures are in place. For instance, at one of these passages, Rafah, Egyptian vehicles unload their goods on the Israeli side for inspection, and then the goods are reloaded into Palestinian vehicles. For entrance into both Allenby and Rafah passages, Palestinian vehicles require security permissiona vehicle permit and a permit for the driver for a period not to exceed 10 hours a day.

Mainly reflecting the effects of security procedures, only a certain number of back-to-back operations can be carried out at the passages during the day. Thus, according to Israeli sources, when there are no border closures, some 20 convoys (of up to 20 trucks each) per day are allowed through the Erez checkpoint. Under normal circumstances only 15 vehicles are allowed to pass through Rafah during a full working day while at Allenby the number of vehicles is 40 .

Israeli security procedures, which include travel permit requirements on Palestinians, also contribute to problems with respect to clearing Palestinian goods at Israeli ports and airports. According to the Palestinian Authority, such requirements make it too costly and/or difficult for Palestinians to make their way to these points of entry to clear their goods. Indeed, Palestinians have no presence at Israeli ports and airports (and are not allowed to be at the borders) and use subcontractors in Israel to clear their goods. ${ }^{9}$ According to the Palestinian Authority, it costs the Palestinians 7-10 percent more than the Israelis to clear and transport their goods; Palestinians pay about 12 to 15 percent for such services while the Israelis usually pay about 5 to 7 percent.

Although the same rules apply for clearing and securing trade licenses in the West Bank and Gaza Strip and Israel, these procedures involving Palestinians are reported to be more time consuming and costly. Thus, for example, clearing goods from countries with which there are free trade agreements requires no import licenses. The process for

Gaza charges about NIS 500 per day. Using the combination of both or, for that matter, just the Israeli truck, adds considerably to the cost of Palestinian trade. For further details, see Palestinian National Authority's "Back to Back, the Palestinian Trade Realities at Crossing Points," January 1997.

${ }^{9}$ According to Israeli authorities, Palestinians are given the same services and are subject to the same costs as Israeli traders. Israelis, moreover, maintain that they put up no clearance barriers to Palestinians.
Palestinians usually takes $2-5$ days while for the Israelis it takes only a day. This is because, for Palestinian imports, the security verification and compliance with standards and specifications require more time and more papers for verification.

\section{Autonomous Palestinian Trade and Trade-Related Measures}

Owing in part to the prevailing framework within which trade must be conducted, the Palestinian Authority has allowed the formation of trading monopolies and initiated agency requirements. At present there appears to be trade monopolies for petroleum products, cement, and possibly meat and other construction materials. The effectiveness of these monopolies varies. Thus, with respect to the trade monopoly for cement, instructions to allow only one company to import cement appear to be disregarded. ${ }^{10}$ Similarly, meat import licenses were being issued even though there were efforts to control such trade. On the other hand, the petroleum monopoly is being enforced owing in part to the requirement of the Interim Agreement that petroleum imports comply with Jordanian standards. Consequently, such products cannot be imported from Egypt but, due to the Iraqi origin of such products, they also cannot be imported from Jordan. Under the circumstances, the Palestinian Authority utilizes an Israeli company to import petroleum products. These monopolies are due, according to the Palestinian Authority, to efforts to generate more fiscal revenues - to overcome the loss of revenue (customs and purchase taxes) stemming from indirect imports (see above).

During the last year or so the Palestinian Authority has started to encourage Palestinian agencies to import goods directly from overseas (outside Israel) and also from Israel (including both goods produced in Israel as well as reexported from Israel). ${ }^{11}$ The objective of these agency requirements is to bypass Israeli agents. The Palestinian Authority issued sole Palestinian agency re-

\footnotetext{
${ }^{10}$ According to the Palestinian Authority the cement monopoly was established in order to allow the Palestinian Authority to benefit from the difference in the high prices at which cement was being marketed in Israel and the actual, lower production cost of cement.

${ }^{11}$ The aim is to have Palestinian dealers or representatives responsible for all foreign products entering the West Bank and Gaza Strip.
} 


\section{THE TRADE SYSTEM}

quirements for goods being imported from countries other than Israel on January 1, 1997, and up to recently some 200 agents have registered to be the sole distributors of their products in the West Bank and Gaza Strip. The Palestinian Authority was also introducing sole Palestinian agency requirements for imports from Israel, but this was being undertaken gradually in order not to disrupt trade, although plans are to eventually firmly implement it. The Palestinian Authority does not intend to apply this latter regulation to basic materials, such as food, raw materials, etc., but rather to goods requiring maintenance and to goods such as foodstuffs for which producers could be held liable. The Palestinian Authority is concerned over the fact that it has no jurisdiction over Israeli distributors and wholesalers who ship to the West Bank and Gaza Strip outdated or defective goods. Thus, the decision on Palestinian agency requirements is based on securing more fiscal revenue (by increasing direct imports to the West Bank and Gaza Strip), on getting better jurisdictional control of the domestic market, and on encouraging the development of the private sector. All these, however, perhaps could be better attained without the likely adverse consequences of sole agency requirement, which to the extent they imply only one Palestinian importer would result in the establishment of monopolies for the products concerned in the West Bank and Gaza Strip. To avoid possible adverse consequences of this requirement on resource allocation, the Palestinian Authority should not confine Palestinians to sole agentries but should advocate competition among the agents.

Primarily in response to the prolonged border closure in the third quarter of 1997, which the Palestinian Authority indicated made importation of only essentials possible, a circular was issued in early September 1997 banning the import from Israel of about 15 groups of goods, such as cigarettes, paint, vegetable oil, electric appliances, electronics, furniture, canned foodstuff, vegetables and fruits, biscuits, chocolates, etc. The boycott was essentially on Israeli goods and, for some of the items in the list, exceptions were made if the goods were directly imported or else imported by a Palestinian agent.

In terms of conducting trade with both Israel and the rest of the world, basically the same import regulations are employed as in Israel, except that these are implemented by Palestinian Authority entities. The implementation of some of the regulations results in the Palestinian Authority and Israel exchanging information on a daily basis. For example, in accordance with Israeli requirements, the Palestinian Authority Ministry of Economy and Trade issues all import licenses and endorses export certificates of origin. Import licenses, according to the Palestinian Authority, are issued without any delay and are valid for a period of six months to a year depending on the product range. This issuance is dependent on information being keyed into the Israeli system in order to allow the goods (both Palestinian and Israeli) to be cleared at customs.

\section{Implications of the Current Trade Regime}

In view of the nature of the West Bank and Gaza Strip's trade regime, both in terms of the situation on the ground as well as the parameters (i.e., Interim Agreement) within which modifications can be made, there appears to be room for some changes in the immediate future - even before permanent status arrangements are concluded-to derive greater benefits from trade. These initial, upfront measures can involve utilizing some of the trade options within the Interim Agreement, removing some of the weaknesses of the Interim Agreement in the trade area, eliminating trade barriers that are not essential for security, making existing security controls more efficient, and implementing regulations that remove impediments to efficient allocations of resources.

In formulating policies, the question arises as to what kind of trade policy would in the years ahead best induce growth in the West Bank and Gaza Strip over the long run. In view of the small size of the economy and limited resources, the development of strong linkages with external markets is critical. Trade needs to be the engine of growth for the West Bank and Gaza Strip. In formulating such a trade policy, account needs also to be taken of the advantages of the West Bank and Gaza Strip, such as the existence of "relatively sophisticated labor force," strategic geographical position, and a relatively open economy with little industrial base at risk and with a revenue base not dependent on customs duties. At the same time, another critical factor that needs to be considered in formulating trade policy for the West Bank and Gaza Strip is the trade 
relationship it has had with Israel since 1967. It would be very costly to end this relationship since at present, as noted above, the bulk of the West Bank and Gaza Strip's trade is conducted with Israel and the West Bank and Gaza Strip has very limited trade infrastructure to carry out trade with third parties.

Taking all these factors into account, the West Bank and Gaza Strip's trade policy would need to be geared to attracting investment and opening up new growth opportunities based on comparative advantage. The former calls for trading rules that are credible and stable and the latter calls for multilateral liberalization, that is, liberalization on a most-favored-nation (MFN) basis. Unimpeded access to all markets, including by securing the necessary trade infrastructure (by diversifying trading routes-airports and seaports, renewing and expanding existing infrastructure, and establishing links between the Gaza Strip and the West Bank), is essential. Given the limited availability of natural resources, the West Bank and Gaza Strip's trade strategy would have to be one that moves gradually from low- and medium-skilled exports to higher-valued manufactured exports derived by processing raw materials and semi-finished regional products.

Thus, the aim of the West Bank and Gaza Strip should be a nondiscriminatory trade regime, that is, multilateral trade liberalization and free trade. The achievement of this objective would have to be in stages. Indeed, until the permanent status arrangements are concluded, some of the existing trade arrangements will have to be continued. After that period, the West Bank and Gaza Strip could possibly move toward a free trade agreement with Israel and eventually toward a completely open trade regime-multilateral free trade. The Palestinian Authority could use the free trade agreement to set tariffs to its trade partners to less than those being affected in Israel, to the extent that this reflects Palestinian development priorities. The preferential trade arrangement with Israel, as well as the free trade agreements with some of its other trade partners, could be used as a building block for multilateral trade liberalization.

A free trade agreement with Israel would give the Palestinians trade policy independence while continuing their preferential arrangement with Israel. The West Bank and Gaza Strip would be able to develop new markets, including by reducing its customs duties to less than those of Israel.
Such an arrangement would allow the West Bank and Gaza Strip to have access to other markets not only through its current arrangements but also by being able to make concessions to third parties (e.g., reductions or elimination of tariffs on an MFN basis) while moving toward realizing its overall trade strategy. ${ }^{12} \mathrm{~A}$ free trade area would also result in higher tax revenues for the Palestinian Authority, since taxes that at present leak to Israel can be collected at the customs borders and the West Bank and Gaza Strip would gather more of the purchase and excise taxes. The disadvantages of a free trade area with Israel would be the introduction of customs borders and also rules of origin, which ensure free trade is confined to goods and commodities that are actually produced within the member countries. ${ }^{13}$ Another problem with the formation of a free trade area might be that since the West Bank and Gaza Strip would be independent to set its tariffs, lobby groups might try to influence the rates. To overcome that problem, the Palestinian Authority would need to set out clearly at the outset its trade policy strategy of liberalizing on an MFN basis (with the aim of multilateral free trade in the near future).

In the short run, it has to be assumed that the Interim Agreement with Israel would not be rescinded or modified significantly. Given this assumption, what can be done at present to enhance the trade prospects of the West Bank and Gaza Strip?

As noted above, the binding constraint on Palestinian trade at present appears to be the barriers entailed by Israeli security procedures through increased costs and occasionally physical disruptions. Therefore, the Gaza airport and the Gaza port are essential to improve the West Bank and Gaza Strip's links with the outside world. Establishment of such infrastructure would remove one of the major barriers to Palestinian access to third markets. In addition, measures could be implemented to make security controls both more efficient and effective. For example, Israelis are at

\footnotetext{
${ }^{12}$ In this context, reductions in external tariffs to below those in Israel would be essential to reap the benefits of a free trade agreement, otherwise there would be trade diversion.

${ }^{13}$ Rules of origin are necessary to prevent trade deflection (i.e., goods are imported into the free trade area through the country with the lowest external customs tariff, then transferred, without tariff, to another country in the area that has higher tariffs).
} 


\section{THE TRADE SYSTEM}

present building a new checkpoint at the border in Qarni to conduct export trade from the Gaza Strip to Israel on an automated basis. The operation involves having some 500 "sterilized" Palestinian trucks on the Israeli side pick up the goods delivered from the Gaza Strip on other Palestinian trucks. The loads of the trucks will be $\mathrm{x}$-rayed at the checkpoint. The "sterilized" trucks will have special "boxes" to allow monitoring within Israel and to ensure they travel to their designated destinations. This facility, which is expected to become operational in early 1998, is anticipated to significantly hasten trade and reduce the transportation costs of trade for the Palestinians-although the Israelis will charge a fee for the use of the facility. Israel is considering a similar arrangement at Allenby and has begun a project to upgrade the Rafah terminal facility to ease the flow of traffic in both directions.

Along the same lines of reducing unnecessary barriers due to security procedures, safe passage is essential for trade between the Gaza Strip and the West Bank. Various possibilities are being debated, such as the utilization of existing Israeli roads but monitoring Palestinian movement through special passes, or having a completely separate passage.

Related to security restrictions, Palestinians need to be given clearance agency privileges at Israeli ports and airports and be issued travel and vehicle permits more leniently. Palestinians should be allowed to compete with Israelis as clearance agents and as transporters of goods. Such measures would contribute to reducing costs of trade and to increasing the competitiveness of Palestinian goods in the regional markets.

Simultaneously with these endeavors to reduce the adverse consequences of security restrictions on trade, the Palestinian Authority should try to utilize the trade options within the Interim Agreement. In particular, the Palestinian Authority should seek to utilize the option to fix customs duties (to below those in Israel), and to reduce tax leakages. Fixing customs duties on goods would provide the Palestinian Authority with some trade policy independence, allowing customs duties to be more in line with the economic circumstances of the West Bank and Gaza Strip, and, more important, providing an opportunity to reciprocate to trade partners. (As noted above, this is at present a very limited option because goods on Lists A1, A2, and B account for about $\$ 5$ million to $\$ 6$ million in West Bank and Gaza Strip's trade.) For essentially the same reasons of trade policy independence (including opportunity to be free of Israeli quality standards), the Palestinian Authority should seek to expand the number of goods for which it can set customs duties. In expanding the coverage of these lists, the issue of goods leaking into the Israeli market would have to be addressed. Under the current Agreement, it is maintained that such leakages are prevented by the low customs duties in Israel, the quantity restrictions (and consequent lack of quality standards) on Lists A1 and A2 imports, and regulations requiring Arabic packaging of goods imported into the West Bank and Gaza Strip. The use of Arabic makes identification of West Bank and Gaza Strip goods easier.

At the same time, to derive the benefits of efficient resource allocation, Palestinians would need to improve their operations at the crossing points (by having the latest equipment to process traders as well as new fleets of special trucks to carry out trade between Jordan and the West Bank); allow competition in the trade area by eliminating monopolies and sole agency requirements; and invest in improvements in the infrastructure.

\section{Conclusion}

To garner the benefits of outward-oriented strategy-economic growth and efficient resource allocation-the Palestinian Authority must in the near future work with the Israeli authorities to eliminate trade barriers that are not essential for security and make existing security controls more efficient so that the focus is on security and maintenance of trade. Simultaneously, efforts should be undertaken to utilize more fully the trade options within the Interim Agreement and to remove some of the weaknesses of that Agreement in the trade area. The Palestinian Authority should also be wary of introducing or maintaining measures that adversely affect efficient allocation of resources - such as sole agency requirements and import monopolies. Indeed, the aim of the Palestinian Authority should be to have economic decisions relating to production and investment based on market-based incentives, which means, among other things, having a nondiscriminatory trade regime-that is, multilateral trade liberalization and free trade. 